\title{
Men as contraceptive users: Programs, outcomes and recommendations
}

\author{
Karen Hardee \\ Population Council \\ Melanie Croce-Galis \\ Jill Gay
}

Follow this and additional works at: https://knowledgecommons.popcouncil.org/departments_sbsr-rh

Part of the Demography, Population, and Ecology Commons, Family, Life Course, and Society Commons, and the International Public Health Commons How does access to this work benefit you? Let us know!

\section{Recommended Citation}

Hardee, Karen, Melanie Croce-Galis, and Jill Gay. 2016. "Men as contraceptive users: Programs, outcomes and recommendations," Working paper. Washington, DC: Population Council, The Evidence Project. 


\section{Men as Contraceptive Users:}

Programs, Outcomes and

Recommendations

Karen Hardee, Evidence Project Director, The Population Council Melanie Croce-Galis, Executive Director, What Works Association Jill Gay, Chief Technical Officer, What Works Association

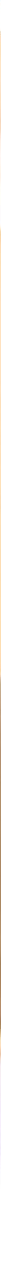




\section{The Evidence Project \\ Population Council}

4301 Connecticut Avenue, NW, Suite 280

Washington, DC 20008 USA

tel +12022379400

evidenceproject.popcouncil.org

The Evidence Project is made possible by the generous support of the American people through the United States Agency for International Development (USAID) under the terms of cooperative agreement no. AID-OAA-A-13-00087. The contents of this document are the sole responsibility of the Evidence Project and Population Council and do not necessarily reflect the views of USAID or the United States Government.

\section{Evidence}

The Evidence Project uses implementation science-the strategic generation, translation, and use of evidence - to strengthen and scale up family planning and reproductive health programs to reduce unintended pregnancies worldwide. The Evidence Project is led by the Population Council in partnership with INDEPTH Network, International Planned Parenthood Federation, PATH, Population Reference Bureau, and a University Research Network.

WHAT WORKS What Works Association aims to improve the lives of women and men through
ASSOCIATION evidence-based guidance on policies and programs that promote gender equality.

Published in 2016.

Suggested citation: Hardee, Karen, Melanie Croce-Galis, and Jill Gay. 2016. "Men as Contraceptive Users: Programs, Outcomes, and Recommendations,” Working Paper. Washington, DC: Population Council, The Evidence Project.

Photo credit on cover page: (C) 2016 Sarah Hoibak/VectorWorks, Courtesy of Photoshare

(C) 2016. The Population Council, Inc. 


\section{Table of Contents}

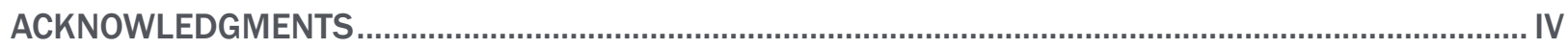

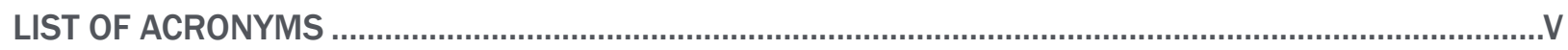

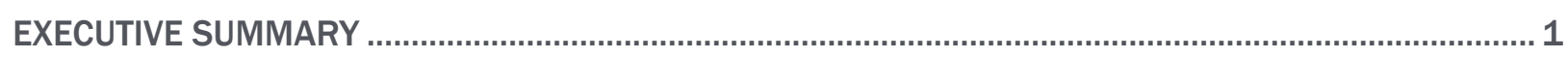

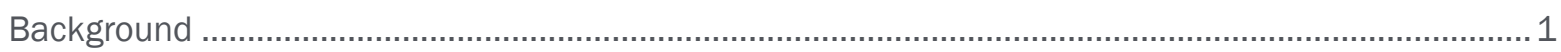

Programming for Men as Contraceptive Users ...............................................................................

Evidence Gaps in Programming for Men as Contraceptive Users ........................................................ 4

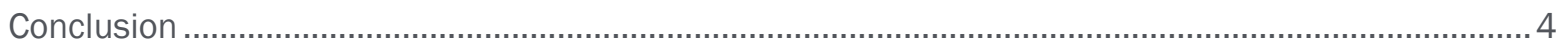

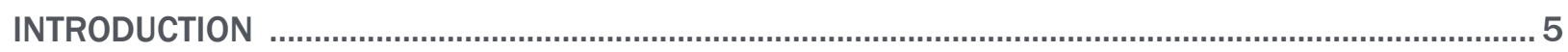

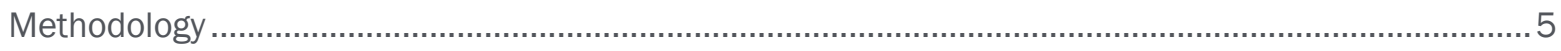

THE FOUR METHODS

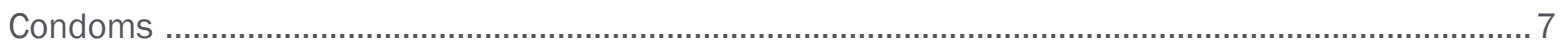

Vasectomy

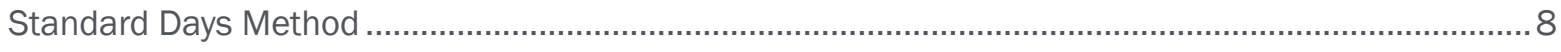

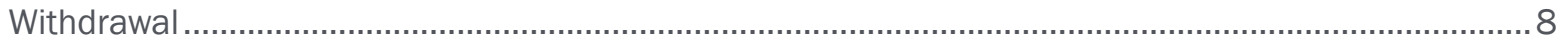

PROGRAMMING FOR MEN AS CONTRACEPTIVE USERS .............................................................10

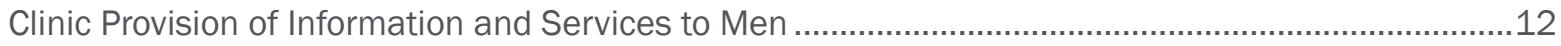

Outreach Programs Through Male Motivators and Peer Educators/Mentors.....................................13

Communications Programming.......................................................................................................15

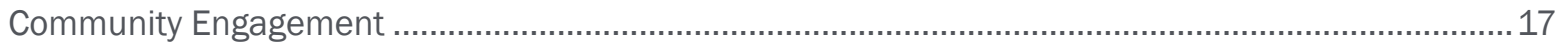

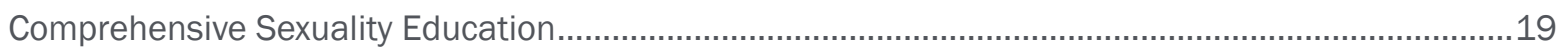

Summary of Key Outcomes from Programming to Promote Men's Use of Family Planning .................20

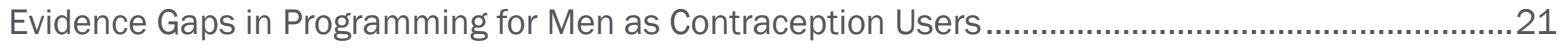

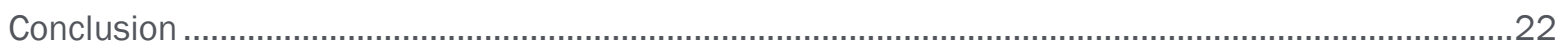

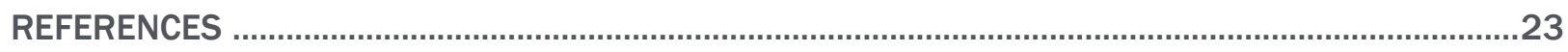

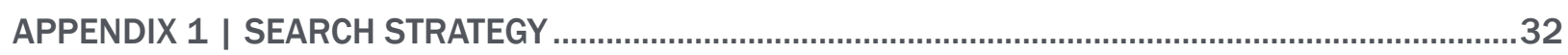

APPENDIX 2 | INDIVIDUALS CONTACTED FOR THE ORGANIZATIONAL REVIEW ...............................33

APPENDIX 3 | LIMITATIONS.......................................................................................................35

APPENDIX 4 | TABLE OF INTERVENTIONS AND OUTCOMES ON MALE USE OF FAMILY PLANNING .36 


\section{Acknowledgments}

This report was based on a scope determined in collaboration with USAID and benefited from the review of Joan Kraft, Michal Avni, and John Townsend. Thanks goes to Margaret Greene who gave helpful comments on the report, MacKenzie Kacmarcik and Christina Memmott who provided research support for this work, and Kay Willson who conducted the search strategy. Many thanks as well go to Kate Gilles for her edits, ideas, and communications expertise and to Anneka Van Scoyoc for making the report, images, and appendices so visually effective. The authors would like to thank the respondents who participated in the interviews and shared information on family planning programming for men. 


\section{List of Acronyms}

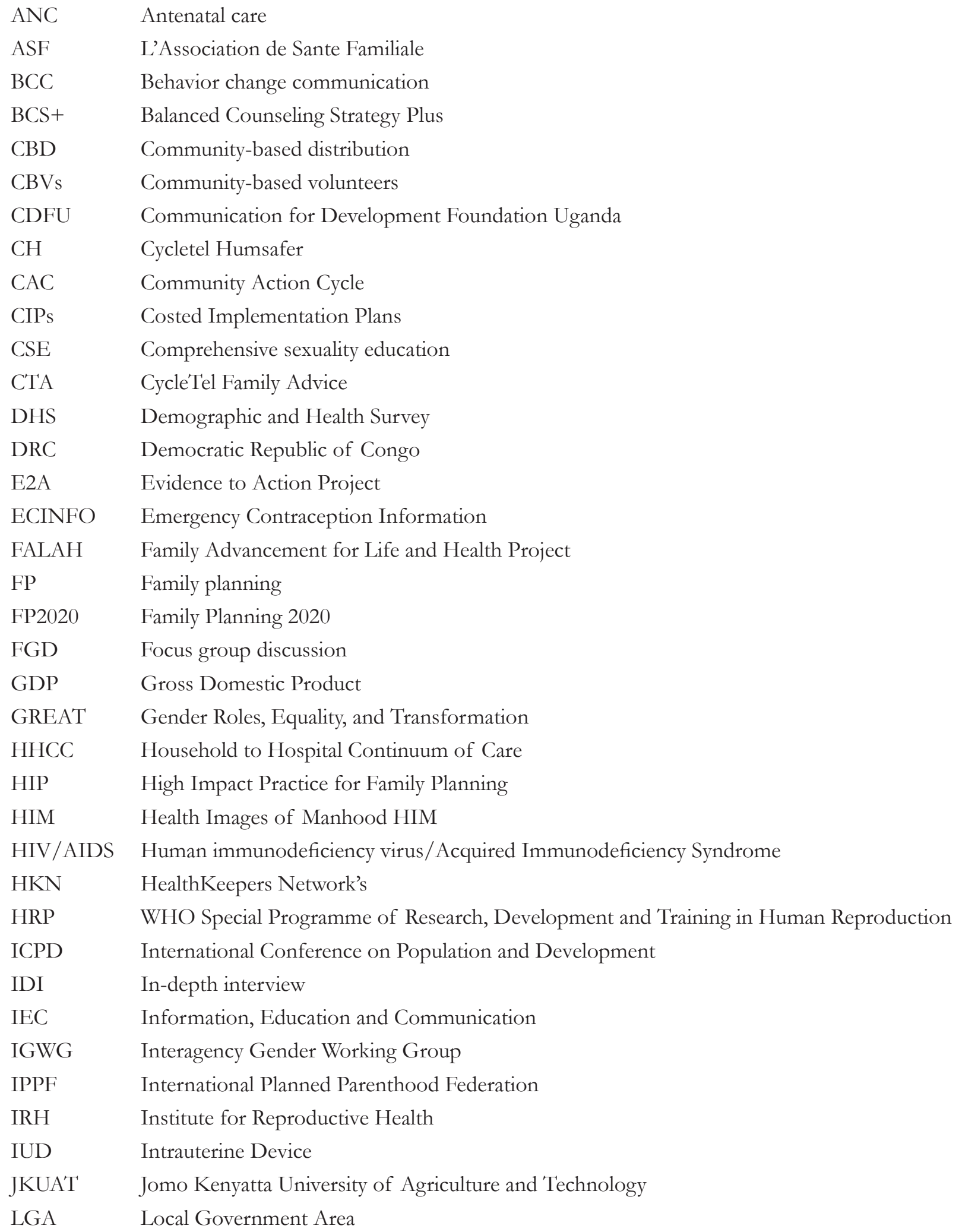


LHWs Lady Health Workers

$\mathrm{MCH} \quad$ Maternal and child health

MCHIP Maternal and Child Health Integrated Program

mHealth Mobile health

MLE Monitoring, Learning and Evaluation

MSH Management Sciences for Health

MSI Marie Stopes International

MkV MEMA kwa Vijana

NGO Non-governmental organization

PEPFAR Presidents Initiative for AIDS Relief

PSI Population Services International

RISUG Reversible Inhibition of Sperm Under Guidance

SBCC Social and behavioral change communication

SDM Standard Days Method

SMS Short message service

SRH Sexual and Reproductive Health

STI Sexually transmitted infection

UNFPA United Nations Population Fund

USAID United States Agency for International Development

VSLAs Village Saving Loaning Associations

VYA Very young adolescents

WHO World Health Organization

WINGS Women's International Network for Guatemalan 


\section{Executive Summary}

\section{BACKGROUND}

Organized family planning efforts focus primarily on women, with less attention to men. Efforts to expand the vision for constructive male engagement are evolving from encouraging men to be supportive partners of women's reproductive health to also focus on meeting men's own reproductive health needs and engaging men as contraceptive users and agents of change in families and communities. Knowledge about reaching men as clients of family planning services in today's programming environment is still limited.

This paper reviews 47 current activities, programs and evidence that affect men's use of contraceptive methods. The review includes three methods that men use directly, namely condoms, vasectomy and withdrawal, and one that requires their direct cooperation, namely the Standard Days Method. A companion review by Perry et al., 2016, includes a more detailed review of vasectomy programming. Evidence comes from: a review of published and grey literature documentation of interventions focused on men as users of contraception in low- and middle-income countries; and interviews with organizations and institutions that are conducting programming and research in the area of men as users of contraceptive methods.

\section{PROGRAMIMING FOR MEN AS CONTRACEPTIVE USERS}

The range of 47 interventions identified in this review found that programming for men generally fell under the following five broad strategies: Communications Strategies; Outreach with Male Motivators and Peer Educators/Mentors; Community Engagement; Comprehensive Sexuality Education; and Clinic Provision of Information and Services for Men. The interventions were spread across 27 countries spanning Africa, Asia, Latin America and the Caribbean, and Europe.

STRATEGIES TO ADDRESS MEN AS CONTRACEPTIVE USERS BY NUMBER OF INTERVENTIONS AND DESIGNATION AS PROVEN, PROMISING OR EMERGING

\begin{tabular}{|c|c|c|}
\hline STRATEGY & $\begin{array}{l}\text { NUMBER OF INTERVENTIONS } \\
\text { INCLUDED IN THE REVIEW }\end{array}$ & $\begin{array}{l}\text { STRENGTH OF EVIDENCE } \\
\text { ON OUTCOMES }\end{array}$ \\
\hline Clinic Provision of Information and Services & 4 & Promising \\
\hline \multicolumn{3}{|l|}{ Outreach with: } \\
\hline Male Motivators & \multirow{2}{*}{10} & Proven \\
\hline Peer Educators/Mentors & & Emerging \\
\hline \multicolumn{3}{|l|}{ Communications Programming } \\
\hline Social Marketing & 3 & Proven, FP HIP \\
\hline Mass Media and Social Media & 7 & Promising \\
\hline mHealth & 4 & $\begin{array}{c}\text { New Technology Enhancement, } \\
\text { FP HIP }\end{array}$ \\
\hline Hotlines & 3 & Emerging \\
\hline \multicolumn{3}{|l|}{ Community Engagement } \\
\hline Community Dialogue & 10 & Strongly promising \\
\hline Engaging Religious Leaders & 2 & Emerging \\
\hline Comprehensive Sexuality Education & 4 & Promising \\
\hline
\end{tabular}




\section{Clinic Provision of Information and Services to Men}

Providing clinical family planning services to men, most notably vasectomy, is a promising intervention. The review includes four interventions that include training providers in both provision of vasectomy and in counseling, including addressing barriers specific to vasectomy, such as myths about loss of virility. The evidence supporting these interventions generally comes from service statistics. Client-provider communication was assessed in one intervention through use of mystery clients. Where vasectomy services were provided, use generally went up. While the numbers of vasectomy users remains small, the trends are in the right direction and show promise of expanding provision of clinical family planning services for men.

\section{Outreach Programs Through Male Motivators and Peer Educators/Mentors}

Providing outreach programs through male motivators is a proven intervention and use of peer educators/ mentors is an emerging intervention. The review includes 10 interventions that had male motivators/educators provide information to other men, build condom use and communication skills and, in some cases, provide contraceptives directly or refer participants to nearby services. In a number of interventions, male motivators were part of complementary programming of female motivators for women. While not all male peer programs are designed to promote increased contraceptive uptake specifically by men (e.g., they include male methods in discussion of a broader range of methods), many do have a positive impact on gender equality and more gender-equitable approaches to contraceptive decision-making.

The evidence supporting these proven interventions ranges from quasi-experimental intervention/control studies, to pre-post intervention studies, qualitative interviews and/or focus group discussions, and service statistics. Overall male motivators/peer educators appear to be able to increase contraceptive use among men, including condom use and participation in SDM, in addition to promoting men's support for their partners' use of family planning. Additionally, many programs had a positive impact on gender equality and more gender-equitable approaches to contraceptive decision-making. Ensuring that these programs include a focus on promoting male contraceptive use would strengthen this approach to reaching men.

\section{Communications Programming}

Social Marketing. Social marketing of contraceptives is considered a proven high impact practice for family planning. The review includes three interventions with measured outcomes related to men's use of condoms, with evidence from pre-post intervention surveys and a post-intervention survey. These social marketing programs were successful in reaching men of various ages and in increasing condom use.

Mass Media and Social Media. Mass media, a promising intervention for reaching men as family planning users, has long been an approach to promote family planning. Use of social media, which is more recent, is an emerging intervention. The review included seven interventions that included media and advertising campaigns carried out via radio, television, newspapers, billboards, brochures, and use of the social media site Facebook to promote family planning. Most reached men to increase men's support for their partners' contraceptive use, while some addressed men's use of contraception as well. The evidence supporting these promising (mass media) and emerging (social media) interventions include: pre-post intervention surveys and service statistics. In addition, two interventions included focus group discussions and one included interviews with men that augmented service statistics. There were a range of outcomes associated with these interventions, from increased use of condoms and vasectomy to shifting the perception that family planning is a women's affair and addressing gender norms and equality in family planning and contraceptive use.

mHealth. Mobile health (mHealth) text messaging programs, considered a new technology by the FP HIP Initiative and a means of enhancing programming, are gaining traction in family planning programming. The review includes four interventions, with evidence from pre-post intervention studies and service statistics. 
Experience with mHealth programming suggests that men, particularly young men, are drawn to them as a means of getting information about family planning and that women often rely on their partners to use SMS systems. Yet, little is known about the extent to which men's knowledge about, access to or use of services increases as a result of these programs due to a lack of evaluation and/or sex-disaggregated data.

Hotlines. The review includes three interventions that included hotlines, an emerging intervention, supported by evidence from call statistics and a survey of hotline users. Similar to SMS services, men use hotlines for information about family planning. Statistics suggest that where hotlines are available, men tend to more heavily use hotlines than women. Men call both for themselves and for their partners. Yet, little is known about the extent to which men's knowledge or access to services increased as a result of these programs due to a lack of evaluation and/or sex-disaggregated data.

\section{Community Engagement}

Promoting Community Dialogue. Engaging the larger community is a strongly promising intervention to foster a sense of legitimacy and normalcy for men's participation in conversations about and use of contraception. Community engagement approaches bring men and women together, sometimes with community and religious leaders, to create a unified understanding of family planning, including norms, values, roles in family planning and availability of and access to services. The review includes 10 interventions that primarily consisted of social and behavioral change communication (SBCC) strategies intended to promote equitable gender norms and attitudes. None of the programs focused solely on male use of contraception, although increasing acceptability of family planning generally could have positive effects on couple communication and use of contraception, including by men.

The evidence to support this intervention for reaching men as family planning users ranges from randomized control trials, quasi-experimental studies with intervention and control groups; baseline/endline surveys, and post-intervention qualitative evaluation. Overall findings from these programs found reductions in myths around family planning, improved communication with partners about family planning and increased use among men (although not all programs indicated if the increased use was of male methods).

Engaging Religious Leaders. Engaging religious leaders, an emerging intervention, to support family planning has been a key part of programming for many years, although few interventions have focused specifically on men's use of family planning. The review includes two evaluated interventions that engaged religious leaders, with evidence from a longitudinal survey with baseline and endline measurements and a baseline/endline survey with qualitative interviews. These interventions provided orientation and updated information on family planning to religious leaders and in turn, the religious leaders reached out to their communities with the information and their support for family planning. Religious outreach was linked with availability of services. The interventions increased men's support for family planning and increased male use of contraception.

\section{Comprehensive Sexuality Education}

Sex education programming, a promising intervention, offers an opportunity to address the sexual and reproductive health needs of boys as well as provide information about family planning and fatherhood. However, relatively few sex education curricula specify anything related to the unique sexual and reproductive health needs of men and boys. The evidence for this promising practice ranges from pre-post intervention surveys with intervention and control groups, to in-depth interviews long-term post intervention, qualitative in-depth interviews and focus group discussions, a pre-post intervention quantitative survey and qualitative interviews. The Comprehensive Sexuality Education (CSE) programs in this review increased boys' awareness of sex and pregnancy prevention and increased gender-equitable attitudes. The retrospective study of a CSE program in Tanzania suggests that while boys may not fully comprehend the messages they are receiving at the time, they 
internalize them later as they become sexually active. While there are a number of ongoing CSE programs, evaluations of the impact of comprehensive sexuality education on boys' use of contraception, particularly beyond condoms, were not found.

\section{EVIDENCE GAPS IN PROGRAMIMING FOR MEN AS CONTRACEPTIVE USERS}

This review has found few robust evaluations of programs to engage men, let alone programs directed at men as users. Not all programs report findings disaggregated by sex, and by contraceptive method, making it difficult to determine the effect of programming on male use of methods. More systematic data collection on men's fertility and relationships could greatly enhance information and service provision for men. Critical research is missing on what are effective programs to increase responsibility by adolescent boys, prior to sexual activity, to prevent unintended pregnancy through male or female contraceptive use, as well as to ensure dialogue on pregnancy prevention, and that the sexual act is consensual. Programming to promote existing male methods could benefit from further evaluation. Funding for evaluation and implementation science of existing interventions remains an ongoing challenge.

The lack of a short- or long-term reversible method for men that falls between condoms and vasectomy is abundantly clear. Work to develop additional male methods of contraception has been going on for decades. Creation of novel hormonal methods for men has stalled, although a number of prospective methods for men are in development, including non-hormonal methods. Funding is a challenge for male contraceptive development. Pharmaceutical companies are not currently investing in new contraceptive development, leaving smaller efforts by non-profit organizations and foundations to fill the gaps. With adequate funding, there could be a new male contraceptive on the market within a decade.

In addition to the programming reviewed above, filling in the gaps in implementation science research and evaluation can begin to change the direction of family planning programming toward more inclusive approaches for men as family planning users.

\section{CONCLUSION}

While there remains a scarcity of direct programming addressing men's contraceptive use, there is sufficient evidence demonstrating men's desire for information and services, as well as men's positive response to existing programming to warrant further programming for men and boys in family planning and contraceptive services. Scaling up successful programming identified in this review will increase men's knowledge and use of family planning services, reduce barriers, increase gender equality and improve the health and well being of men and women, boys and girls worldwide. 


\section{Introduction}

While reproduction involves both women and men and some contraceptive methods require the active participation of men, organized family planning efforts in the developing world since the 1960s and global initiatives including FP2020 focus primarily on women, with less attention to men. Yet, it is increasingly clear that family planning cannot be successful without engaging men and that "unless men are actively engaged in supporting better health and well-being for family and the empowerment of women, progress will remain slow..." (IGWG, 2009). Attention to gender at the 1994 International Conference on Population and Development (ICPD) resulted in a call to involve men more actively in reproductive health (Drennan, 1998; Ringheim, 1999; Boender et al. 2004), although some questioned whether attention to men would take away from meeting women's reproductive health needs (Berer, 1996). Since the ICPD, this expanded perspective on family planning programs has led to a range of strategies to involve men in family planning and reproductive health. Yet, the framing of ICPD emphasized men as partners to support the autonomous decisions of women regarding reproductive health, with less regard for men's reproductive health and rights (Wentzell and Inhorn, 2014).

Evidence suggests that engaging men as supportive partners in reproductive health does lead to improved health outcomes (Boender et al., 2004; IGWG, 2006; Rottach et al., 2009; Green et al., 2011; IRH, 2013a; Kraft et al., 2014). More recently, efforts to expand the vision for constructive male engagement are evolving from encouraging men to be supportive partners of women's reproductive health to also focus on meeting men's own reproductive health needs and engaging men as contraceptive users and agents of change in families and communities (IGWG, 2009). Less is known about reaching men as clients of family planning services in today's programming environment.

This paper reviews current activities, programs and evidence, including those that address the gender norms that affect men's use of contraceptive methods. The findings, augmented with evidence from earlier programming, where relevant, are intended to inform needed programming and implementation research as well as identify gaps in the evidence base of contraceptive programming for men.

\section{METHODOLOGY}

Evidence for this paper comes from three sources:

1. A review of published documentation of interventions focused on men as users of contraception in low- and middle-income countries;

2. A review of the grey literature; and

3. Interviews with organizations and institutions that are conducting programming and research in the area of men as users of contraceptive methods.

The primary focus of the literature search was on interventions for men as users of contraception (specifically the four methods: condoms, withdrawal, vasectomy and the Standard Days Method [SDM]). Interventions focusing on male involvement in family planning were considered if a male contraceptive method was included. Of the more than 500 articles, reports and abstracts from the International Conference on Family Planning in January 2016 reviewed, the majority focused on men as supporters of women's contraceptive use; we selected 47 that addressed men as users of contraception for inclusion in this review. The information in the interviews was used to ensure that all essential programming was covered, including ongoing programming that may not yet be evaluated as well as used to get expert opinions on the state of programming for men as contraceptive users. 
This review was coordinated with FHI360 to reduce overlap with their concurrent review on vasectomy programming, also conducted under the Evidence Project (see Perry et al., 2016).

Appendix 1 includes more detail about the search strategy and a list of organizations, the individuals interviewed and the guiding questions can be found in Appendix 2. Limitations are included in Appendix 3. 


\section{The Four Methods}

While ideally men discuss and decide on contraceptive use with their partners, four contraceptive methods are either male-controlled (i.e., male condom, vasectomy, withdrawal) or require men's active participation in use as a cooperative method (i.e., SDM). Use of these methods ${ }^{1}$ has remained steady over the past few decades at around one-quarter of contraceptive users worldwide (Gallen et al., 1986; Hardee-Cleaveland, 1992; Ross and Hardee, 2016). The methods range in effectiveness in both perfect and typical use, but do offer alternatives to female-controlled methods (e.g., vasectomy as an alternative to tubal ligation, condom as an alternative to diaphragm).

\section{CONDOMS}

Condoms, when used consistently and correctly, result in low rates of unintended pregnancy (2 out of 100 women in the first year of use), are highly effective at preventing sexual transmission of HIV and reduce the risk of other sexually transmitted infections (STIs). Because condoms protect against HIV and other STIs, condom promotion and use of condoms have risen substantially since HIV was first identified in the 1980s. Family planning clients are told that the condom is the only form of contraception that protects against HIV/STIs, and encouraged to use condoms for "dual protection" (against disease and pregnancy) or as part of "dual method" use (condoms plus a hormonal method, IUD or a permanent method) (Cates and Steiner, 2002; Lopez, 2013). Much of the recent research on condoms has focused on HIV-related outcomes, rather than pregnancy prevention.

Men identify advantages and disadvantages to condoms. The chief advantage is that condoms can be obtained or purchased without interactions with any health service and with relative privacy (Kamran et al., 2015; Sonfield, 2015). However, disadvantages may outweigh the condom's advantages. "The condom's reputation as a coitus-dependent method that interferes with sexual functioning or enjoyment is difficult to overcome" (Ringheim, 1999: 87).

More specifically, men may dislike condoms because of the reduced sensitivity, along with a loss of both pleasure and the possibility of conception. Some men, especially younger men, find obtaining condoms embarrassing (Kamran et al., 2015).

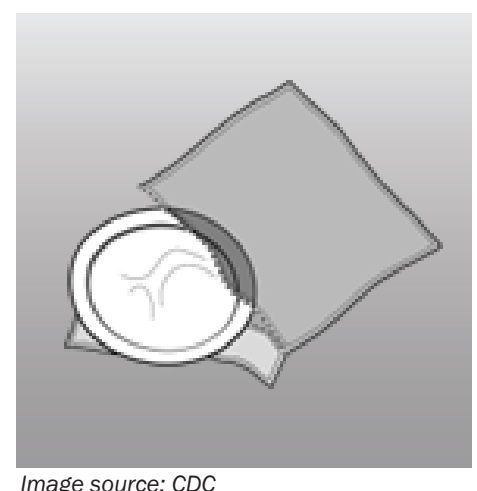

Because of their association with HIV, condoms are often seen by men as only being used for extra-marital sex, or for use with sex workers, and therefore not for use within committed relationships (Ntata et al., 2013). Finally, although the global stock of condoms has risen, men in some studies reported challenges accessing condoms, as well as stock outs (Kamran et al., 2015).

\section{VASECTOMY}

Vasectomy, a permanent method of contraception for men, is highly effective. Only 1.5 out of every 1,000 couples will experience an unplanned pregnancy in their first year using vasectomy (Trussell, 2011). Vasectomies are less invasive and carry fewer risks than female sterilization (Sonfield, 2015), yet vasectomy is not a popular method in most countries. Positive views expressed about vasectomy include the efficacy of the method and the idea that men would not have children out of wedlock, a relief expressed by some men and women (Pomales, 2013).

\footnotetext{
This analysis includes the Rhythm Method rather than SDM, which is a recently developed contraceptive method and is only measured in a few countries, with prevalence between 0.1 percent and 0.6 percent.
} 
Many studies, however, have shown that men and women hold negative perceptions about vasectomy, likely "tied to inaccurate knowledge and fueled by erroneous assumptions about how vasectomy impacts men" (Perry et al., 2016: 9). For example, research in Kenya showed that men incorrectly considered vasectomy to be the same as castration (MSI, 2015) and data from several countries (Uganda, Malawi, India, Bangladesh, Nepal and Pakistan) found that vasectomy was equated with a loss of masculinity (Kabagenyi et al., 2014; John et al., 2015; IPPF, 2013). A qualitative study of vasectomy in Ghana found that men feared the reaction of their spouses, as the title of their paper suggests... "If you ... do...vasectomy and come back here weak, I will divorce you" (Adongo et al., 2014). Such fears may stem from women's

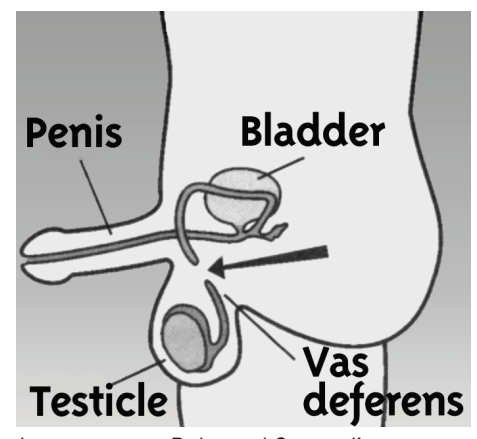

Image source: Balanced Counseling Strategy Plus fear (i.e., in India) that vasectomy would lead to a lack of interest in sex (Singh et al., 2014).

Provider attitudes toward vasectomy can also influence uptake. Providers are often poorly trained on how to discuss these concerns with both male clients and their female partners (Singh et al., 2014; Johnson, 2014). Providers in some countries subscribe to the same myths and fears as do clients and thus discourage vasectomy (Ebeigbe et al., 2011). Vasectomy services are not widely available. In Pakistan, there is "highly limited availability" of vasectomy (Kamran et al., 2015: 13). Cost can also be an issue. In South Africa the cost of vasectomy is a factor leading to low uptake of vasectomy services (Johnson, 2014). Higher costs may be due to the use of hospital stays instead of the safer no scalpel vasectomy (Singh et al., 2014).

\section{STANDARD DAYS METHOD}

The Standard Days Method (SDM), although technically not a "male method," requires active participation of men and continuation has been associated with higher levels of male involvement (Dosajh et al., 2006; Johri et al., 2005). SDM is a fertility awareness-based method that uses CycleBeads ${ }^{\circledR}$ as an aid to help couples identify and track fertile periods, and calls for abstinence or use of barrier methods during fertile periods (Dosajh et al., 2006). When used correctly, the failure rate is only 5 per 100 woman years (Arevalo et al., 2002). Positive attributes of SDM, according to women, are that it does not have health risks or side effects, it is effective, simple to use, affordable, does not involve medication, and involves partners in family planning (Bekele and Fantahun 2012; IRH 2013b; Kursun et al., 2014, Blair et al. 2007, Capo-Chichi and Anastasi 2005, Johri et al.; Wright et al., 2015).

Although SDM has been established as a modern method (Malarcher et

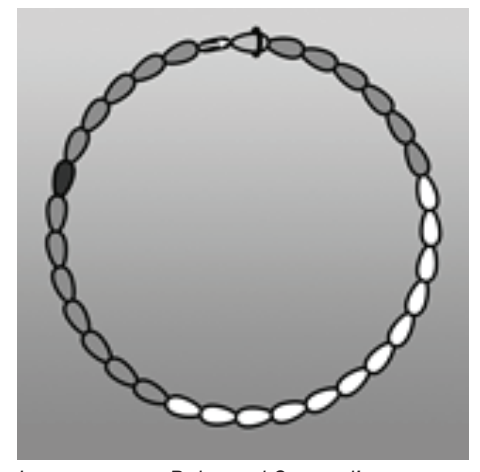

Image source: Balanced Counseling Strategy Plus al., 2016; IRH 2012), it suffers from lack of respect among family planning programmers and providers who think of it as a traditional method that is not effective, and who malign it as a "religious" method. Data from pilot sites in Benin, Ecuador, El Salvador, Honduras, India, and the Philippines indicate that providers have initial biases against fertility awareness methods, but their attitudes toward SDM improved following training and several months of service delivery (Gribble et al. 2008). SDM also helps couples better understand the reproductive cycle and could be useful as a back up method.

\section{WITHDRAWAL}

Withdrawal is the world's oldest method of contraception (Santow, 1993; Bullough, 2001). With perfect use, during the first year of use, 4 percent of women will experience an unintended pregnancy, and with typical use, that rises to 22 percent. WHO (2015) notes that the benefits of withdrawal, if used correctly, are that there are no health risks, it does not affect breastfeeding, and it has no economic cost. It can be used as a primary or as a back up method. 
Withdrawal, labeled a traditional method, is widely disparaged as ineffective and hardly discussed in family planning programming (Santow, 1993; Piet-Pelon, 1999). It is not counted towards contraceptive use in statistics measuring achievement of the FP2020 global goal, which only counts modern contraceptive use (mCPR). Yet, WHO (2015: 231) notes that the method may be appropriate for couples "who are highly motivated and able to use this method effectively; with religious or philosophical reasons for not using other methods of contraception; who need contraception immediately and have entered into a sexual act without alternative methods available; who need a temporary method while awaiting the start of another method; or who have intercourse infrequently." Withdrawal can also be used as a back up method (Higgins et al., 2014).

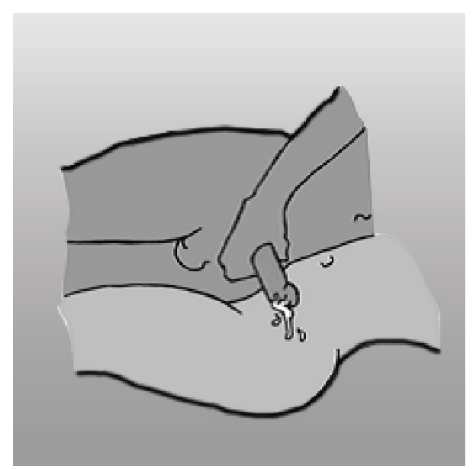

Image source: Balanced Counseling Strategy Plus 


\section{Programming for Men as Contraceptive Users}

This review identifies and summarizes the evidence for interventions that engaged men in family planning and encouraged their use of male methods of contraception. Interventions were included if men were the target population (either themselves or with women) and the intervention addressed male-controlled or cooperative contraceptive methods (i.e., condoms, vasectomy, withdrawal, and SDM); some interventions addressed broader reproductive health issues (e.g., HIV, STI) and some specifically addressed gender issues (e.g., joint decision-making).

The range of interventions identified in this review found programming for men generally fell under five broad strategies that are designed to increase demand for and improve the supply of contraceptive information and services. The strategies include: 1) Clinic Provision of Information and Services for Men; 2) Outreach with Male Motivators and Peer Educators/Mentors; 3) Community Engagement; 4) Communications Programs; and 5) Comprehensive Sexuality Education. Two of the strategies, namely communication programs and community engagement, include sub-strategies. Table 1 lists the 47 identified interventions under the five strategies. Map 1 shows the 27 countries, spanning Africa, Asia, Latin America and the Caribbean, and Europe, in which the 47 interventions were implemented.

MAP 1 | COUNTRIES WITH INTERVENTIONS RELATED TO USE OF MALE METHODS OF CONTRACEPTION

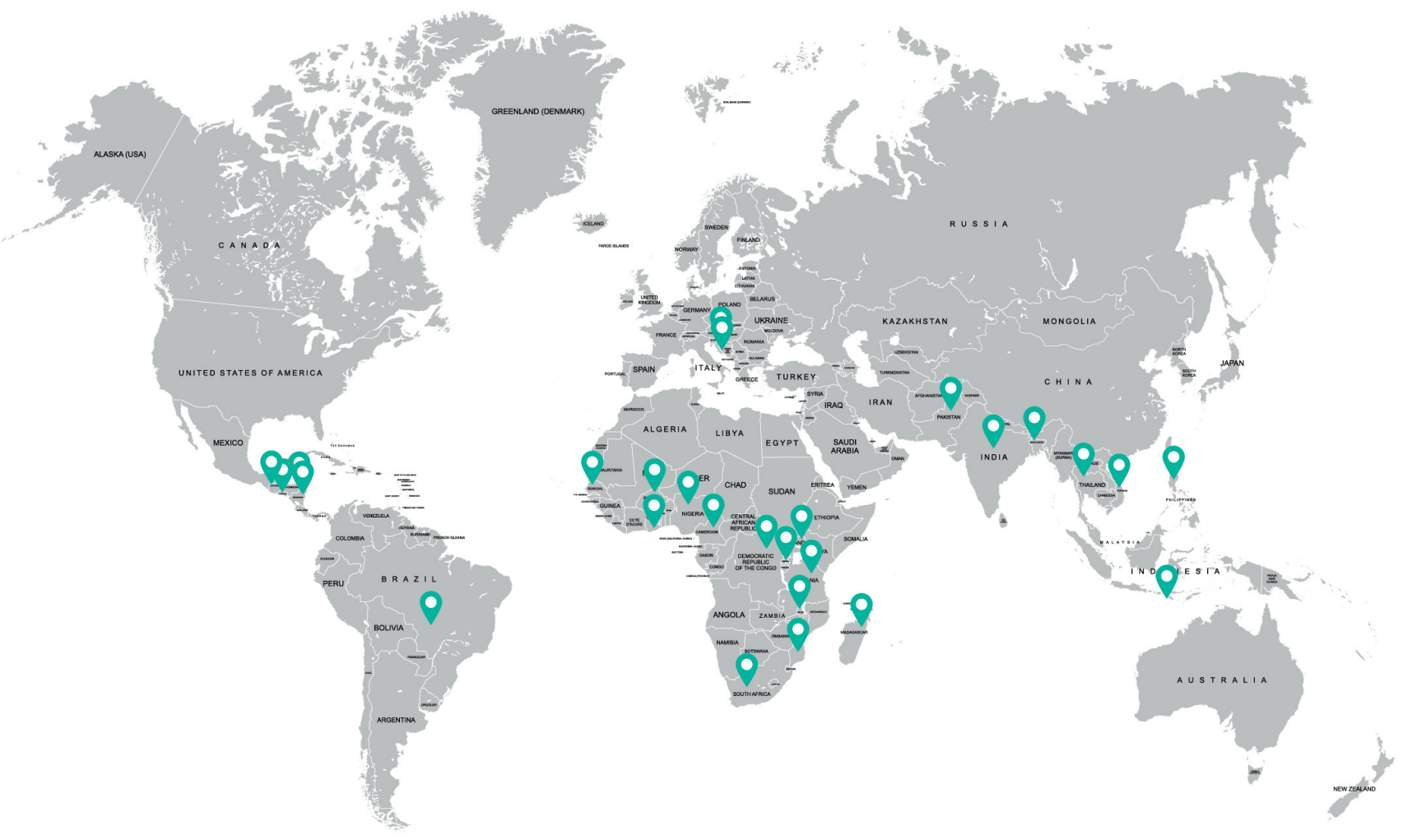


TABLE 1 | PROGRAM INTERVENTIONS ON MEN AND FAMILY PLANNING USERS AND DESIGNATION OF THE INTERVENTIONS AS PROVEN, PROMISING OR EMERGING BASED ON THE STRENGTH OF EVIDENCE ON OUTCOMES

\section{Clinic Provision of Information and Services (Promising)}

Provision of Vasectomy - Marie Stopes International, various countries

\begin{tabular}{l|l} 
Provision of Vasectomy, Uttar Pradesh, India & Provision of Vasectomy, Rwanda
\end{tabular}

Outreach with Male Motivators (Proven) and Peer Educators/Mentors (Emerging)

\begin{tabular}{|c|c|}
\hline Male Motivators Project in Malawi & The HIM Approach in Madagascar \\
\hline Male Community-based Volunteers in Pakistan & Clinic Café Timor in Timor Leste \\
\hline Male Change Agents in India & Male StationGuards in Ghana \\
\hline $\begin{array}{l}\text { Male Outreach Worker Provision of SDM in El Salvador, } \\
\text { Guatemala, India and the Philippines }\end{array}$ & Peer Providers for Young Men in El Salvador and Nicaragua \\
\hline Male Outreach Workers in Nigeria & Life-Planning Mentors for University Students in Kenya \\
\hline \multicolumn{2}{|c|}{ Communications Programming } \\
\hline \multicolumn{2}{|c|}{ Social Marketing (Proven, FP HIP) } \\
\hline Condom Social Marketing in Pakistan & Social Marketing in Senegal \\
\hline \multicolumn{2}{|l|}{ Condom Social Marketing in Cameroon } \\
\hline \multicolumn{2}{|c|}{ Mass Media (Promising) and Social Media (Emerging) } \\
\hline $\begin{array}{l}\text { Get a Permanent Smile: Vasectomy Programming in } \\
\text { Bangladesh, Ghana and Honduras }\end{array}$ & Green Star Media Campaign and m4RH in Tanzania \\
\hline Mass Media to Reach Men in Pakistan & $\begin{array}{l}\text { Reaching Youth Through Communications for Social Change in } \\
\text { Nicaragua }\end{array}$ \\
\hline $\begin{array}{l}\text { Promoting Male-centered Methods through the Media } \\
\text { in India and Vietnam }\end{array}$ & Social Media and Vasectomy in Guatemala \\
\hline \multicolumn{2}{|l|}{$\begin{array}{l}\text { Using Radio Serial Drama to Promote Family Planning } \\
\text { in Burkina Faso }\end{array}$} \\
\hline \multicolumn{2}{|c|}{ mHealth (New Technology Enhancement) } \\
\hline Text message/SMS for College Students in Nigeria & SMS for Fertility Awareness and Use of SDM in India \\
\hline Text message/SMS Intervention in Mozambique & $\begin{array}{l}\text { Role Model Stories as Part of m4RH in Ghana, Tanzania and } \\
\text { Rwanda }\end{array}$ \\
\hline \multicolumn{2}{|c|}{ Hotlines (Emerging) } \\
\hline $\begin{array}{l}\text { Mass Media Campaign and Hotline for Prevention of } \\
\text { Teen Pregnancy: Uganda }\end{array}$ & Ligne Verte Hotline in DRC \\
\hline \multicolumn{2}{|l|}{ Hotlines/EVouchers in Uganda } \\
\hline \multicolumn{2}{|c|}{ Community Engagement } \\
\hline \multicolumn{2}{|c|}{ Promoting Community Dialogue (Strongly Promising) } \\
\hline Family Planning Results Initiative, Care Kenya & Group Meetings for Men in Pakistan \\
\hline Transforming Gender Roles in Uganda & Participatory Group Learning for Young Men in Brazil \\
\hline Community Mobilization( SASA!) in Uganda & Participatory Group Learning for Young Men in India \\
\hline $\begin{array}{l}\text { Participatory Engagement with Young People (Stepping } \\
\text { Stones) in South Africa }\end{array}$ & Participatory Learning Groups for Men in India \\
\hline Group Education with Men in Nigeria & Village Savings and Loan Associations for Men in Uganda \\
\hline \multicolumn{2}{|c|}{ Engaging Religious Leaders (Emerging) } \\
\hline Engaging Religious Leaders in Kenya & Engaging Religious Leaders in Pakistan \\
\hline \multicolumn{2}{|c|}{ Comprehensive Sexuality Education (CSE) (Promising) } \\
\hline CSE in Primary Schools: Tanzania & CSE in Vocational High Schools: Balkans \\
\hline CSE in Secondary Schools: Uganda & Program to Reduce Risky Sex Among Adolescent Boys: T \\
\hline
\end{tabular}


The interventions under the five strategies are summarized below. The table in Appendix 4 contains more detail about each of the 47 interventions and the outcomes associated with each intervention.

The strategies are characterized as proven, promising or emerging, drawing from the criteria used by the Family Planning High Impact Practices (FP HIP) Initiative. The definitions are as follows:

Proven: Sufficient evidence exists to recommend widespread implementation, provided that there is careful monitoring of coverage, quality and cost, and implementation research to help understand how to improve implementation.

Promising: Good evidence exists that these interventions can lead to impact; more information is needed to fully document implementation experience and impact. These interventions should be promoted widely, provided that they are implemented within the context of research and are being carefully evaluated both in terms of impact and process.

Emerging: Although emerging practices have a strong theoretical basis, they have limited evidence to assess impact. Therefore, emerging practices should be implemented within the context of research or an impact evaluation.

This review describes the range of evidence supporting the interventions comprising each strategy and also shows the countries in which the interventions under the strategy have been implemented. This gives a sense of the geographic spread of experience implementing the strategies.

\section{CLINIC PROVISION OF INFORMATION AND SERVICES TO MEN}

Providing clinical services to men is a promising intervention. The review found few instances of clinical provision of contraceptive services for men that were evaluated. Various USAID-funded projects (e.g. the ACQUIRE and RESPOND projects through EngenderHealth and the CAPACITY Plus and PROGRESS Projects through IntraHealth and FHI 360) have promoted vasectomy use, and while organizations like Marie Stopes International provide vasectomy services at local clinics, clinic provision of information and contraceptive services for men is largely lacking in most regions.

Interventions and Countries: The review includes four interventions on clinic provision of information and vasectomy services that included some evaluation. These programs were in Bangladesh, Tanzania, Papua New Guinea, India, Ghana, and Rwanda.

Description of the Interventions: The interventions included training providers in both provision of the method and in counseling. In these programs, addressing barriers specific to vasectomy is important (e.g., myths about loss of virility, lack of provider knowledge of vasectomy, and the perception that demand for male sterilization is low and that female sterilization is preferable) (Perry et al., 2016).

Supporting Evidence: The evidence supporting these promising interventions generally comes from service statistics. Client-provider communication was assessed in the intervention in Ghana through use of mystery clients.

Outcomes: Among MSI clinics with available statistics on vasectomy, Bangladesh and Papua New Guinea showed positive trends in use, while outreach in Tanzania yielded negligible use (MSI, 2010; Fandim, 2016; MSI, ND; and Ntinginya et al., 2016). In India, non-scalpel vasectomy programming under the USAID-RESPOND program increased three-fold, from 1,646 in 2010 to 5,009 in 2012 (Singh et al., 2014). In Rwanda, between 2010 and 2012, 2,523 vasectomies were performed under a program supported by the CAPACITY 
Plus and PROGRESS Projects. At each program site, more clients were available than could be accommodated (Perry et al., 2016). While the numbers of vasectomy users remains small, the trends are in the right direction and show promise for expanding provision of clinical family planning services for men.

While not an intervention included in this review, World Vasectomy Day, a global effort to shift views on vasectomy, including increasing men's comfort level with the procedure, was started in 2012 (www.worldvasectomyday.org). It is an annual educational event to increase awareness of, conversations about and demand for vasectomy, and thus support men's use of contraception and support for women, who are often responsible for family planning. World Vasectomy Day 2014 was widely publicized and events were streamed to more than 10,000 followers. Five hundred doctors in 32 countries performed an estimated 3,000 vasectomies. World Vasectomy Day 2015 was also celebrated around the world, with special events in Indonesia linked to the International Conference on Family Planning.

\section{OUTREACH PROGRAMS THROUGH MALE MOTIVATORS AND PEER EDUCATORS/MENTORS}

Providing outreach programs through male motivators is a proven intervention and use of peer educators/ mentors is emerging. Although most family planning outreach workers are women, some programs have used male outreach workers to engage men. Operations research in a number of countries, including Peru in the late 1980s, showed that male outreach workers could successfully reach men, that community-based distribution (CBD) programs that include male workers can influence both client- and method-mix, and that male CBD workers do not require special training or client materials (Foreit et al., 1992). A review of more recent programming has found a resurgence in the targeted use of trained male peers to encourage frank discussions about male contraceptive use, family planning and gender norms.

Number of Interventions and Countries: The review includes 10 interventions that included Male Motivators and Peer Educators/Mentors. These programs were in Malawi, Pakistan, India, El Salvador, Guatemala, India, the Philippines, Nigeria, Madagascar, Timor Leste, Ghana, Ecuador, Nicaragua, and Kenya.

Description of the Intervention: Male motivator or peer educator interventions had male motivators/educators provide information to other men, build condom use and communication skills and, in some cases, provide contraceptives directly or refer participants to nearby services. Some interventions also covered alcohol, smoking, violence, maternal/child health, and sexually transmitted infections. In a number of interventions, male motivators were part of complementary programming of female motivators for women. While not all male peer programs are designed to promote increased contraceptive uptake specifically by men (e.g., they include male methods in discussion of a broader range of methods), many do have a positive impact on gender equality and more gender-equitable approaches to contraceptive decision-making (Adizue et al., 2016; Mugore et al., 2016).

Supporting Evidence: The evidence supporting these proven interventions ranges from randomized intervention/control studies (3), to pre-post intervention studies using non-randomized intervention and control designs (3), a post-intervention survey (1), qualitative interviews and/or focus group discussions (3), service statistics (4), and one intervention as yet to be evaluated.

Outcomes: Male peer programming found in this review often directly encouraged male contraceptive use. In India and the Philippines, among other countries, male outreach workers successfully facilitated the use of SDM among community members (Johri et al., 2005; León et al. 2014; Lundgren et al., 2012). Most other interventions, however, focused on condom use - in many cases for both family planning and disease protection. The StationGuards in Ghana (commercial lorry drivers and their assistants) talked to their peers about the benefits of family planning and sold condoms and oral contraceptive pills. One driver said his peers 
initially teased him, but those men ultimately became clients and purchased condoms themselves (Owusu et al., 2016). The Clinic Café in Timor Leste also promoted use of condoms among male peers, but found little contraceptive uptake, likely attributable to a lack of condom availability - an important provision of any programming designed to create demand (Tekponon Kikuagou Project, 2013).

Many of the male motivator interventions were particularly focused on addressing gender norms and reducing barriers to service as key issues in supporting male contraceptive use. For example, male motivators in the Malawi Male Motivators project disclosed their own experience in family planning and fostered frank discussions with men about their experiences, in addition to reinforcing the importance of spousal communication in family planning. Although men remained the decision-makers within the household, the experience facilitated greater discussion among couples. Women reported they felt more respected by their partners, representing a positive shift toward more equitable decision-making (Shattuck et al., 2011). The HIM (Health Images of Manhood) Approach in Madagascar helped young men (ages 15-24) explore the effects of gender norms on both their own health and that of their partners in addition to promoting men's use of health services (Lalaharimanitra et al., 2016).

In addition to the HIM Approach, interventions in Kenya and Latin America used peer providers and mentors to reach young men with contraceptive information and services. The Peer Provider project in Ecuador and Nicaragua found at endline that $47 \%$ and 35\% (respectively) of the youth surveyed used condoms. In both countries, more than $60 \%$ of respondents were male (Tebbets and Redwine, 2013). Life Planning mentors in Kenya partnered with university students to discuss basic facts on contraception and the role of contraception in achieving life goals. As a result, twenty-five percent of students started using a contraceptive method; $12 \%$ said they intended to start using a method and $63 \%$ initiated a discussion about contraceptive with their partner (Nijiri et al., 2016). This data was not disaggregated by sex or method use, however, so it difficult to know the true impact on men in the study.

Some interventions educated men about birth spacing and reproductive and maternal health in order to help men understand the importance of family planning not only to encourage men to seek services themselves, but also as a way to lower the barriers to women's access to services. The Access/MCHIP project in Nigeria noted in their final report that trained male birth spacing motivators counseled and referred 11, 371 men, of whom, $28.3 \%$ accepted a family planning method for themselves or their spouses. Data was not provided, however, on male or female use of contraception (MCHIP, 2015). In the FALAH project in Pakistan, male community-based volunteers provided information about contraceptive methods, allaying any misconceptions and encouraging men and women to access family planning. About half of the female respondents reported that their husbands participated in intervention activities conducted by male outreach workers. Men were not included in the evaluation, however (Ashfaq and Sadiq, 2015).

Overall, male motivators/peers appear to be able to increase contraceptive use among men, including condoms and participation in SDM, in addition to promoting men's support for their partners' use of family planning. A qualitative evaluation of a male engagement project in India found that participatory learning sessions led to increased partner communication and more than 300 men who opted for male sterilization (Liem and Choudhury, 2016). The Malawi Male Motivators project saw increased contraceptive use in the intervention group (78\%) versus the control group (59\%), with men's discussion with their wives a significant factor in their uptake; fifty-six percent of the men reporting family planning uptake used condoms (Hartmann et al., 2012).

To improve male motivator/peer educator programs, it would be useful to have a clear idea about how these programs reach men directly as users, and also how they reach men to support their partners' family planning use. Male motivators programs should have strong monitoring and evaluation, while peer educators/mentors programming needs more robust research as they are being developed and implemented. 


\section{COMIMUNICATIONS PROGRAMIMING}

\section{Social Marketing}

Social marketing of contraceptives, considered a high impact practice for family planning (HIP, 2013c) is a proven practice. Social Marketing has had positive effects on knowledge of and access to contraceptive methods, including condom use (Piet-Pelon et al., 1999; Harvey, 2008; Chapman, 2003; Madhavan, 2010; Sweat et al. 2012). Social marketing is intended to fill the gap between public sector and commercial sector programming. It aims to increase access to contraceptive products in private sector outlets (e.g. pharmacies and shops) through the use of commercial marketing techniques for a public health end.

Number of Interventions and Countries: The review includes three social marketing interventions with measured outcomes related to men's use of family planning. These interventions were in Pakistan, Cameroon and Senegal and primarily focused on condoms for men.

Description of the Interventions: Social marketing interventions have used television and radio advertising campaigns focusing on condoms - to increase awareness of the effectiveness of condoms, reduce embarrassment when purchasing or negotiating condom use, and increase use of condoms. Social marketing can challenge social norms and help overcome barriers to acceptability of contraceptive use. The three social marketing programs included in this review generally aimed to increase awareness of contraceptive methods overall and addressed method-specific challenges, information and service provision and gender norms and equality.

Supporting Evidence: The evidence to support this proven practice comes from pre-post intervention surveys (2) and a post-intervention survey (1).

Outcomes: The social marketing interventions in Pakistan and Cameroon, used television and radio advertising campaigns focusing on condoms in particular - to increase awareness of the effectiveness of condoms, reduce embarrassment when purchasing or negotiating condom use, and to increase use of condoms generally. In Pakistan, consistent condom use with wives increased and in Cameroon, among youth condom use increased from $58.7 \%$ to $70.2 \%$ after the intervention. It is worth noting that neither withdrawal nor SDM were the primary subject of any of the social marketing campaigns in this review.

Social marketing program have been successful in reaching men of all ages, particularly to promote condom use. Ensuring that messages promote men's potential for using family planning in addition to supporting their partners' use would further strengthen social marketing programming.

\section{Mass Media and Social Media}

Mass media has long been used to promote family planning and is considered a promising intervention, while use of social media is more recent and is considered emerging.

Number of Interventions and Countries: The review included seven interventions that used mass media and social media to reach men. These programs were in Bangladesh, Ghana, Honduras, Guatemala, Pakistan, India, Vietnam, Burkina Faso, Tanzania, and Nicaragua.

Description of the Interventions: This type of programming, including media and advertising campaigns carried out via radio, television, newspapers, billboards, brochures, and social media sites, such as Facebook, can address men's use of contraception as well as to increase men's support for their partners' contraceptive use. They can shift the perception that family planning is a women's affair. They can also address gender norms and equality in family planning and contraceptive use. For example, the Get a Permanent Smile campaign in Bangladesh, Ghana and Honduras directly targeted myths and misperceptions about vasectomy 
through radio, television, billboard and other campaigns to increase men's uptake of the procedure (Perry et al., 2016; Rajani, 2005; Subramanian et al., 2010).

Supporting Evidence: The evidence supporting these promising (mass media) and emerging (social media) interventions include: pre-post intervention surveys (4), and service statistics (3). In addition, two interventions included focus group discussions and one included interviews with men that augmented service statistics.

Outcomes: A radio serial drama in Burkina Faso sought to shift the perception that family planning is a woman's affair. Results showed that listeners were 1.5 times more likely to discuss family planning with their spouse/partner, 3.5 times more likely to approve of family planning and 2.6 times more likely to know sources of family planning information (Jah et al., 2016). In Vietnam, an information, education and communications (IEC) program promoted male responsibility in family planning with messages such as "he is very manly, he always cares for his family." In addition to the IEC materials, radio broadcasts promoted couple communication about reproductive health and encouraged men to use condoms. By the end of the project, condom use increased by 50\% (MacDonald et al., 2013).

Use of social media is in its inception phase so accompanying such programming with robust research will be beneficial. With its scale of implementation, mass media programming has the potential to promote normative change around gender norms and male engagement in family planning, including contraceptive use. For example, in Pakistan, 50 million people were exposed to FALAH Project messages, at least half of whom were men. Ensuring that messages are gender transformative and that they promote men as users in addition to supportive partners remains crucial. Including strong monitoring and evaluation as part of mass media programming will be important to measure their impact on men's use of family planning.

\section{mHealth}

Mobile health (mHealth) text messaging programs, considered a new technology by the FP HIP Initiative and a means of enhancing programming (HIP, 2013b) are gaining traction in family planning programming.

Number of Interventions and Countries: The review includes four interventions that used mHealth to reach men. These programs were in Nigeria, Mozambique, India, Ghana, Tanzania and Rwanda.

Description of the Interventions: These interventions build on evidence that providing family planning information through phones, particularly knowledge-based fertility awareness methods, offers an acceptable and effective means of increasing knowledge.

Supporting Evidence: The evidence for this FP HIP new technology enhancement comes from a pre-post intervention study (1) and service statistics (3).

Outcomes: Experience with mHealth programming suggests that men, particularly young men, are drawn to them as a means of getting information about family planning and that women often rely on their partners to use SMS systems. An SMS program in India to provide information about fertility awareness and Standard Days Method found that users were on average age 33, married and 72\% male (Ettinger et al., 2016). mHealth text messaging programs in Nigeria and Mozambique attracted substantial numbers of men - particularly younger men - as well (Ajidagba et al., 2016; Feyisetan et al., 2016).

While this type of programming to reach men is growing, little is known about the extent to which men's knowledge about, access to or use of services increases as a result of these programs due to a lack of evaluation and/or sex-disaggregated data. Further mHealth programming should be accompanied by robust evaluation of what men do with the information they receive from mHealth platforms and if their use of contraception and/or support for their partners' use of family planning increases. 


\section{Hotlines}

Hotlines have long been part of family planning programming, although their use for reaching men has not been fully explored, so they are still an emerging intervention.

Description of the Intervention: Similar to SMS services, hotlines provide information to men and women on sexual and reproductive health, including family planning.

Number of Interventions and Countries: The review includes three interventions that included hotlines. These programs were in Uganda and the Democratic Republic of Congo.

Supporting Evidence: Evidence to support this emerging practice including user call statistics (2) and a survey of users of a hotline (1).

Outcomes: Information and service needs were the subject of a campaign in Uganda. Statistics from the National Toll Free Hotline for information, counselling and referral in Uganda found that from October 2014-February 2015, the Hotline received a total of 877 calls mostly from youth ages 15-19 years, with 559 male callers and 318 female callers. Some of the males indicated that they called on behalf of their girlfriends.

Men are attracted to hotlines for information about family planning. Statistics suggest that where hotlines are available, men tend to be more heavy users of them than women. Men call both for themselves and for their partners. While use statistics show that men can be heavier users of hotlines than women, little is known about the extent to which men's knowledge or access to services increased as a result of these programs due to a lack of evaluation and/or sex-disaggregated data.

Given that men find hotlines an acceptable means of accessing information about family planning and reproductive health, these programs should ensure that they are tailoring messages for men as family planning users. Programing through hotlines should Similar to mHealth, further programming that includes hotlines should include evaluation of what men do with the information they receive from mHealth platforms and if their use of contraception and/or support for their partners' use of family planning increases.

\section{COMMUNITY ENGAGEMENT}

\section{Promoting Community Dialogue}

Engaging the larger community is a strongly promising intervention to foster a sense of legitimacy and normalcy for men's participation in conversations about and use of contraception. Community engagement approaches bring young people, men and women together, sometimes with community and religious leaders, to create a unified understanding of family planning, including such things as norms, values, roles in family planning and availability of and access to services.

Number of Interventions and Counties: The review includes 10 interventions that included Promoting Community Dialogue. These programs were in Kenya, Uganda, South Africa, Nigeria, Pakistan, Brazil, and India.

Description of the Interventions: Content for these programs primarily consisted of social and behavioral change communication (SBCC) strategies intended to promote equitable gender norms and attitudes. Some of the interventions were tailored to changing gender norms and risking sexual behavior among young men, while others focused on adult men, including in group meetings. Most programs also included women as part of community dialogues. Somos Differentes, Somos Iguales (We're Different, We're Equal) in Nicaragua focused on empowerment through communication for social change (Solarzano et al., 2008). In CARE's Family Planning Results Initiative, Chiefs' community dialogues involved men in conversations about family planning 
(CARE, 2013). The participation of prominent male leaders helped legitimize men's participation in family planning. A different approach to promoting community dialogue involved the Village Saving Loaning Associations in Uganda, a microfinance program focused on men and included in family planning activities such as dialogues, board games, and SMS messages for discussion by men (Nakasagga and Nalule, 2016).

None of the programs included in this strategy have focused solely on male use of contraception, although increasing acceptability of family planning generally could have positive effects on couple communication, and use of contraception, including by men.

Supporting Evidence: The evidence to support this strongly promising intervention for reaching men as family planning users ranges from randomized control trials (2); quasi-experimental, with intervention and control groups (4); baseline/endline surveys (3) and post-intervention qualitative evaluation (1). Promoting community dialogue is strongly promising for men as family planning users because it has mostly been used to address HIV and gender norms.

Outcomes: While not explicitly directed at men as contraceptive users, many of these programs resulted in increased condom use. Overall findings from these programs found reductions in myths around family planning, improved communication with partners about family planning and increased use among men (although not all programs indicated if the increased use was of male methods). CARE's Family Planning Results Initiative in Kenya found an increase in current use of modern contraceptives (male condoms and sterilization) among men (24.7\% to $51.1 \%$ over the course of the three-year project) as well as a statistically significant increase in knowledge of female condoms and withdrawal (Care, 2013). None of the men began the program with Village Saving Loaning Associations in Uganda using family planning though $38 \%$ of spouses reportedly used contraception. After 12 months, $15 \%$ of men were using family planning (with use by partners even higher) (Nakasagga and Nalule, 2016). Men in intervention communities of the SASA! program to reduce gender based violence in Uganda were significantly more likely than men in the control communities to be using condoms (Abramksy et al., 2014; Kyegombe et al., 2014). Similar findings resulted from implementation of Stepping Stones among young men in South Africa (Jewkes et al., 2007: Jewkes et al., 2008).

Among a follow up of 217 boys in Brazil, Program H led to a significant increase in condom use among young men from $58 \%$ at baseline to $87 \%$ at endline, as well as a significant change in attitudes to be more gender equitable (Ricardo et al., 2010). Men in the Yaari Dosti intervention sites in Mumbai were 1.9 times more likely and in rural Uttar Pradesh 2.8 times more likely to have used condoms with all types of partners than were young men in the comparison sites in each place (Verma et al., 2008).

Community dialogue has been successful in promoting more equitable gender norms and reducing risky sex. These programs have promoted condom use among men. This approach has been used to promote family planning, including men's support for their partners. Including attention to men as family planning users would strengthen these programs.

\section{Engaging Religious Leaders}

Religious leaders can have a large influence on men's and women's attitudes towards family planning. Ensuring that religious leaders are educated about family planning and their faith tradition can in turn help ensure that the messages they share with their communities are evidence-informed and supportive. Engaging religious leaders to support family planning has been a key part of programming for many years, although few interventions have focused specifically on men's use of family planning. This strategy is considered an emerging intervention.

Number of Interventions and Countries: The review includes two evaluated interventions that engaged religious leaders. These programs were in Kenya and Pakistan. 
Description of the Interventions: These interventions included providing orientation and updated information on family planning to religious leaders. In turn the religious leaders reached out to their communities with the information and their support for family planning. Religious outreach was linked with availability of services. The Tupange Project in Kenya employed strategies to work with religious leaders (Christian and Muslim) to advocate and provide correct and accurate information on family planning in the community (Sirera et al., 2016). In Pakistan, 1,500 religious scholars and leaders were trained under the FALAH Project to enable them to advocate for birth spacing (Asfaq and Saddiq, 2015).

Supporting Evidence: The evidence to support this emerging practice include: longitudinal survey with baseline and endline (1) and baseline/endline surveys with qualitative interviews (1).

Outcomes: In Kenya, the Tupange project found a 25\% decline in myths and misconceptions about family planning over the course of the project where religious leaders were linked with community health focal persons and religious leaders referred 22 men from two areas for vasectomy (Sirera et al., 2016). In Pakistan, many religious leaders agreed with the consideration of family planning as birth spacing and could correct the perception that religion is opposed to family planning. Men who attended talks by sensitized religious leaders had a 23 percentage point higher predicted probability of responding positively to their wives about family planning (Ashfaq and Sadiq, 2015).

Religious leaders have been successful in promoting support for family planning and dispelling myths about religious opposition to it. Given the respect for religious leaders within communities, adding their voices to supporting men's use of contraception would strengthen this programming.

\section{COMPREHENSIVE SEXUALITY EDUCATION}

School-based comprehensive sexuality education, a promising intervention, can reach large numbers of young people when their ideas of appropriate behavior and roles of men and women are forming (Haberland, 2015). Sex education programming offers an opportunity to address the sexual and reproductive health needs of boys as well as provide information about family planning and fatherhood. However, relatively few sex education curricula specify anything related to unique sexual and reproductive health needs of men/boys due to entrenched gender norms (Stern, 2015). Furthermore, few comprehensive sexually education programs disaggregate outcomes by sex, so it is difficult to identify the effects of these programs on boys.

Number of interventions and countries: The review includes four interventions that included comprehensive sexuality education. These programs were in Tanzania, Uganda, the Balkans and Thailand.

Description of the Interventions: Three of the four interventions included school-based CSE curricula that promoted gender-equitable attitudes on sex, health and well-being, and the fourth, an out-of-school program, included five one-hour interactive group sessions that included discussion of contraceptive methods.

Supporting Evidence: The evidence for this promising practice ranges from pre-post intervention surveys with intervention and control groups (1); in-depth interviews long-term post intervention (1); qualitative indepth interviews and focus group discussions (1); and pre-post intervention quantitative survey and qualitative interviews (1).

Outcomes: The CSE programs in this review increased boys awareness of sex and pregnancy prevention and increased gender-equitable attitudes. The retrospective study of a CSE program in Tanzania suggests that while boys may not fully comprehend the messages they are receiving at the time, they internalize it later as they become sexually active (Wayomi et al., 2012). In that study, nine years after the intervention, all the young men interviewed said they had used condoms. The men reported that they only saw the benefits of the 
pregnancy prevention information after they finished school and were married. Three of the four programs were conducted in school with secondary or vocational students. Participants were predominantly boys, with the exception of Uganda where boys made up 44.8\% of participants (Rijsdik et al., 2011). The Thailand program was carried out among adolescent boys in a non-school-based setting. The programs were generally a series of 5-10 hour-long sessions providing information and discussion about sexual and reproductive health, pregnancy, communication and condom use skills. The Balkans program also focused specifically on gender attitudes and sexual behavior.

While there are a number of ongoing CSE programs, evaluations of the impact of comprehensive sexuality education on boys' use of contraception, particularly beyond condoms, are elusive. Further evaluation that includes long-term follow up would be useful to guide CSE. Furthermore, such programs should incorporate the sexual reproductive health needs of boys and their role in preventing unintended pregnancy.

\section{SUMMARY OF KEY OUTCOMES FROM PROGRAMIMING TO PROMOTE MEN'S USE OF FAMILY PLANNING}

While some of the interventions included in this review did not specifically measure use of male methods, nor did they all disaggregate data by sex, it is nevertheless possible to draw some conclusions about the effect of programming on male use of contraception. In short, interventions reviewed sought to improve men's attitudes towards family planning, their knowledge of specific methods of contraception, and their use of family planning generally or male methods specifically. Furthermore, most of the interventions sought to address gender norms around family planning use - mostly to promote male support for their partner's use, but also some to promote male use of methods. The interventions found, as other cross sectional studies show, that men want information on family planning and the notion that family planning is women's business only is antiquated (MacQuarrie et al., 2015). When male methods, notably condoms, vasectomy and SDM, were made available through interventions, uptake generally increased.

Much of the condom programming has focused on HIV, with some attention to dual protection for pregnancy prevention as well. Condom use increased through communications programming, outreach, and community engagement in Pakistan, Cameroon, Senegal, Nicaragua; Uganda, Malawi, India, Nigeria, Madagascar; Ghana; El Salvador; Kenya; South Africa; Brazil, and India. The evaluations of three of the four CSE did not measure condom use. The fourth, which was a retrospective evaluation of a CSE program nine years after it was implemented, found that all men interviewed had used condoms since the CSE.

Fewer interventions included vasectomy; yet where vasectomy programming exists, use generally goes up. Evaluations of the Permanent Smile campaign in Ghana, Bangladesh and Honduras also found that use decreased after the end of the project. The RESPOND Project in India showed that with training and improved quality of services, that uptake of no scalpel vasectomy rose. Marie Stopes International is finding increased interest in vasectomy in some countries, such as the highlands in Papua New Guinea and Madagascar. MSI is increasing the scope of its vasectomy programming. Innovative social media programming shows promise, as demonstrated by the WINGS program's use of Facebook to promote vasectomy services in Guatemala. Under the Tupange project in Kenya, religious leaders referred men for vasectomy. While small, these efforts, combined with initiatives such as World Vasectomy Day, show promise for vasectomy.

Reviews of programming on SDM in a range of countries show that where the programming exists, use goes up and it improves couple communication about family planning. None of the interventions reviewed included promotion of withdrawal; however programming for men in Pakistan did increase use of that method in addition to increases in use of female methods.

Other outcomes of the interventions reviewed include more favorable attitudes towards family planning among men. Furthermore, the interventions resulted in better knowledge about family planning and specif- 
ic contraceptive methods. Findings from the range of interventions reinforced that men want information about family planning for themselves and their partners. Men want information and seek it from hotlines and SMS and listen to it from a range of media and outreach workers/peer mentors. Stories about male engagement and men as family planning users resonate with both men and women.

Finally, a number of the interventions had positive outcomes related to promoting more equitable gender norms related to family planning and increasing couple communication on fertility and contraceptive use.

\section{EVIDENCE GAPS IN PROGRAMIMING FOR MEN AS CONTRACEPTION USERS}

This review has found few robust evaluations of programs to engage men, let alone programs directed at men as users. Many of the male-focused programs have positioned men as partners and supporters of women's contraceptive use and thus it is difficult to separate those interventions from those aimed at increasing male contraceptive use and engaging men in their own sexual and reproductive health. Furthermore, not all programs report findings disaggregated by sex, and by contraceptive method, making it difficult to determine the effect of programming on male use of methods. Few studies ask men directly about their experiences with contraception, but instead are most likely to ask female partners what changes have occurred in male partners' attitudes and practices based on interventions with women (Hosseini et al., 2010; Yadav et al., 2010; Kamran et al., 2015; PMNCH, 2013).

More systematic data collection on men's fertility and relationships could greatly enhance information and service provision for men. There is little literature on factors to increase uptake or barriers that prevent men from using contraception from the viewpoint of men themselves (Kabagenyi et al., 2014), including documenting and measuring how household decisions and contraceptive decisions are made (Firestone, 2015). Regional and country contexts are important in developing this research.

Critical research is missing on what are effective programs to increase responsibility by adolescent boys, prior to sexual activity, to prevent unintended pregnancy through male or female contraceptive use, as well as to ensure dialogue on pregnancy prevention, and that the sexual act is consensual.

Programming to promote existing male methods could benefit from further evaluation. For example, though it does not have recurrent costs, SDM requires counseling and provider training. Further evaluation of SDM programming could lead to a greater understanding of how to better position the method for increased use. Condom programming would benefit from additional research on how to sustain condom use after marriage, especially as a dual strategy. Vasectomy programming may benefit from further evaluation of successful interventions that have dispelled myths and fears of loss of potency for men and that have changed community norms around the acceptability of men being sterilized. While programs do not promote withdrawal, research could help position it at least as a method couples could use if needed in the absence of another method.

In reviewing evidence on programming for men as family planning users, the lack of a short or long-term reversible method for men that falls between condoms and vasectomy is abundantly clear. There is sizable demand for a novel male contraceptive option, particularly for reversible contraception (Glasier, 2010; Kabagenyi et al., 2014). In a survey of more than 9,000 men ages $18-59$ across nine countries, $28.5-71.4 \%$ of men of various nationalities expressed a willingness to use a hormonal male contraceptive (Heinemann et al., 2005). Work to develop additional male methods of contraception has been going on for decades with a focus on hormonal and non-hormonal approaches. Creation of novel hormonal methods for men has stalled, however. Development of hormonal methods for men has proved complicated in that there is no natural non-fertile state in men to mimic. Many of the attempted hormonal formulations created for men have had a number of intolerable side effects (Dorman and Bishai, 2012). Still, a number of prospective methods for men are in 
development, including non-hormonal methods (http://www.malecontraceptive.org/prospective/). Funding is a challenge for male contraceptive development. Pharmaceutical companies are not currently investing in new contraceptive development, leaving smaller efforts by non-profit organizations and foundations to fill the gaps. With adequate funding, there could be a new male contraceptive on the market within a decade. Without adequate funding, efforts may take 20 or more years to bear fruit.

Finally, funding for evaluation and implementation science remains an ongoing challenge. Some efforts would benefit from rigorous evaluation but do not have funds to carry out endline surveys or evaluate that data. For example, there is a current effort to increase contraceptive use among both boys and girls in Togo using the "It's All One" curriculum, but evaluation of gender-related and contraceptive uptake outcomes is needed (Toliver, 2015). CARE may have plans to adapt the United States curriculum "Gender Matters", which promotes gender equality and discusses boys and contraception, for West Africa, but has no funding or plans for evaluation. (De Atley, 2015).

In addition to the programming reviewed above, filling in the gaps in implementation science research and evaluation can begin to change the direction of family planning programming toward more inclusive approaches for men as family planning users.

\section{CONCLUSION}

There remains a scarcity of direct programming addressing men's contraceptive use and gaps remain in programming interventions that will both increase and meet demand. However, there is more than enough evidence demonstrating men's desire for information and services, as well as men's positive response to existing programming to warrant further programming for men and boys in family planning and contraceptive services. Such programming should be accompanied by strong monitoring and evaluation and rigorous implementation science. This review and synthesis of current work, along with recommendations for further implementation science research, highlights the need to engage men as family planning users in addition to efforts to address gender-based norms and behavior that hinder family planning use. 


\section{References}

Abramsky, T., Devries, K., Kiss, L., Nakuti, J., et al. 2014. "Findings from the SASA! Study: a cluster randomized controlled trial to assess the impact of a community mobilization intervention to prevent violence against women and reduce HIV risk in Kampala, Uganda.” BMC Medicine 12(1): 1-17.

Adizue, J., Anonyuo, N., Guraguri, A. and Anyanti, J. 2016. "Community Based Distribution as a Tool to Reducing the Modern Contraceptive Unmet Need Gap in Rural Communities in Zamfara State, Nigeria." Abstract at the 2016 International Conference on Family Planning. Nusa Dua, Indonesia. January 25-28.

Adongo, P.B., Tapsoba, P., Phillips, J.F., Tabong, P.T., et al. 2014. "'If you do vasectomy and come back here weak, I will divorce you': a qualitative study of community perceptions about vasectomy in Southern Ghana." BMC International Health and Human Rights 14(1): 1-8.

Agha, S. and Beaudoin, C.E. 2012. "Assessing a thematic condom advertising campaign on condom use in urban Pakistan.” Journal of Health Communication 17(5): 601-623.

Agha, S. and Meekers, D. 2010. "Impact of an advertising campaign on condom use in urban Pakistan." Studies in Family Planning 41(4): 277-290.

Ajidagba, E.B., Adenipekun, A., Mapayi, B., Bello, B.M. et al. 2016. "Breaking Barriers of Youth's Access to Contraceptives: The Mobile Phones Technology Approach.” Abstract at the 2016 International Conference on Family Planning. Nus Dua, Indonesia. January 25- 28.

Ashfaq, S. and Sadiq, M. 2015. "Engaging the Missing Link: Evidence from FALAH for Involving Men in Family Planning in Pakistan.” Washington, DC: Population Council, The Evidence Project.

Arevalo, M., Jennings, V., \& Sinai, I. 2002. "Efficacy of a new method of family planning: the Standard Days Method." Contraception 65(5): 333- 338.

Bekele, B., and Fantahun, M. (2012). "The Standard Days Method: an addition to the arsenal of family planning method choice in Ethiopia." Journal of Family Planning and Reproductive Health Care, 38(3): 157-166.

Berer, M. 1996. “Men.” Reproductive Health Matters 7: 7-10.

Bietsch, K.E. 2015. “Men's Attitudes towards Contraception in Sub-Saharan Africa.” African Journal of Reproductive Health 19(3): 41-54.

Blair, C., Sinai, I., Mukabatsinda, M. and Muramutsa, F. (2007). "Introducing the standard days method: expanding family planning options in Rwanda." African Journal of Reproductive Health 11(2): 60-68.

Boender, C., Santana, D., Santillán, D., Hardee, K., et al. 2004. “The 'So What?’ Report: A Look at Whether Integrating a Gender Focus into Programs Makes a Difference to Outcomes.” Washington, DC: Interagency Gender Working Group.

Bullough, V.L. 2001. Encyclopedia of Birth Control. Santa Barbara, CA: ABC-CLIO.

Cabinet Sen Ingénierie Consult [Senegal]. 2014. "Evaluation a mi-parcours de la campagne de communication sur la planification familiale 2013-2014.” Dakar, Senegal: Ministère de la Sante et de l'Action Sociale. 
Capo-Chichi, V. and Anastasi, E. 2005. "Introduction of the Standard Days Method of family planning into reproductive health programs in Benin West Africa." Washington, DC: The Institute for Reproductive Health, Georgetown University.

Cates, W. and M. Steiner. 2002. "Dual Protection Against Unintended Pregnancy and Sexually Transmitted Infections: What Is the Best Contraceptive Approach?” Sexually Transmitted Diseases 29(3): 168-174.

CARE. 2013. "The Family Planning Results Initiative in Kenya (2009 - 2012): Initial Findings from the End Line Program Evaluation.” Atlanta, GA: CARE.

Chapman, S and Astatke, H. 2003. "Review of DFID Approach to Social Marketing. Annex 5: Effectiveness, Efficiency and Equity of Social Marketing. Appendix to Annex 5: The Social Marketing Evidence Base." London, UK: DFID Health Systems Resource Centre.

Contech International. 2011. "Impact Evaluation of Community-Based Volunteers: A Third-Party Evaluation Study.” Lahore, Pakistan: Contech International.

Croce-Galis, M., Salazar, E., and Lundgren, R. 2014. "Male Engagement in Family Planning: Reducing Unmet Need for Family Planning by Addressing Gender Norms.” Washington, DC: Institute for Reproductive Health, Georgetown University.

Daniel, E.E., Masilamani, R. and Rahman, M. 2008. "The effect of community-based reproductive health communication interventions on contraceptive use among young married couples in Bihar, India." International Family Planning Perspectives 34(4): 189-197.

Daniel, E.E, Hainsworth, G., Kitzandtides, I., Simon, C., et al. 2013. "PRACHAR: Advancing Young People's Sexual and Reproductive Health and Rights in India." Watertown, MA: Pathfinder.

De Atley, J. 2015. Personal communication with Jill Gay, December 2.

Dorman, E. and Bishai, D. 2012. "Demand for male contraception." Expert Review of Pharmacoeconomics \& Outcomes Research 12(5): 605-613.

Dosajh, U., Ghosh, I. and Lundgren, R. 2006. "Feasibility of incorporating the standard days method into CASP family planning services in urban slums of India." Washington, DC: The Institute for Reproductive Health, Georgetown University.

Drennan, Megan. 1998. “New Perspectives on Men’s Participation.” Population Reports Series J, no. 46. Johns Hopkins University.

Ebeigbe, P.N., Igberase, G.O. and Eigbefoh, J. 2011. "Vasectomy: a survey of attitudes, counseling patterns and acceptance among Nigerian resident gynaecologists." Ghana Medical Journal 45(3): 101-104.

Ettinger, A., Ashcroft, C.N., Ahmad, D., Chadha, C. and Shelus, V. 2016. "The linkages between Fertility Awareness and Family Planning Uptake: Program findings of scaling mHealth services in India." Abstract at the 2016 International Conference on Family Planning. Nusa Dua, Indonesia. January 25-28.

Exner, T.M., Mantell, J.E., Adeokun, L.A., Udohl, I.A., et al. 2009. "Mobilizing men as partners: the results of an intervention to increase dual protection among Nigerian men." Health Education Research: Theory and Practice 24(5): 846-854. 
Extending Service Delivery (ESD) Project. 2010. "Healthy Images of Manhood: A Male Engagement Approach for Workplaces and Community Programs Integrating Gender, Family Planning and HIV/ AIDS. A Case Study." Washington, DC: ESD.

Fandim, F. 2016. "Why are men in rural Papua New Guinea choosing vasectomy?” Abstract at the 2016 International Conference on Family Planning. Nusa Dua, Indonesia. January 25-28.

Feyisetan, B., Benevides, R., Badiani, R. and Mutombo, N. 2016. "Improving Youth's Sexual and Reproductive Health Knowledge, Attitudes, and Self-Efficacy Related to Contraception through Short Message Services (SMS) Education: Evidence from Mozambique." Abstract at the 2016 International Conference on Family Planning. Nusa Dua, Indonesia. January 25-28.

FHI 360, Rwanda Ministry of Health. Rwanda takes no scalpel vasectomy nationwide. Research Triangle Park, NC: FHI 360; 2011.

Firestone, R. 2015. Personal communication with Jill Gay. October 28.

Foreit, J.R., Garate, M.R., Brazzoduro, A., Guillen, F., et al. 1992. "A comparison of the performance of male and female CBD distributors in Peru." Studies in Family Planning 23(1): 58-62.

Freij, L.S., Lane, C., Muhuhu, P., and Wofford, D. 2011. Healthy Images of Manhood: A Facilitator Training Manual. Washington, DC: Pathfinder International, Extending Service Delivery Project.

Gallen, M.E., Liskin, L. and Kak, N. 1986. "Men-new focus for family planning programs.” Population Reports. Series J, No. 33. Baltimore, MD: Population Information Program, Johns Hopkins University.

Glasier, A.F., Anakwe, R., Everington, D., Martin, C.W., et al. 2000. "Would women trust their partners to use a male pill?” Human Reproduction 15(3): 646-649.

Glasier, A. 2010. “Acceptability of contraception for men: a review." Contraception 82(5): 453-456.

Greene, M.E., Barker, G., Olukoya, P., Pawlak, P., et al. 2011. "What Happens When We Engage Men? Analysis and Review of the Benefits and Risks. An analysis and review of the benefits and risks." Geneva: WHO. Unpublished Paper.

Gribble, J.N., Lundgren, R.I., Velasquez, C. and Anastasi, E.E. 2008. "Being strategic about contraceptive introduction: the experience of the Standard Days Method®." Contraception 77(3): 147-154.

Haberland, N.A. 2015. "The case for addressing gender and power in sexuality and HIV education: a comprehensive review of evaluation studies" International Perspectives on Sexual and Reproductive Health 41(1): 31-42.

Hardee-Cleaveland, K. 1992. "Use of Male Methods Varies by Region.” Network. Aug; 13(1):10-2.

Hartmann, M., Gilles, K., Shattuck, D., Kerner, B., et al. 2012. "Changes in couples' communication as a result of a male-involvement family planning intervention." Journal of Health Communication 17(7): 802-819.

Harvey, P.D. 2008. "Social marketing: no longer a sideshow" Studies in Family Planning 39(1): 69-72.

Heinemann, K., Saad, F., Wiesemes, M., White, S., et al. 2005. "Attitudes toward male fertility control: results of a multinational survey on four continents.” Human Reproduction 20(2): 549-556. 
Higgins, J. A., Gregor, L., Mathur, S., Nakyanjo, N., et al. 2014. "Use of withdrawal (coitus interruptus) for both pregnancy and HIV prevention among young adults in Rakai, Uganda." The Journal of Sexual Medicine 11(10): 2421-2427.

High Impact Practices in Family Planning (HIP). 2012. "Health Communication: Enabling voluntary and informed decision-making." Washington, DC: USAID. Accessed December 30, 2015. Retrieved from: http:/ / www.fphighimpactpractices.org/resources/health-communication-enabling-voluntary-and-informed-decision-making.

High-Impact Practices in Family Planning (HIP). 2013a. "Drug Shops and Pharmacies: Sources for family planning commodities and information." Washington, DC: USAID. Accessed January 5, 2016. Retrieved from http://www.fphighimpactpractices.org/resources/drug-shops-and-pharmacies-sources-family-planning-commodities-and-information.

High-Impact Practices in Family Planning (HIP). 2013b. mHealth: Mobile technology to strengthen family planning programs. Washington, DC: USAID; 2013 August. Available from http://www.fphighimpactpractices.org/resources/mhealth-mobile-technology-strengthen-family-planning-programs.

High Impact Practices in Family Planning (HIP). 2013c. "Social Marketing: Leveraging the Private Sector to Improve Contraceptive Access, Choice, and Use.” Washington, DC: USAID. Accessed January 5, 2016. Retrieved from https://www.fphighimpactpractices.org/sites/fphips/files/hip sm brief.pdf.

Hosseini, H., Naji, H., Mashhadizadeh, A., and Rezaei, A. 2010. “Evaluation of men's participation in group training of their wives in family planning programs." Iranian Journal of Nursing and Midwifery Research 15(Suppl 1): 292-295.

Interagency Gender Working Group (IGWG). 2006. "SysteMALEtizing Resources for Engaging Men in Sexual and Reproductive Health.” Washington, DC: IGWG. Available from: https://www.k4health.org/ sites/default/files/SysteMALEtizing.pdf. Accessed on June 28, 2016.

IGWG, 2009. Engaging Men for Gender Equality and Improved Reproductive Health.” Washington, DC: IGWG. Available from http://www.igwg.org/igwg media/engag-men-gendr-equal.pdf. Accessed on June 28, 2016.

International Planned Parenthood Federation (IPPF). 2013. "Gender, Masculinities \& Sexual Health in South Asia.” New Delhi, India: IPPF, South Asia Regional Office.

Institute for Reproductive Health (IRH). 2012. “The Standard Days Method®: A Modern Family Planning Method. FAM Project.” Washington, DC: Institute for Reproductive Health, Georgetown University.

IRH. 2013a. "From Family Planning to Fatherhood: Analysis of Recent Male Involvement Initiatives and Scale-up Potential.” Washington, DC: Institute for Reproductive Health, Georgetown University.

IRH. 2013b. "Using Most Significant Change Methodology to Evaluate Impact of a Health Innovation in Four Countries." Washington, DC: The Institute for Reproductive Health, Georgetown University.

IRH. 2016. “GREAT Project Endline Report: Gender Roles, Equality and Transformations Project.” Washington, DC: IRH, Georgetown University.

Irani, L., Ilene, S.S. and Fotso, J.C. 2014. "Relationship Characteristics and Contraceptive Use Among Couples in Urban Kenya." International Perspectives on Sexual and Reproductive Health 40(1): 11-20. 
Jah, F, Connolly, S., and Barker, K. 2016. 'Saving Mothers' and Children's Lives: Using Radio Serial Dramas (RSDs) to Promote Family Planning (FP) and Influence Maternal and Infant Health Attitudes, Intentions and Behavior in Burkina Faso." Abstract at the 2016 International Conference on Family Planning. Nusa Dua, Indonesia. January 25-28.

Jewkes, R., Nduna, M., Levin, J., Jama, N., et al. 2007. "Evaluation of Stepping Stones: A gender transformative HIV prevention intervention.” Pretoria, South Africa: Gender and Health Research Unit, Medical Research Council.

Jewkes, R., Nduna, M., Levin, J., Jama, N., et al. 2008. "Impact of stepping stones on incidence of HIV and HSV-2 and sexual behaviour in rural South Africa: cluster randomised controlled trial." British Medical Journal 337: a506.

Joanita, K., Nankunda, B. and Achola, R. 2016. "Using an Integrated Media Approach to Prevent Teenage Pregnancy in Order to Promote Delayed Marriage and First Pregnancy." Abstract at the 2016 International Conference on Family Planning. Nusa Dua, Indonesia. January 25-28.

John, N. A., Babalola, S., and Chipeta, E. 2015. "Sexual Pleasure, Partner Dynamics and Contraceptive Use in Malawi.” International Perspectives on Sexual and Reproductive Health 41(2): 99-107.

Johnson, T., Tucker, P. and Molokele, D. 2014. "Reflection.” In AIDS Accountability International and Sonke Gender Justice (eds.), Setting the national agenda and sharing contraceptive responsibilities: Spotlight on vasectomy access and uptake in South Africa. South Africa, pp. 6-7.

Johri, L., Panwar, D. and Lundgren, R. 2005. "Introduction of the Standard Days Method in CARE-Indias community based reproductive health programs." Washington, DC: The Institute for Reproductive Health, Georgetown University.

Kabagenyi, A., Jennings, L., Reid, A., Nalwadda, G., et al. 2014. "Barriers to male involvement in contraceptive uptake and reproductive health services: a qualitative study of men and women's perceptions in two rural districts in Uganda." Reproductive Health 11(1): 21.

Kamran, I., Tasneem, Z., Parveen, T. and Niazi, R. 2015. "Family Planning through the Lens of Men: Readiness, Preferences, and Challenges." Washington, DC: Population Council, The Evidence Project.

Kasongo, G. and Makuta, A. 2016. "Ligne Verte : Outil d’informations sur la Planification Familiale en République Démocratique du Congo.” Abstract at the 2016 International Conference on Family Planning. Nusa Dua, Indonesia. January 25-28.

Kothari, Shilpa. 2016. Using Social Media to promote family planning among Guatemalan men. WINGS. Unpublished Memo. Also see: https://www.facebook.com/183423425039015/photos La.307242555990434.65344.183423425039015/925820204132663/?type=3\&theater. Accessed June 27, 2016.

Kraft, J.M., Wilkins, K.G., Morales, G.J., Widyono, M., et al. 2014. “An evidence review of gender-integrated interventions in reproductive and maternal-child health.” Journal of Health Communication 19(Suppl 1): $122-141$.

Kursun, Z., Cali, S. and Sakarya, S. 2014. "The Standard Days Method®: efficacy, satisfaction and demand at regular family planning service delivery settings in Turkey." European Journal of Contraception \& Reproductive Health Care 19(3): 203-210. 
Kyegombe, N., Abramsky, T., Devries, K. M., Starmann, E., Michau, L., Nakuti, J., Musyua, T., Heise, L., and Watts, C. 2014. The impact of SASA!, a community mobilization intervention on reported HIV-related risk behaviors and relationship dynamics in Kampala, Uganda. Journal of the International AIDS Society, 17: 19323.

Lalaharimanitra, H., Hurley, L. and Rafalimanana, A.E. 2016. "Images of Manhood Approach: How Changing Gender Norms with Young Men Increased FP Use in Madagascar.” Abstract at the 2016 International Conference on Family Planning. Nusa Dua, Indonesia. January 25-28.

León, F., Lundgren, R., Sinai, I., Sinha, R., \& Jennings, V. 2014. Increasing literate and illiterate women's met need for contraception via empowerment: a quasi-experiment in rural India. Draft Version. Levack, A., Rolleriand, L. and DeAtley, J. 2013. "Gender matters: A gender-transformative teenage pregnancy prevention curriculum.” New York, NY: EngenderHealth.

Liem, L. and Choudhury, M. 2016. "Engaging Males in Family Planning in India." Abstract at the 2016 International Conference on Family Planning. Nusa Dua, Indonesia. January 25-28.

Lopez, L.M., Otterness, C., Chen, M., Steiner, M., et al. 2013. "Behavioral interventions for improving condom use for dual protection.” The Cochrane Database of Systematic Reviews 26(10).

Lundgren, R., Cachan, J. and Jennings, V. 2012. "Engaging Men in Family Planning Services Delivery: Experiences Introducing the Standard Days Method ${ }^{\circledR}$ in Four Countries." World Health \& Population 14(1): 44- 51.

MacDonald, L., Jones, L., Thomas, P., Thi Thu, L., et al. 2013. "Promoting male involvement in family planning in Vietnam and India: HealthBridge experience.” Gender \& Development 21(1): 31-45.

MacQuarrie, K.L.D., Edmeades, J., Steinhaus, M. and Head, K.S. 2015. "Men and Contraception: Trends in Attitudes and Use.” DHS Analytical Studies No. 49. Rockville, MD: ICF International. Retrieved from http://www.dhsprogram.com/pubs/pdf/AS49/AS49.pdf).

Madhavan, S. and Bishai, D. 2010. "Private Sector Engagement in Sexual and Reproductive Health and Maternal and Neonatal Health: a Review of the Evidence." London, UK: DFID Human Development Resource Centre.

Mahmood, A. 2012. Birth Spacing and Family Planning Uptake in Pakistan: Evidence from FALAH. Islamabad: Population Council.

Malarcher, S., Spieler, J., Fabic, M.S. and Jordan, S. 2016. "Fertility Awareness Methods: Distinctive Modern Contraceptives." Global Health: Science and Practice.

Marie Stopes International (MSI). N.D. "We Go Where They Go. The Story of Outreach in Tanzania." Accessed on February 13, 2016. Retrieved from http://outreach-in-tanzania.mariestopes.org/.

MSI. 2010. "Marie Stopes Vasectomy: Expanding Access in Bangladesh.” London, UK: MSI. Accessed on February 13, 2016. Retrieved from https://mariestopes.org/sites/default/files/MSV-expanding-access $\% 20$ in-Bangladesh.pdf

MSI. 2015. "Vasectomy Services and Research at MSI: An overview of projects in Ethiopia, Kenya, Tanzania, Uganda and Papua New Guinea.” Presentation Prepared by MSI. London, UK: MSI. 
Maternal and Child Health Integrated Program (MCHIP). 2015. "MCHIP Country Brief: Nigeria." MCHIP End-of- Project Report. Baltimore, MD: MCHIP, pp. 159-163. Accessed January 5, 2016. Retrieved from http:/ / www.mchip.net/ files/MCHIP-EOP-Combined-without-PPI-Redacted.pdf.

Mugore, S. 2016. "Implementing multi-pronged strategies to improve access to family planning (FP), method choice and new acceptors among underserved communities in Burundi." Abstract at the 2016 International Conference on Family Planning. Nusa Dua, Indonesia. January 25-28.

Nakasagga, M.F. and Nalule, S. 2016. "Village Saving and Loaning associations (VSLAs), a Platform for Increased Male Involvement for Continued Uptake of Modern Family Planning Among Marrieds.” Abstract at the 2016 International Conference on Family Planning. Nusa Dua, Indonesia. January 25-28.

Namy, S., Heilman B., Stich, S. and Edmeades, J. 2014. "Be a man, change the rules! Findings and lessons from seven years of CARE International Balkans' Young Men Initiative.” Washington, DC: International Center for Research on Women.

Nassozi, F. and Mugoya, V. 2016. "Increasing Access to Family Planning Services for Youth using the Hotline and Electronic Voucher." Abstract at the 2016 International Conference on Family Planning. Nusa Dua, Indonesia. January 25-28.

Njiri, N., Dotson, M., Ayuyo, C., Omulokoli, E., Lynam, P., and Omutsani, J. 2016. "Peer Education reloaded: a re-imagined model empowers students to be effective agents of change." Abstract at the 2016 International Conference on Family Planning. Nusa Dua, Indonesia. January 25-28.

Ntata, P., Mvula, P. and Muula, A.S. 2013. "'Condoms make you lose both the child and pleasure:' perceptions on contraceptives use in Malawi." Tanzania Journal of Health Research 15(1): 1-10.

Ntinginya, M, Phillipo, E., Kowihangiro, J. and Ngemera, M. 2016. "Expanding Access to Modern Family Planning Methods among Rural Women and Men through Mobile Outreach Model: Marie Stopes Tanzania." Abstract at the 2016 International Conference on Family Planning. Nusa Dua, Indonesia. January 25-28.

Obasi, A. I., Cleophas, B., Ross, D. A., Chima, K. L., Mmassy, G., Gavyole, A. et al. 2006. "Rationale and design of the MEMA kwa Vijana adolescent sexual and reproductive health intervention in Mwanza Region, Tanzania." AIDS Care, 18, 311-322.

Orkis, J., Kaufman, M., Madinda, R., Hiza, M. and Karam, R. 2016. "Impact of the National "Green Star" Family Planning Demand Creation Campaign in Tanzania." Abstract at the 2016 International Conference on Family Planning. Nusa Dua, Indonesia. January 25-28.

Owusu, P.A., Mensah, D.E. and Halm, M. 2016. "Male Involvement in Family Planning: The StationGuard Concept.” Abstract at the 2016 International Conference on Family Planning. Nusa Dua, Indonesia. January 25-28.

Partnership for Maternal, Newborn and Child Health (PMNCH). 2013. "Knowledge Summary \#26: Engaging men and boys in RMNCH.” PROMUNDO, UNFPA and WHO.

Perry, B., Packer, C., Chin Quee, D., Zan, T., et al. 2016. "Recent Experiences and Lessons Learned in Vasectomy Programming in Low-Resource Settings: A Document Review.” Durham, NC: FHI 360 and Washington, DC: Population Council, the Evidence Project. 
Piet-Pelon, N.J. 1999. Men in Bangladesh, India and Pakistan: Reproductive Health Issues. India: Hindustan Publishing Corporation.

Plautz, A. and Meekers, D. 2007. "Evaluation of the reach and impact of the $100 \%$ Jeune youth social marketing program in Cameroon: findings from three cross-sectional surveys." Reproductive Health 4(1).

Plourde, K., Vahdat, H. and L’Engle, K. 2016. “Engaging Audiences Through FP Role Model Story Narratives Delivered Via Mobile Phone in Ghana, Tanzania and Rwanda." Abstract at the 2016 International Conference on Family Planning. Nusa Dua, Indonesia. January 25-28.

Pomales, T.O. 2013. "Men's narratives of vasectomy: rearticulating masculinity and contraceptive responsibility in San Jose, Costa Rica.” Medical Anthropology Quarterly 27(1): 23-42.

Pulerwitz, J., Barker, G., Segundo, M. and Nascimento, M. 2006. "Promoting More Gender-equitable Norms and Behaviors Among Young Men as an HIV/AIDS Prevention Strategy: Horizons Program." Washington, DC: Population Council.

Rajani, N. 2006. “'Get a Permanent Smile' - Increasing Awareness of, Access to, and Utilization of Vasectomy Services in Ghana.” New York, NY: The ACQUIRE Project and EngenderHealth.

Ricardo, C., Nascimento, M., Fonseca, V. and Segundo, M. 2010. "Program H and Program M: Engaging young men and empowering young women to promote gender equality and health." Washington, DC: Pan American Health Organization and Best Practices in Gender and Health.

Rijsdik, L. E., Bos, A. ER., Ruiter, R.A.C., Leerlooijer, J. N., de Haas, B., and Schaalma, H. P. (2011). “The world starts with me: A multilevel evaluation of a comprehensive sex education programme targeting adolescents in Uganda." BMC Public Health, 11:334

Ringheim, K. 1999. "Revising the Downward Trend in Men’s Share of Contraceptive Use." Reproductive Health Matters 7(9): 83-96.

Ross, J and Hardee, K. 2016. “Trends in Male Contraceptive Use.” Paper submitted for publication.

Rottach, E, SR Schuler and K Hardee. 2009. Gender Perspectives Improve Reproductive Health Outcomes: New Evidence. Washington, DC: The Interagency Gender Working Group.

Santow, G. 1993. "Coitus Interruptus in the Twentieth Century." Population and Development Review 19(4): 767-792.

Shattuck, D., Kerner, B., Gilles, K., Hartmann, M., et al. 2011. "Encouraging contraceptive uptake by motivating men to communicate about family planning: the Malawi Male Motivator project." American Journal of Public Health 101(6): 1089-1095.

Singh, H., Mishra, A., Alam, D. and Pandey, V. 2014. "Increasing male participation in the uptake of vasectomy services.” Journal of Family Planning and Reproductive Health Care 40(1): 64-65.

Sirera, M, Kimondo, L. and Mutisya, R. 2016. "Increasing Uptake of Family Planning Through Religious Leaders; A Case of Makadara and Embakasi Religious Leaders.” Abstract At the 2016 International Conference on Family Planning, Nusa Dua, Indonesia, January 25-28.

Solarzano, I., A. Bank, R. Pena, H. Espinosza, M. Ellsberg and J. Pulerwitz. 2008. Catalyzing Personal and Social Change around Gender, Sexuality and HIV: Impact Evaluation of Puntos de Encuentro's Communication Strategy in Nicaragua. Horizons Final Report. Washington, DC: Population Council. 
Sonfield, A. 2015. "Rounding Out the Contraceptive Coverage Guarantee: Why 'Male' Contraceptive Methods Matter for Everyone." Guttmacher Policy Review 18(2): 34-39.

Spade, B. and Randawa, A.J. 2012. “Access to Clinical and Community Maternal, Neonatal and Women's Health (Access)/Maternal and Child Health Integrated Program (MCHIP).” Mitchell Group.

Subramanian, L., Cisek, C., Kanlisi, N, and Pile, Jo. 2010. “The Ghana vasectomy initiative: Facilitating clientprovider communication on no-scalpel vasectomy." Patient Education and Counseling 81: 374-380.

Sweat, M., Denison, J., Kennedy, C., Tedrow, V., et al. 2012. "Effects of condom social marketing on condom use in developing countries: a systematic review and meta-analysis, 1990-2010.” Bulletin of the World Health Organization 90: 613-622A.

Tebbets, C. and Redwine, D. 2013. "Beyond the clinic walls: empowering young people through Youth Peer Provider programmes in Ecuador and Nicaragua." Reproductive Health Matters 21(41): 143-153.

Tekponon Kikuagou Project. 2013. "From family planning to fatherhood: Analysis of recent male involvement initiatives and scale up potential.” Washington, DC: Institute for Reproductive Health.

Tipwareerom, W., Powwattana, A., Lapvongwatana, P. and Crosby, R.A. 2011. "Effectiveness of a model of risky sexual behavior prevention among adolescent boys in Thailand." The Southeast Asian Journal of Tropical Medicine and Public Health 42(3): 726-736.

Verma, R., Pulerwitz, J., Mahendra, V.S., Khandekar, S., et al. 2008. "Promoting Gender Equity as a Strategy to Reduce HIV Risk and Gender- Based Violence Among Young Men in India.” Washington, DC: Population Council.

Vogelsong, K. 2005. “WHO Research in Male Fertility Regulation.” In B. Donta., K. Vogelsong, P.F.A. Van Look, and C. Puri (eds.), Enhancing Male Partnership in Sexual and Reproductive Health. Geneva: WHO. pp. 103-110.

Wamoyi, J., Mshana, G., Doyle, A.M. and Ross, D.A. 2012. "Recall, relevance and application of an in-school sexual and reproductive health intervention 7-9 years later: perspectives of rural Tanzanian young people.” Health Promotion International 28(3): 311-321.

Wegs, C., Andreea A. Creanga, AA., Galavotti, C., and Wamalwa, E. 2016. "Community Dialogue to Shift Social Norms and Enable Family Planning: An Evaluation of the Family Planning Results Initiative in Kenya." Plos One. DOI:10.1371/journal.pone.0153907.

Wentzell, E.A. and Inhorn, M.C. 2014. "Reconceiving masculinity and 'men as partners' for ICPD Beyond 2014: insights from a Mexican HPV study.” Global Public Health 9(6): 691-705.

World Health Organization. 2015. Medical Eligibility Criteria for Contraceptive Use. Fifth Edition 2015. Geneva: World Health Organization.

Wright, K., Iqteit, H. and Hardee, K. 2015. "Standard Days Method of Contraception: Evidence on Use, Implementation, and Scale Up.” Washington, DC: Population Council.

Yadav, K., Singh, B. and Goswami, K. (2010). "Agreement and Concordance Regarding Reproductive Intentions and Contraception Between Husbands and Wives in Rural Ballabgarh, India." Indian Journal of Community Medicine 35(1): 19-23. 


\section{Appendix 1 | Search Strategy}

The literature review included a search strategy for articles and reports from 2010-2015, and included selected programming from years prior to 2010. To identify current programming that has not made its way into the published literature, abstracts related to men as contraceptive users from the January 2016 International Conference on Family Planning are also included. The search strategy is available on request.

For literature from 2010- September 2015, a search of bibliographic databases (PubMed and POPLINE), websites and hand-search of key journal tables of contents (e.g., Culture, Health \& Sexuality, Sexual Health, and Studies in Family Planning; full list in detailed search strategy), was undertaken to retrieve peer reviewed and grey literature. The search aimed to identify recent and current activities, programs and evidence on the role of men as users of family planning, including those that address gender norms affecting men's use of male-controlled family planning methods. The search was limited to the years 2010-2015 and countries of low- or middle-income levels. Four methods, vasectomy, condoms for dual protection, SDM (Standard Days Methods) and withdrawal, were individually searched to find information related to knowledge, access and use of the methods, including gender-related power dynamics. The PubMed searches utilized Medical Subject Headings (MeSH) (e.g., family planning services, contraception, male, men, vasectomy, condoms, natural family planning, and coitus interruptus). Various combinations of $\mathrm{MeSH}$, as well as words or phrases (in titles or abstracts) were employed. Keywords searched in POPLINE included: male role, family planning, family planning programs, contraception, contraceptive methods, contraceptive usage, men, men's involvement, condom use, vasectomy, withdrawal, calendar method, fertility awareness. Phrases for Standard Days Method were specifically searched.

The initial review of results compared the references from each database and removed duplicates iteratively. References were collected in an EndNote Library. The full ENL contains 2254 references (over 1700 were eliminated after initial review). There were 447 references submitted for further screening. The supplementary searches for conference abstracts, current journal contents, and websites discovered an additional 99 references. 


\section{Appendix 2 | Individuals Contacted for the Organizational Review}

The organizations included in this review were identified in collaboration with USAID, using a snowball technique. The list of organizations covered and individuals interviewed in shown in Table 2.1 Interviews were conducted between October 2015 and January 2016 and were conducted by Melanie Croce-Galis and Jill Gay by telephone or Skype or in some cases, the respondents replied via email. The following questions guided the conversations.

- What is the work you are currently doing or have done recently on men, gender equity and contraceptive use?

- Where is this work being conducted?

- We are looking for successful interventions with evaluated outcomes related to contraceptive use. Do you know of any such interventions related to men as users of contraception/family planning that would recommend we review? (separate from addressing men as supporters of female FP use)

- Particular areas of interest are: condoms for dual protection; vasectomy; withdrawal, and the Standard Days Method (SDM).

- Among those, which would you say are gender transformative? Gender harmful? Are you aware any data disaggregation by age or other characteristics (e.g. adolescents, married, etc.?) in the evaluated interventions you are recommending?

- What would you define as success in increased contraceptive use among boys and men? What are the potential barriers?

- What about the trade off between promoting men's use of SRH services compared to promoting women's autonomy in contraceptive use?

- What do you see as key research, programming and/or implementation gaps related to uptake by men of condoms for pregnancy prevention; vasectomy; SDM; and/or withdrawal?

- Do you have any other comments on the topic of programming or research for men as users of family planning?

\begin{tabular}{|l|l|}
\hline \multicolumn{1}{|c|}{ NAME } & \multicolumn{1}{c|}{ TITLE } \\
\hline Babcheck, Amy & Senior Manager, Nike Foundation, Portland, Oregon, USA. \\
\hline Biddlecom, Ann & $\begin{array}{l}\text { Chief, Fertility and Family Planning Section, Population Division, UN, New York, New York, } \\
\text { USA. }\end{array}$ \\
\hline Billings, Deborah & Director of Choose Well Initiative, New Morning Foundation, Columbia, South Carolina, USA. \\
\hline Blanc, Ann & $\begin{array}{l}\text { Vice President and Director, Poverty, Gender, and Youth Program, Population Council, New } \\
\text { York, New York, USA. }\end{array}$ \\
\hline Bun Bida, Mohammed & Executive Director, Muslim Family Planning Counselling Services, Accra, Ghana. \\
\hline Choi, Helena & $\begin{array}{l}\text { Program Officer, Global Development and Population Program, Hewlett Foundation, Menlo } \\
\text { Park, California, USA. }\end{array}$ \\
\hline Cogan, Matthew & $\begin{array}{l}\text { Technical Specialist for HIV/AIDS Branch, Technical Division, UNFPA, New York, New York, } \\
\text { USA. }\end{array}$ \\
\hline Das, Madhumita & $\begin{array}{l}\text { Senior Technical Specialist on Men and Masculinities, Asia Regional Office, ICRW, Delhi, } \\
\text { India. }\end{array}$ \\
\hline
\end{tabular}




\begin{tabular}{|c|c|}
\hline NAME & TITLE \\
\hline DeAtley, Jenifer. & Director of US Programs \& AYSRH Program Advisor, EngenderHealth, Austin, Texas, USA. \\
\hline Firestone, Rebecca & Senior Technical Advisor, Population Services International, Washington, DC, USA. \\
\hline Hainsworth, Gwyn & $\begin{array}{l}\text { Senior Advisor, Adolescent Sexual and Reproductive Health, Pathfinder, Boston, Massachu- } \\
\text { setts, USA. }\end{array}$ \\
\hline Hamlin, Aaron & Executive Director, Male Contraceptive Initiative, USA. \\
\hline Hasen, Nina & Director, HIV and TB Programs, Population Services International, Washington, DC, USA. \\
\hline Jackson, Ashley & Technical Advisor for Reproductive Health, PSI, Washington, DC, USA. \\
\hline Kerner, Brad & $\begin{array}{l}\text { Adolescent Sexual and Reproductive Health Advisor, Department of Global Health, Save the } \\
\text { Children USA, Westport, Connecticut, USA. }\end{array}$ \\
\hline Kothari, Shilpa & Program Director, WING/ ALAS, Antigua, Guatemala. \\
\hline Kreinin, Tamar & $\begin{array}{l}\text { Director of Population and Reproductive Health, Packard Foundation, Los Altos, California, } \\
\text { USA. }\end{array}$ \\
\hline Levtov, Ruti & $\begin{array}{l}\text { Program Officer, Co-Coordinator of the MenCare Campaign, Promundo-US, Washington, DC, } \\
\text { USA. }\end{array}$ \\
\hline Lissner, Elaine & Executive Director, Parsemus Foundation, San Francisco, California, USA. \\
\hline Lundgren, Rebecka & Director of Research, Department of Obstetrics and Gynecology, IRH, Washington, DC, USA. \\
\hline Moore, Ann & Senior Research Associate, Guttmacher Institute, New York, New York, USA. \\
\hline Munive, Alexander & $\begin{array}{l}\text { Development and Gender Specialist, Global Girls Innovation Program, Plan International, } \\
\text { Helsinki, Finland. }\end{array}$ \\
\hline Rodriguez, Mariela & $\begin{array}{l}\text { Senior Program Officer, Knowledge Management and Global Coordination, Sexual, Repro- } \\
\text { ductive and Maternal Health, CARE, Atlanta, Georgia, USA. }\end{array}$ \\
\hline Santillan, Diana & Senior Sexual and Reproductive Health Specialist, ICRW, Washington, DC, USA. \\
\hline Sarpal, Nisha & Technical Advisor for AYSRH, Pathfinder, Boston, Massachusetts, USA. \\
\hline Schuler, Sidney & Senior Advisor for Research and Gender, FHI360, Washington, DC, USA. \\
\hline Shand, Tim & Sonke Gender Justice, South Africa (joining IRH in February 2016). \\
\hline Sharafi, Leyla & $\begin{array}{l}\text { Technical Specialist, Gender and Youth, Gender, Human Rights and Culture Branch, UNFPA, } \\
\text { New York, New York, USA. }\end{array}$ \\
\hline Shattuck, Dominick & $\begin{array}{l}\text { Senior Research Officer, Department of Obstetrics and Gynecology, IRH, Washington, DC, } \\
\text { USA. }\end{array}$ \\
\hline Stern, Erin & $\begin{array}{l}\text { Gender and Health Consultant, Honorary Research Associate at School of Public Health, } \\
\text { University of Cape Town, Cape Town, South Africa. }\end{array}$ \\
\hline Taft, Julia & Technical Advisor, SIFPO, Marie Stopes International, London, UK. \\
\hline Thompson, Kirsten & $\begin{array}{l}\text { Project Director, Bixby Center for Global Reproductive Health, University of California, San } \\
\text { Francisco, San Francisco, California, USA. }\end{array}$ \\
\hline Toliver, Maimouna & Senior Program Associate, Gender/Men As Partners, EngenderHealth, Abijan, Cote d'Ivoire. \\
\hline Verani, Fabio & Technical Advisor, EngenderHealth, New York, New York, USA. \\
\hline Warner, Ann & $\begin{array}{l}\text { Formerly Senior Gender and Youth Specialist, ICRW, Washington, DC, USA. Currently South } \\
\text { Carolina Coalition for Healthy Families, Columbia, South Carolina, USA. }\end{array}$ \\
\hline Zamir, Jameel & Acting Director of Programmes, South Asia Region, New Delhi, India. \\
\hline
\end{tabular}




\section{Appendix 3 | Limitations}

Identifying new programs proved somewhat difficult since men, quite frankly, are not widely considered in reproductive health programming (Bongaarts et al, 2012). For example, a review of 50 years of family planning programming in Latin America and the Caribbean made scant reference to men (Bertrand et al., 2015). This review therefore faced certain limitations.

One limitation was the years of the literature search. The literature search covered the years 2010-2015, under the assumption that previous literature reviews, most notably IRH, 2013a, covered the earlier programming and evidence. This assumption turned out not to be completely valid, and additional hand searches were conducted by the authors to review earlier relevant programming, including programming from the 1980s and 1990s before funding for family planning programming lost ground to the rising HIV/AIDS pandemic. In only including literature from 2010 to 2015 , much of the early programming on men and family planning, including programming that preceded the 1994 ICPD, was lost. To understand current programming on men and family planning, understanding the context of earlier programming, both positive and negative, is important.

A second limitation is that programming for men as contraception users tends to be part of larger multidimensional programming, including to promote men's support for their partners' contraceptive use. Thus it is difficult to separate programming specifically on men as contraceptive users. Reports of men's use of contraception in the programs sometimes come from men, but more often from women, which may distort the contributions of men. Furthermore, if the outcome of an intervention with men is that contraceptive use by interested couples increases, but through use of a female-controlled method, does that mean the intervention has "failed" because the man did not take up contraceptive use? We think not, but if programming is trying to have men participate in contraceptive use and take the burden for use off of their partners, identifying a "successful" outcome of an intervention to promote men as contraceptive users becomes complicated.

A third limitation is that one of the primary methods of contraception used by men, namely condoms, is heavily linked with disease prevention, therefore unpacking the use of condoms for contraception versus use for disease prevention is difficult. Furthermore, most of the programming for condom use over the past 20 years has focused on disease prevention and has been funded through PEPFAR and other organizations and agencies focused on HIV. Outcomes of evaluations of these programs and other studies on condom use did not tend to include any questions on use of condoms for contraception. Thus it is impossible to know if the same programming to promote condom use for disease prevention will also work for family planning. Nonetheless, some programs to promote condom use for HIV prevention, particularly as they address gender norms, are included in this review. 


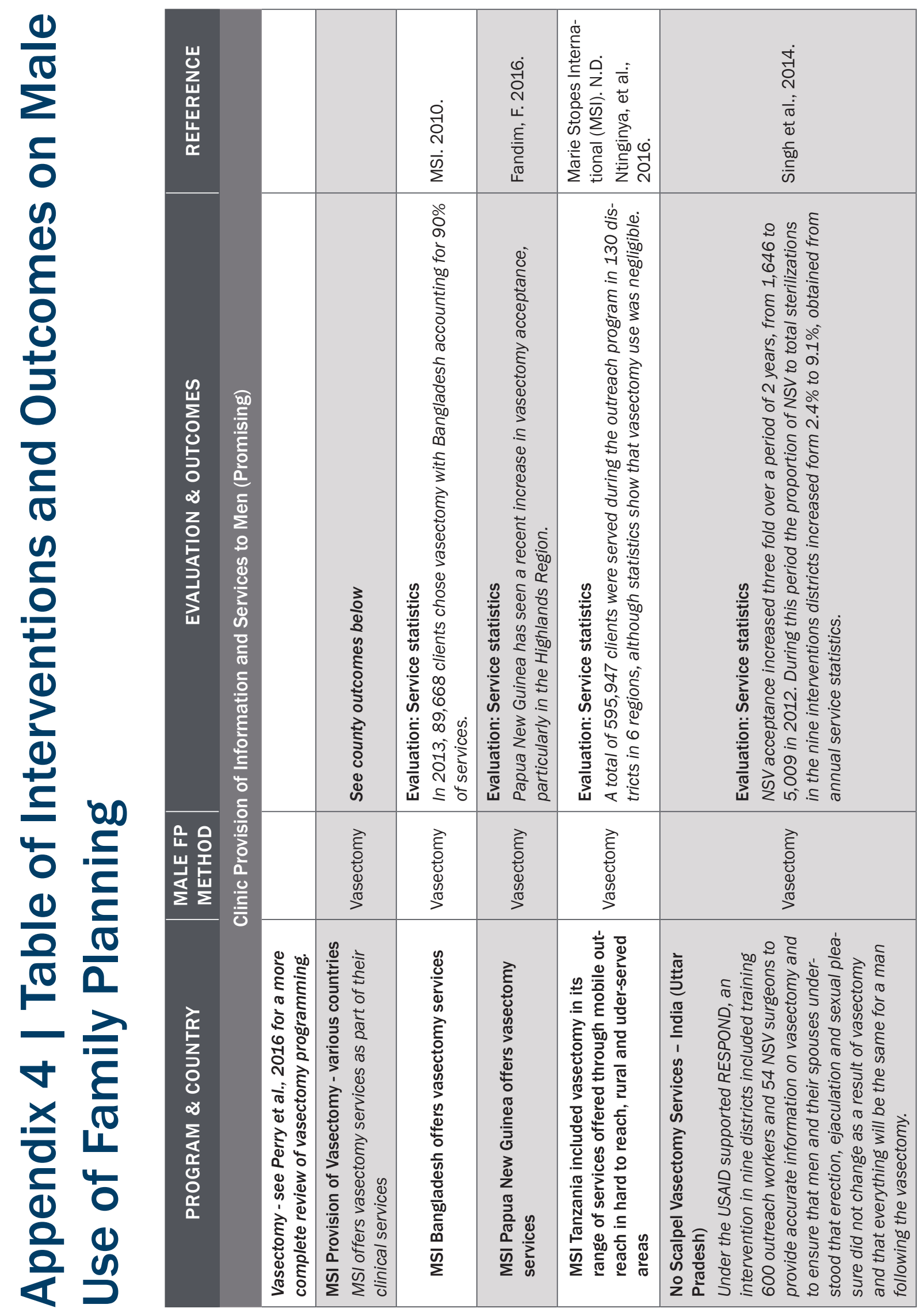

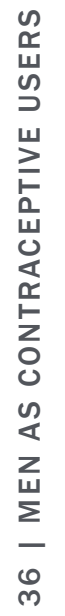




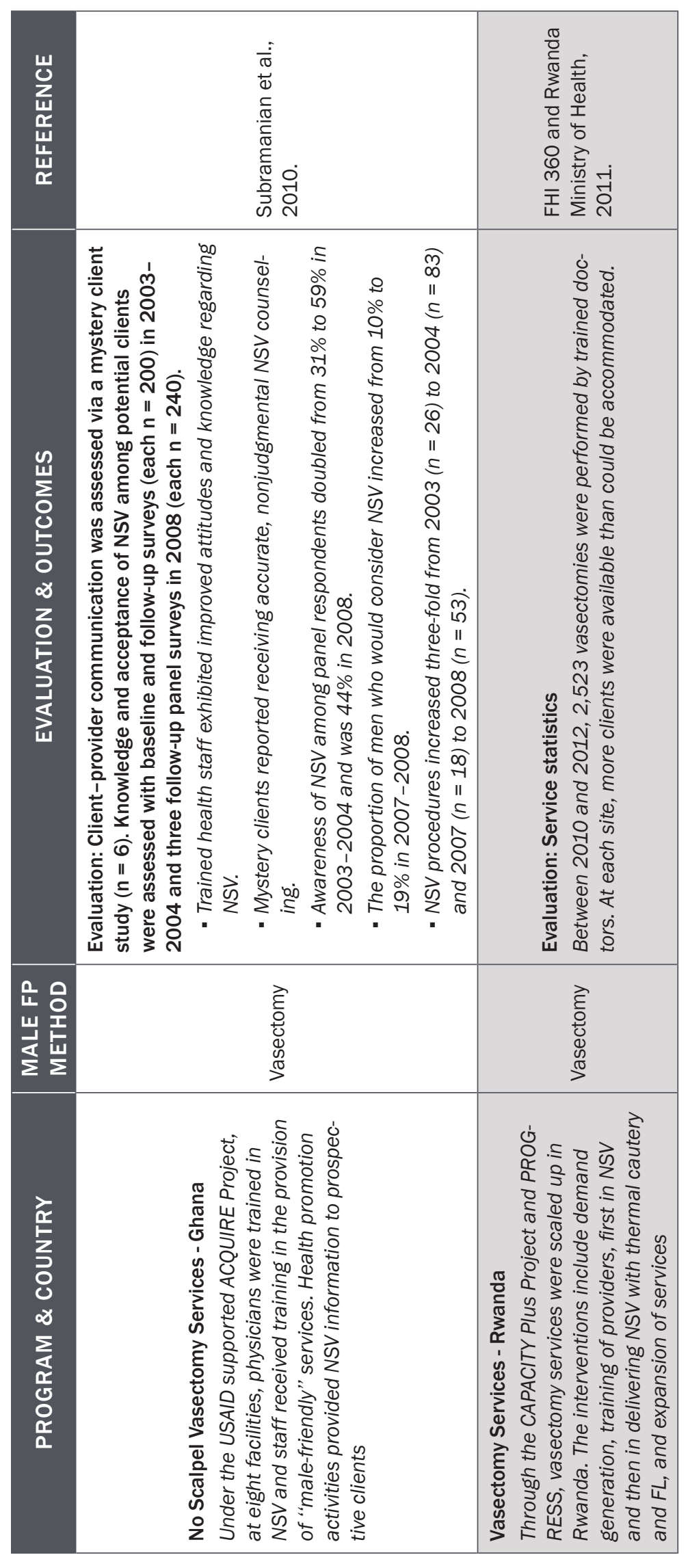




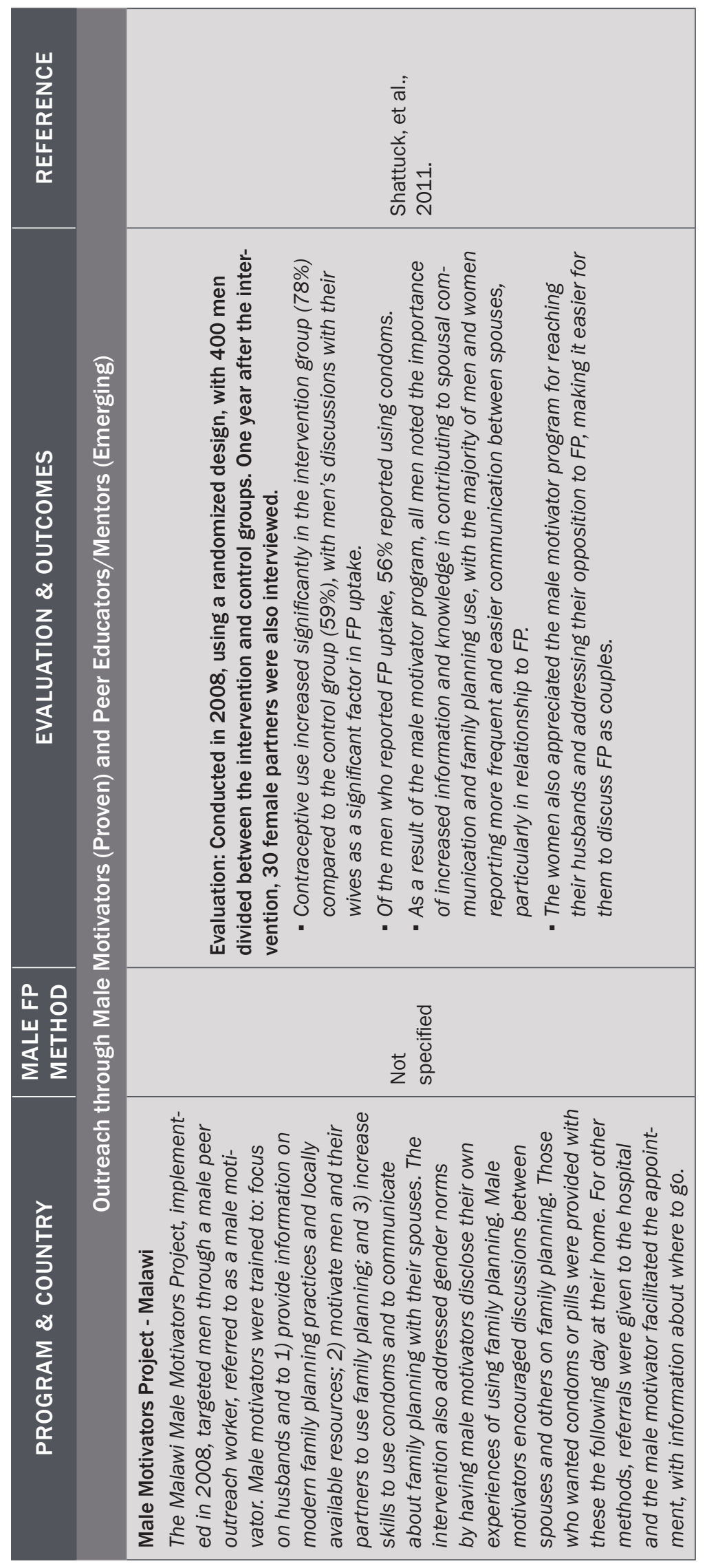




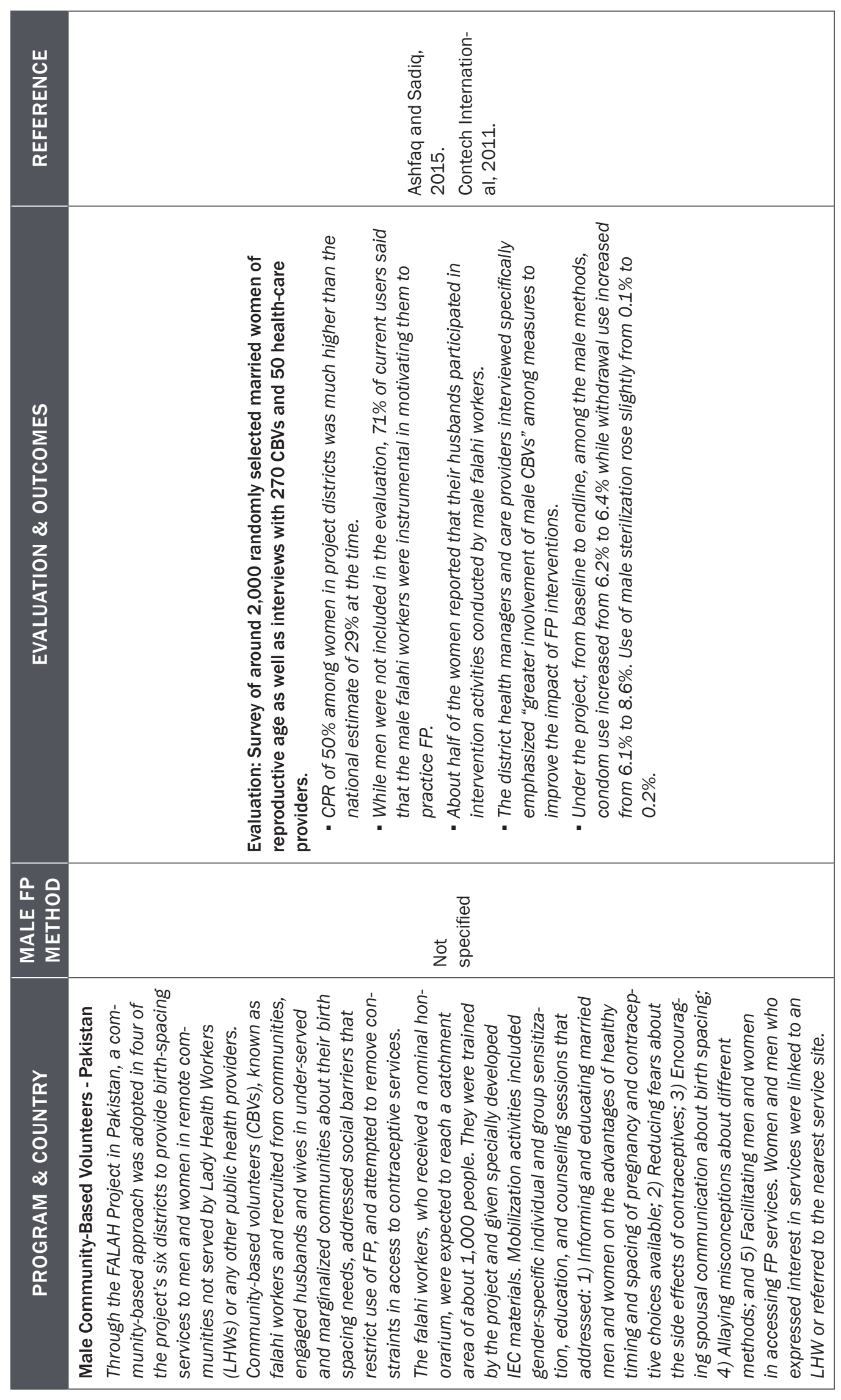




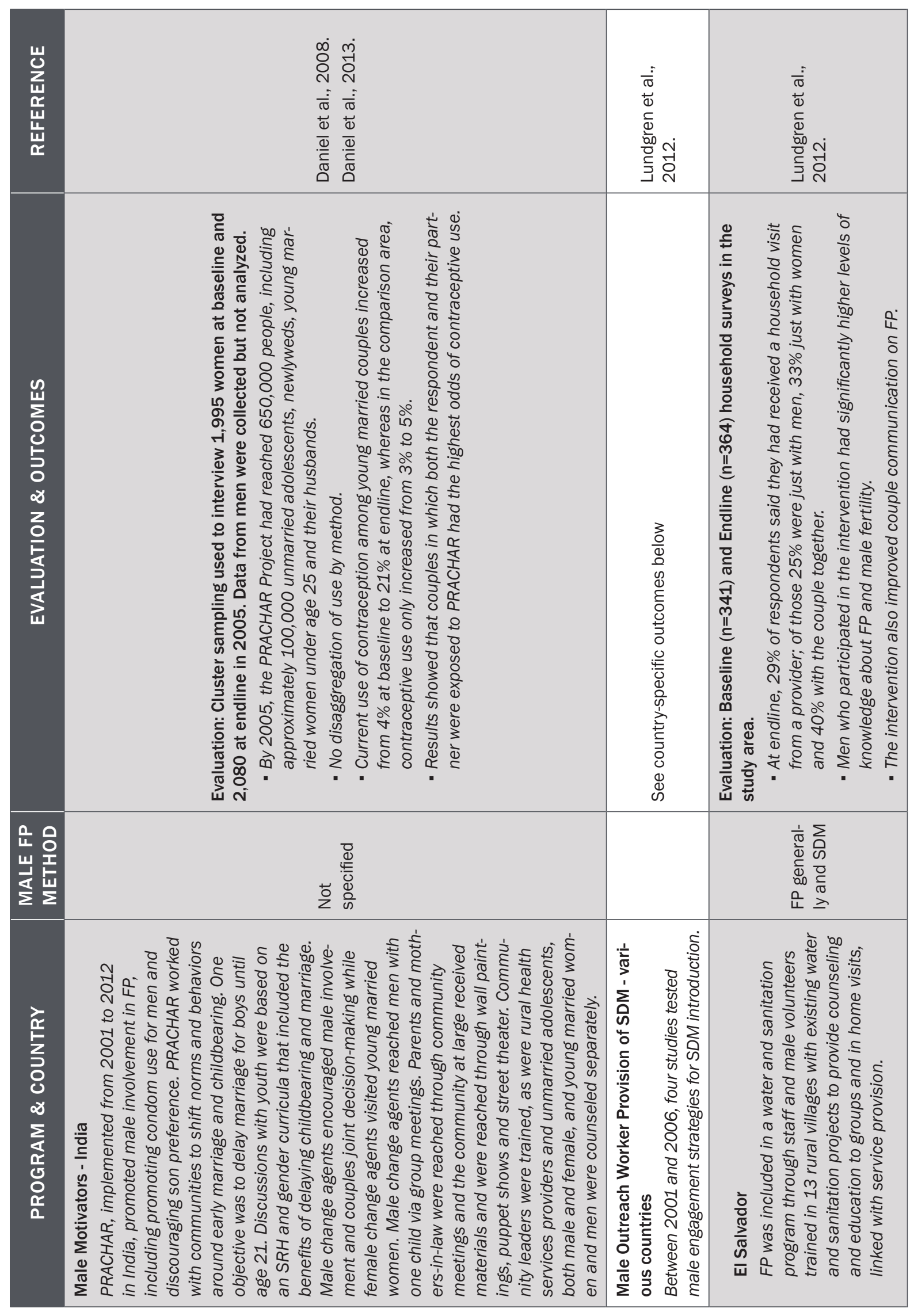




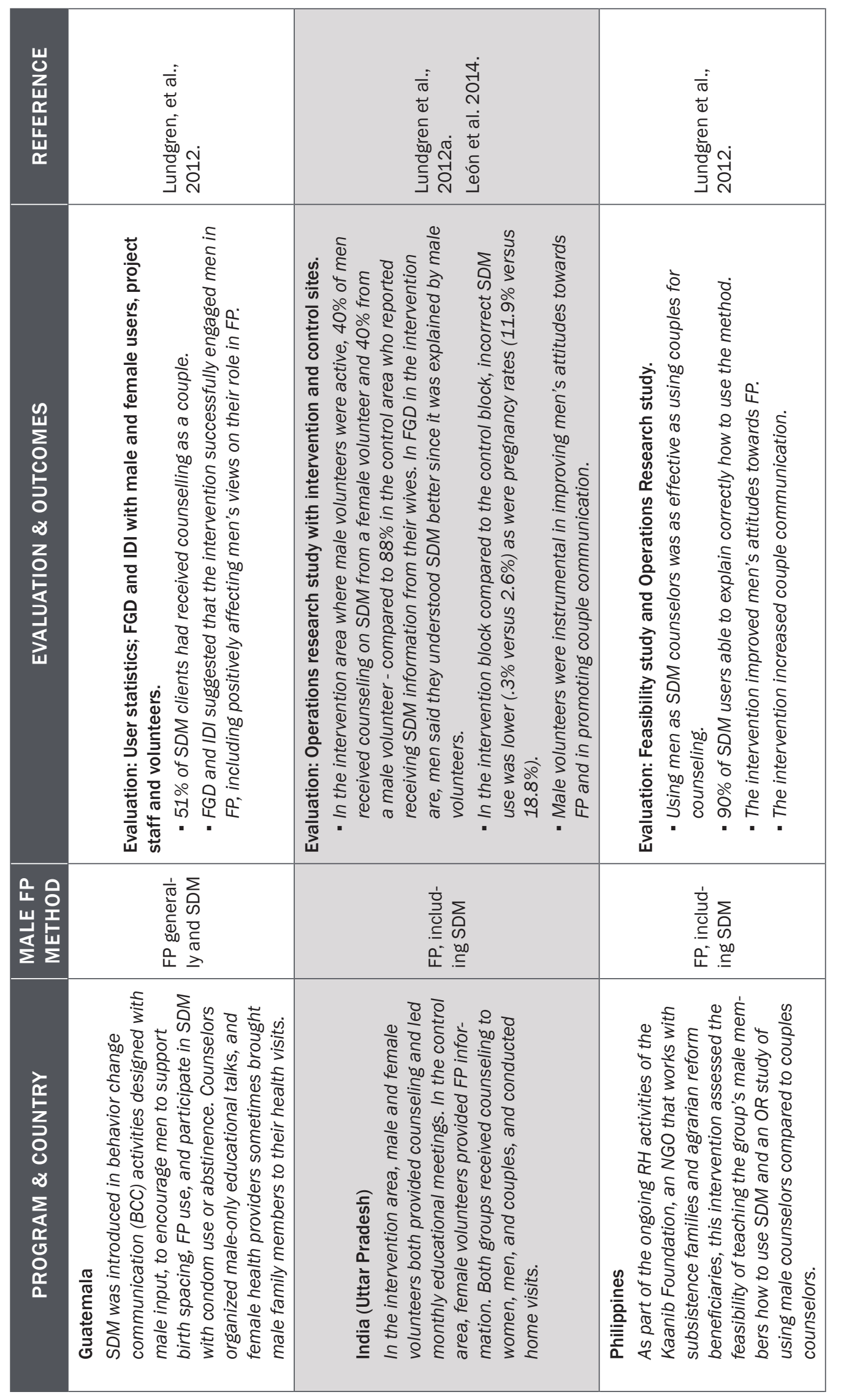




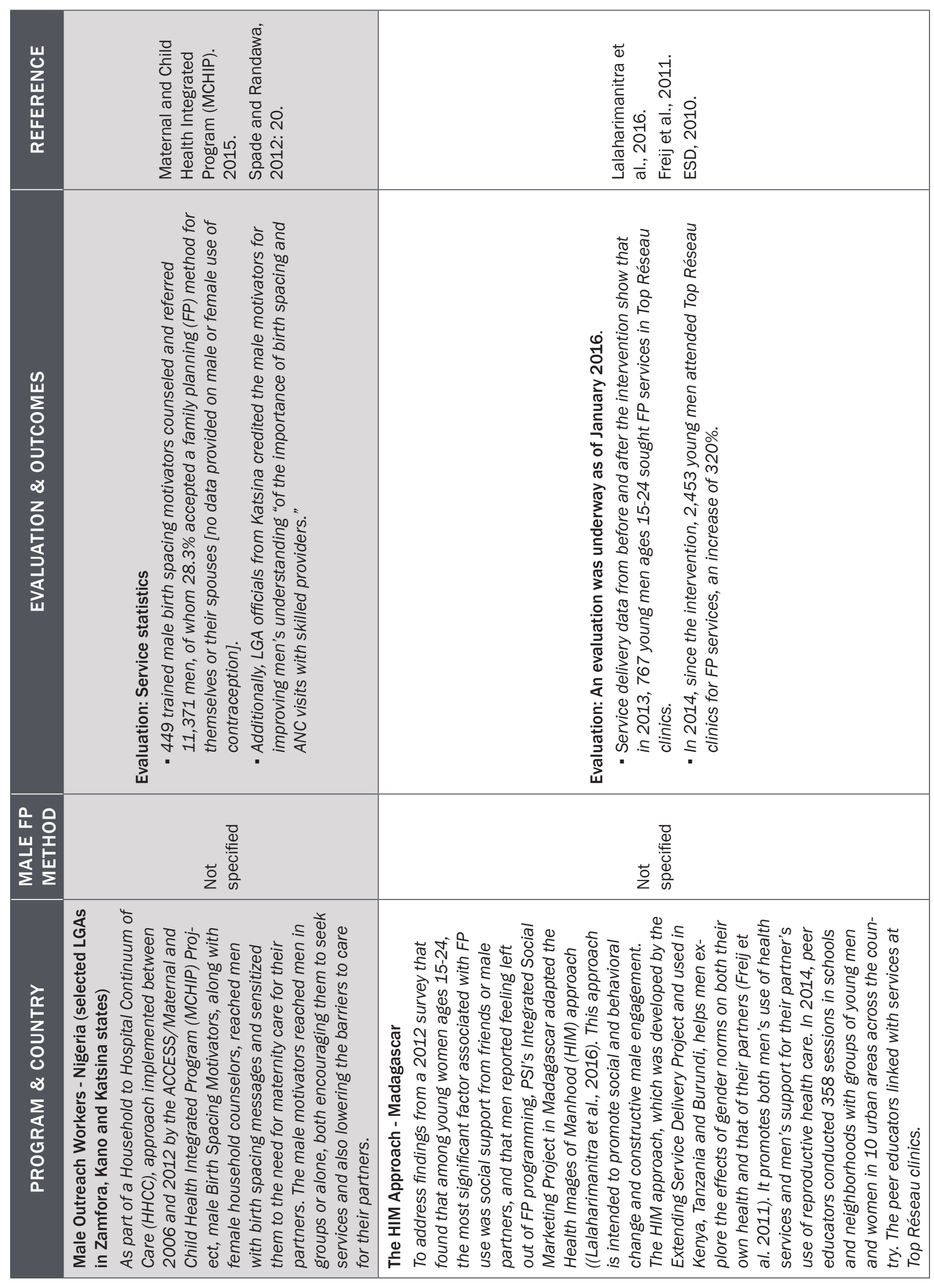




\begin{tabular}{|c|c|c|c|}
\hline 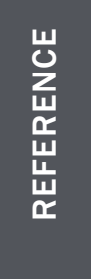 & 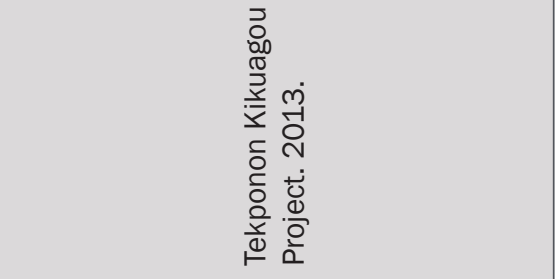 & 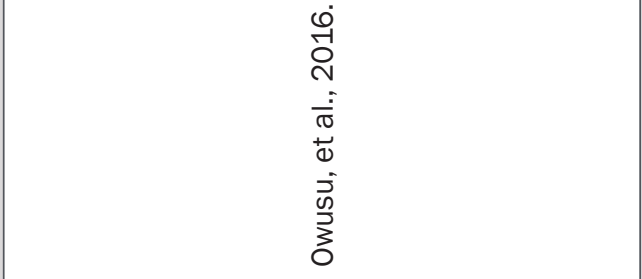 & 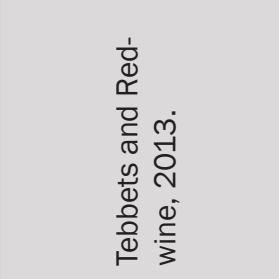 \\
\hline 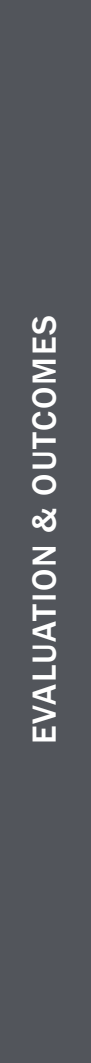 & 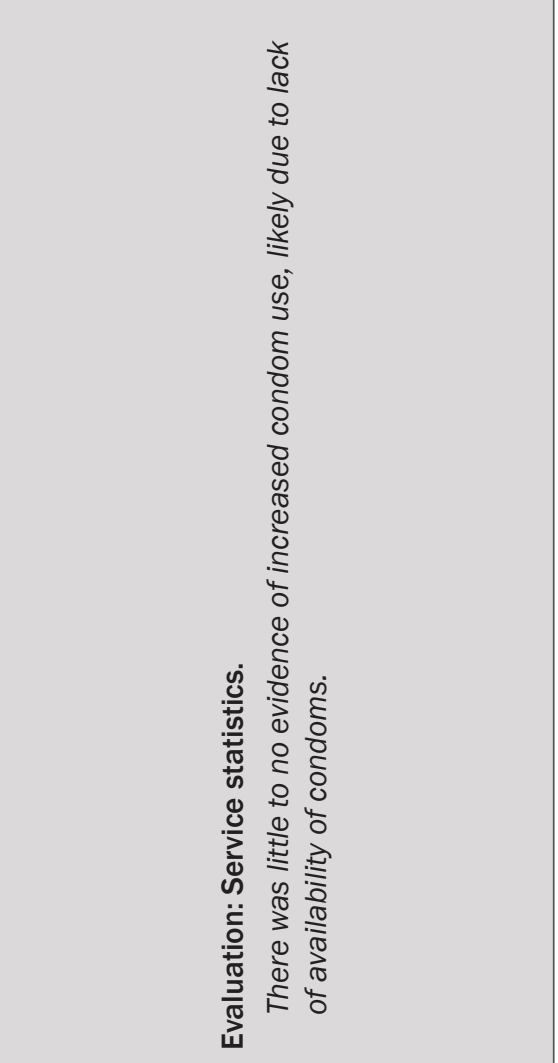 & 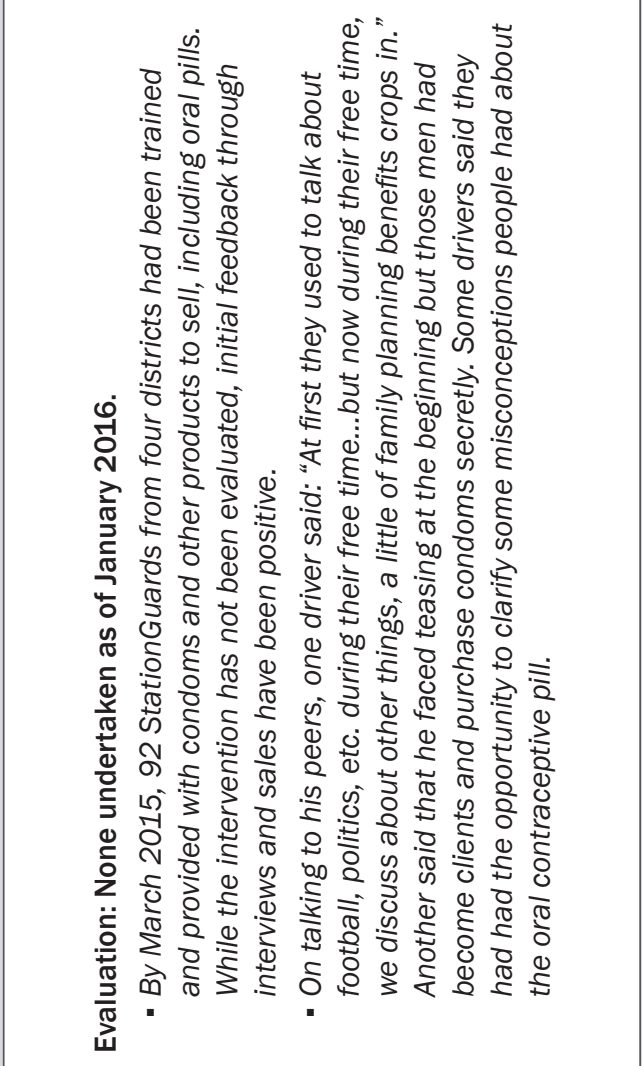 & 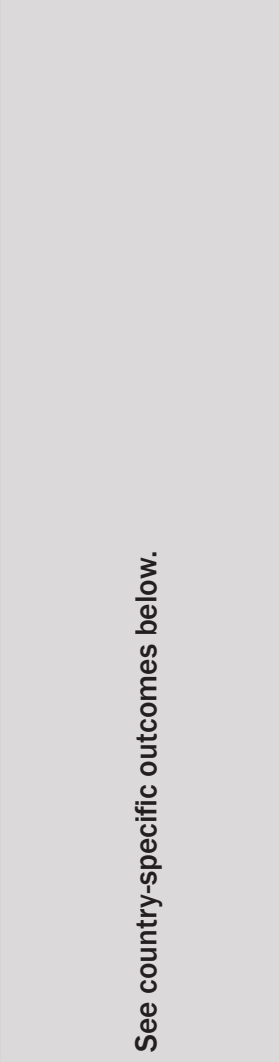 \\
\hline 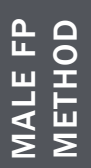 & $\begin{array}{l}\text { n } \\
\tilde{0} \\
0 \\
\delta \\
0\end{array}$ & $\begin{array}{l}\text { है } \\
\text { о } \\
\overline{0} \\
\overline{0} \\
0\end{array}$ & \\
\hline 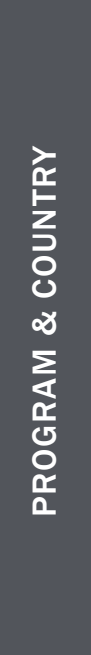 & 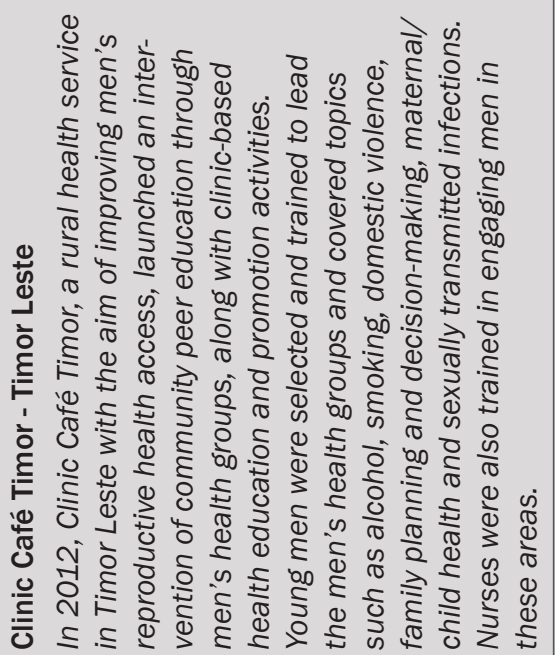 & 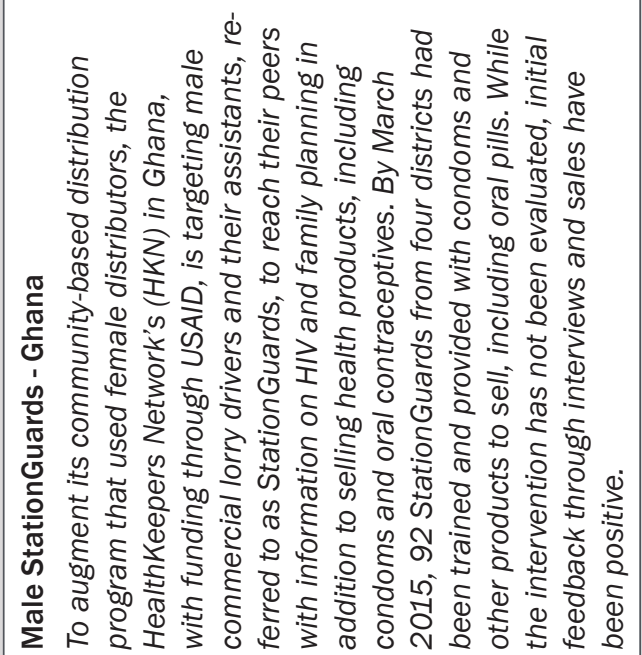 & 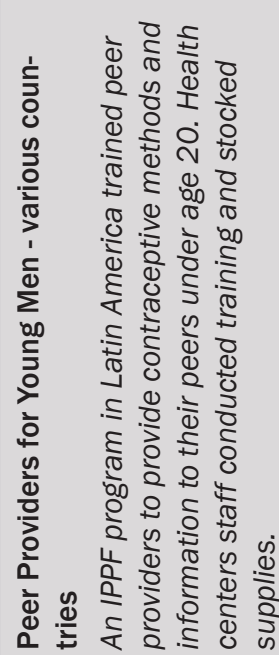 \\
\hline
\end{tabular}




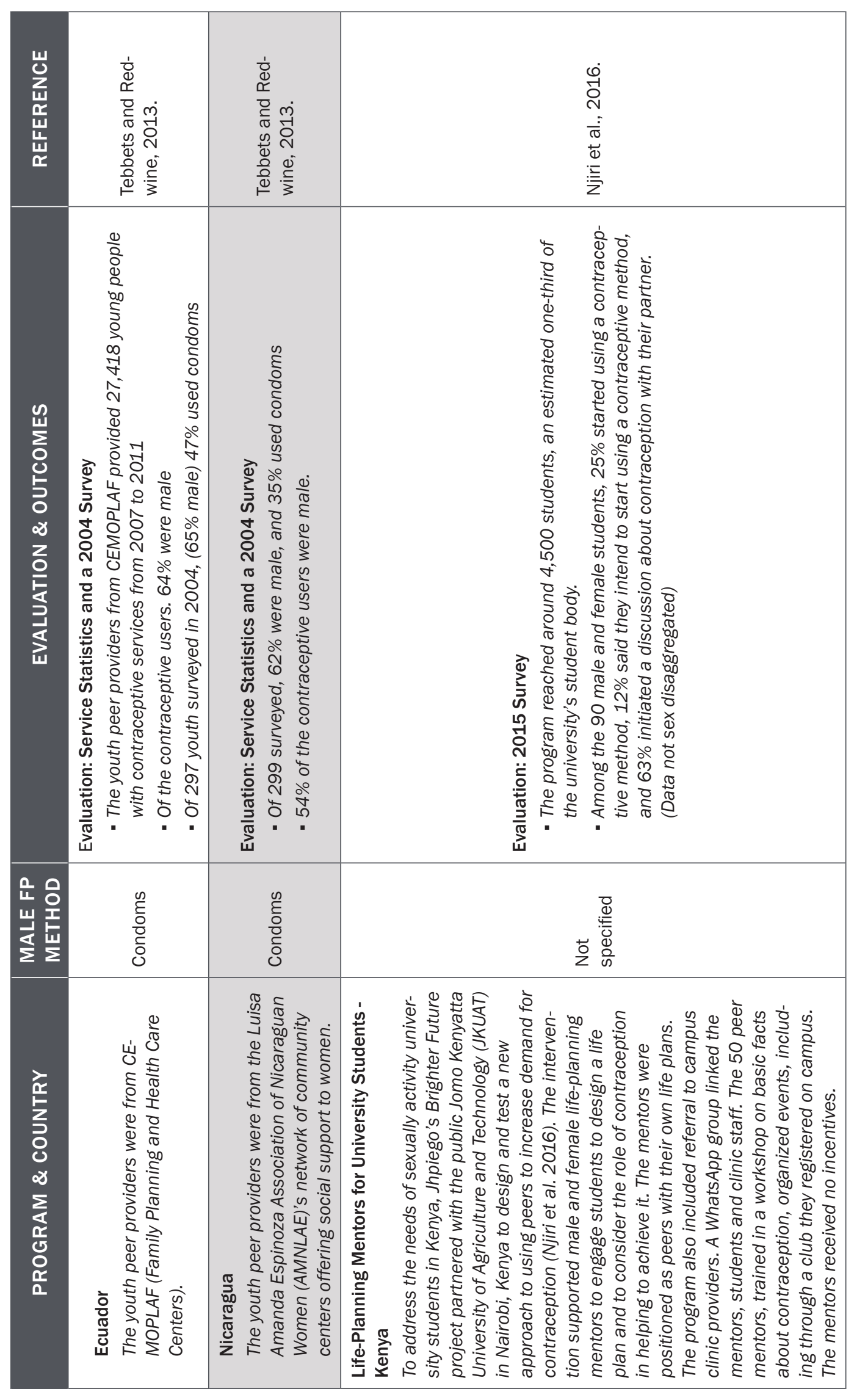




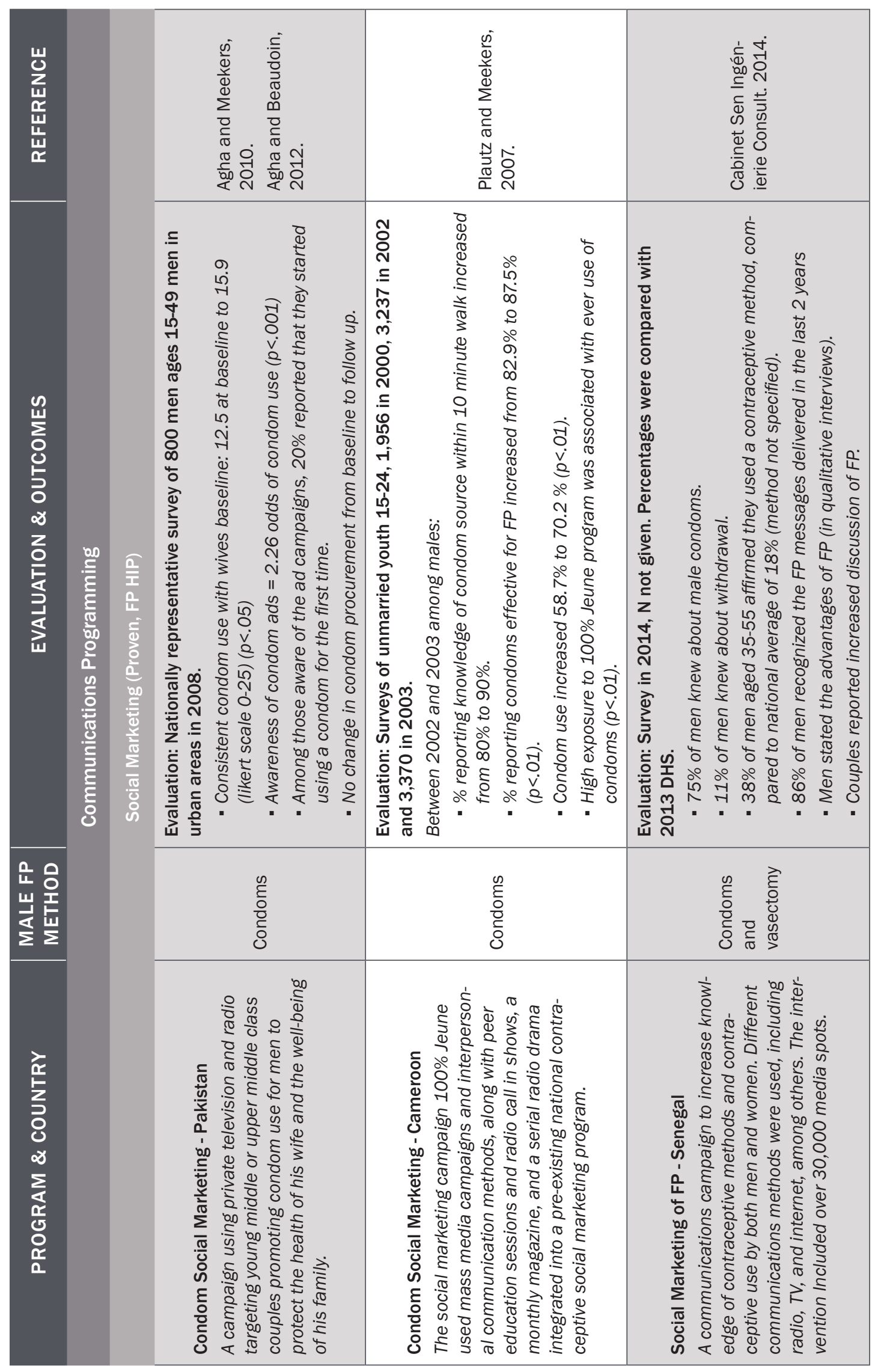

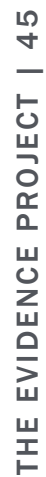




\begin{tabular}{|c|c|c|c|c|}
\hline 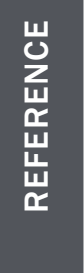 & 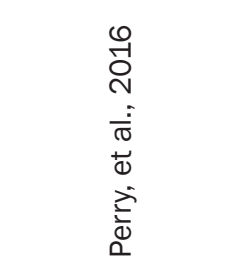 & 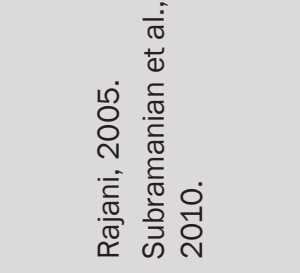 & 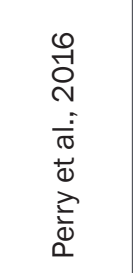 & 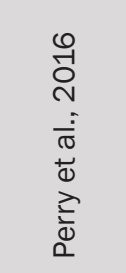 \\
\hline 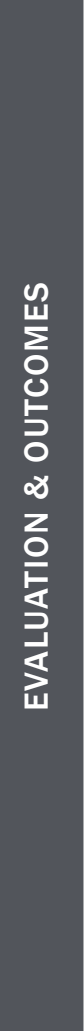 & 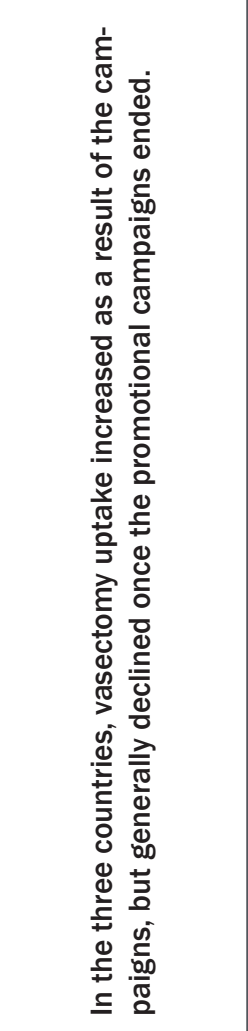 & 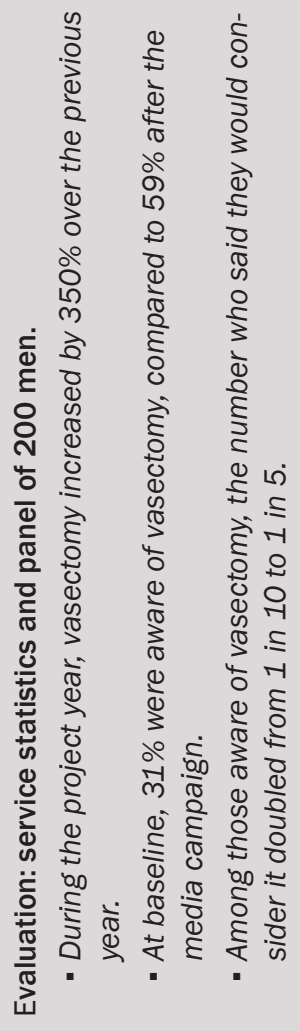 & 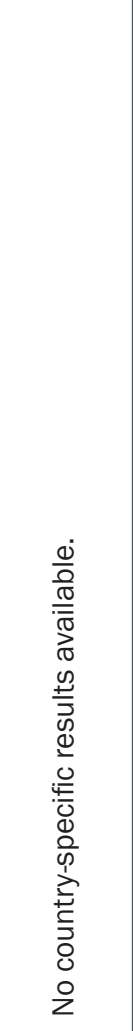 & 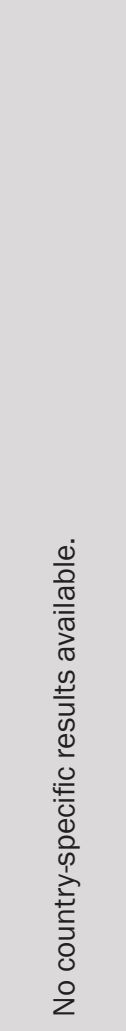 \\
\hline $\begin{array}{l}\frac{0}{4} \text { 으 } \\
\frac{1}{\frac{1}{4}} \\
\frac{5}{\Sigma} \\
\frac{5}{\Sigma}\end{array}$ & 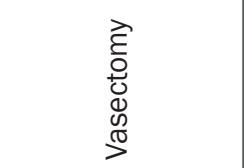 & 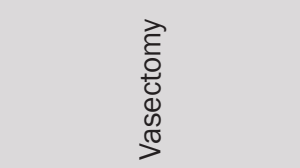 & 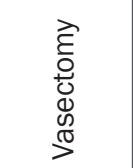 & 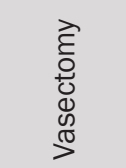 \\
\hline 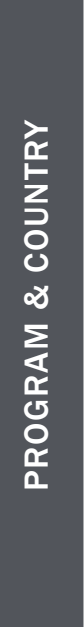 & 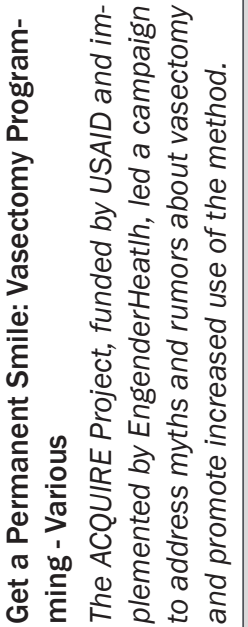 & 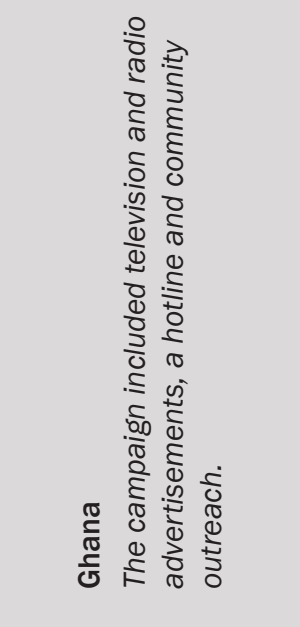 & 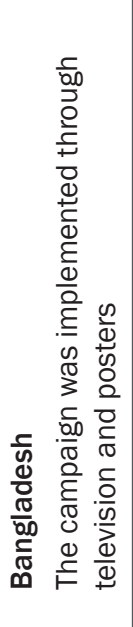 & 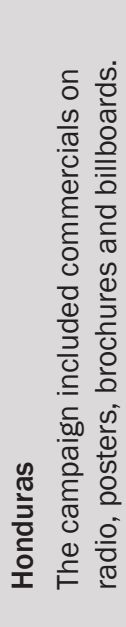 \\
\hline
\end{tabular}




\begin{tabular}{|c|c|c|c|}
\hline & 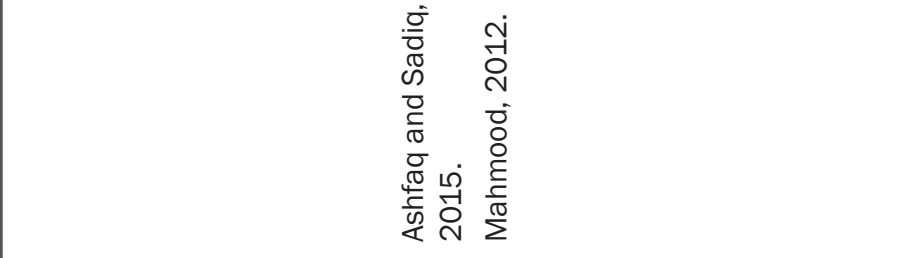 & 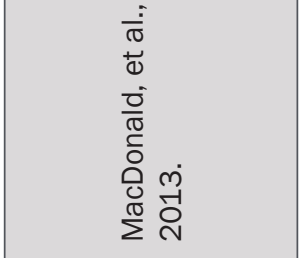 & 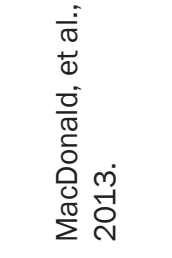 \\
\hline & 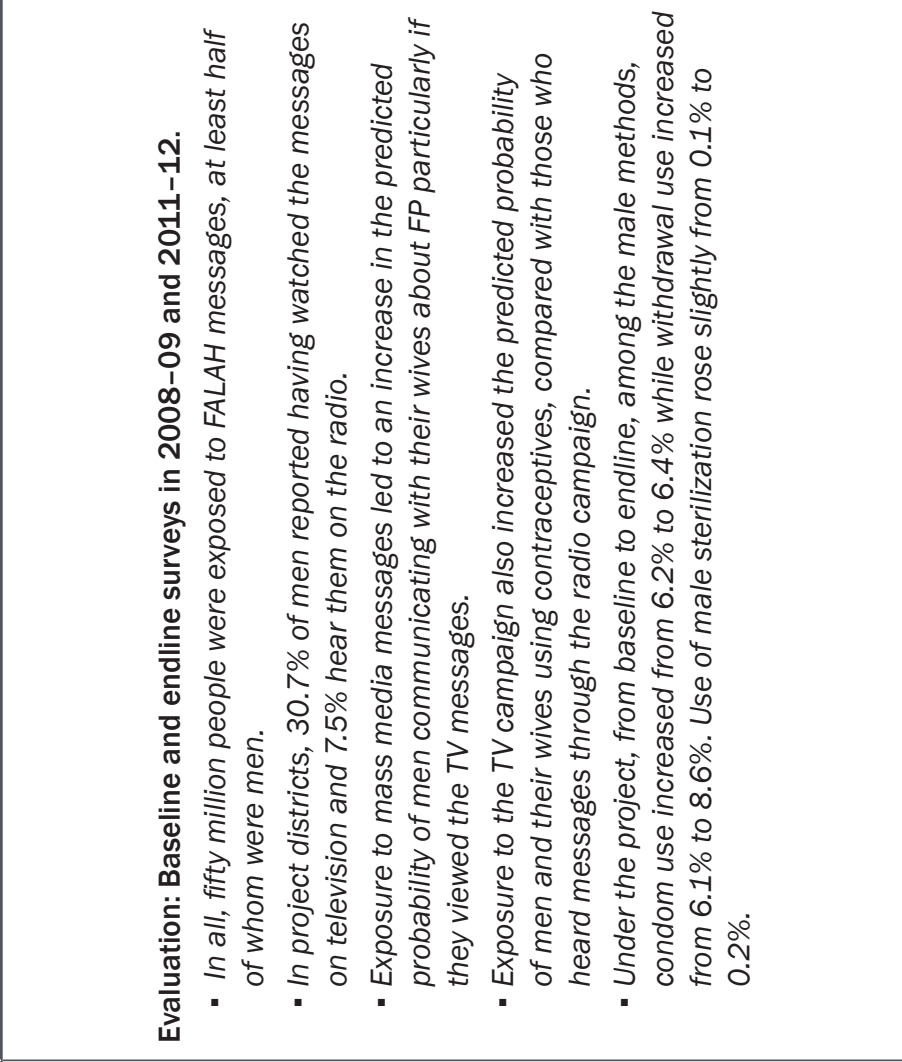 & 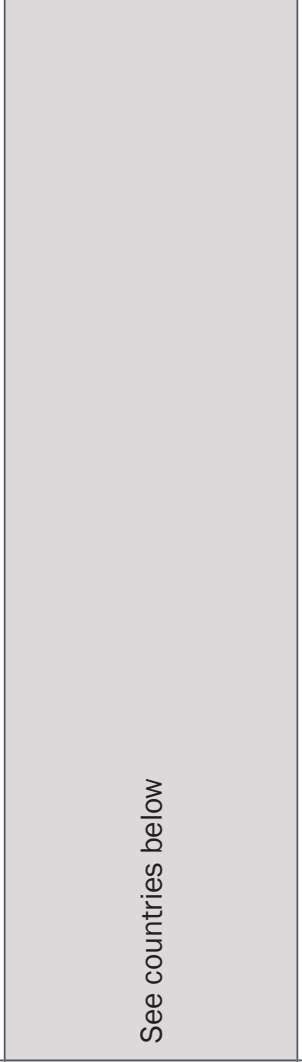 & 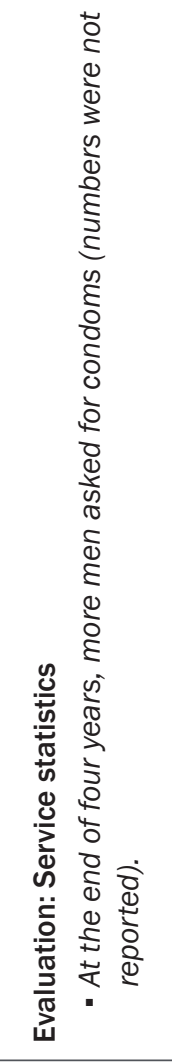 \\
\hline & 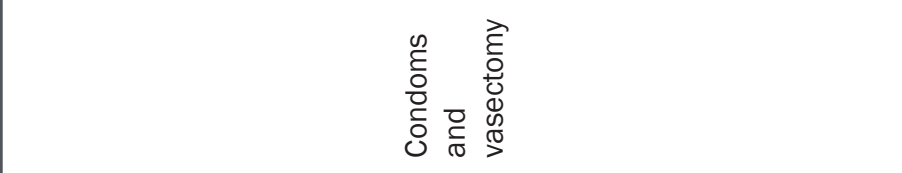 & & 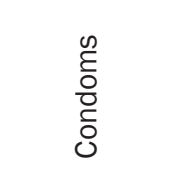 \\
\hline & 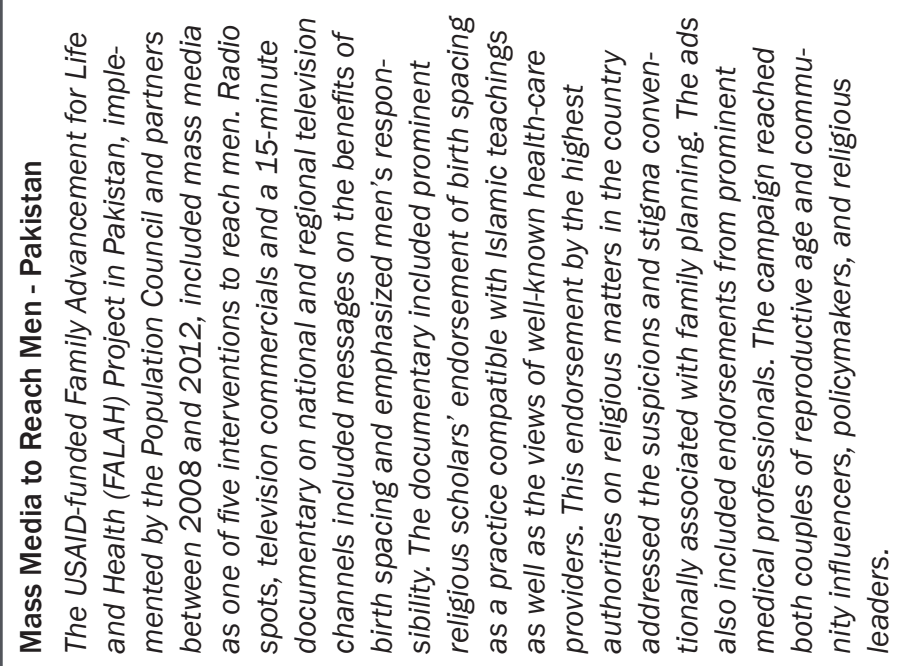 & 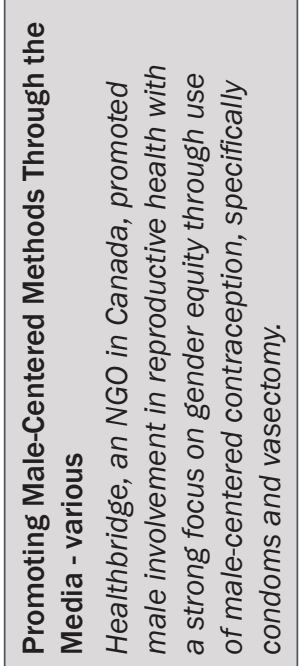 & 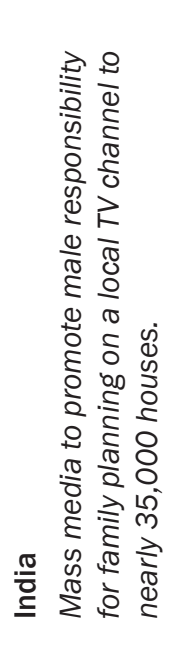 \\
\hline
\end{tabular}




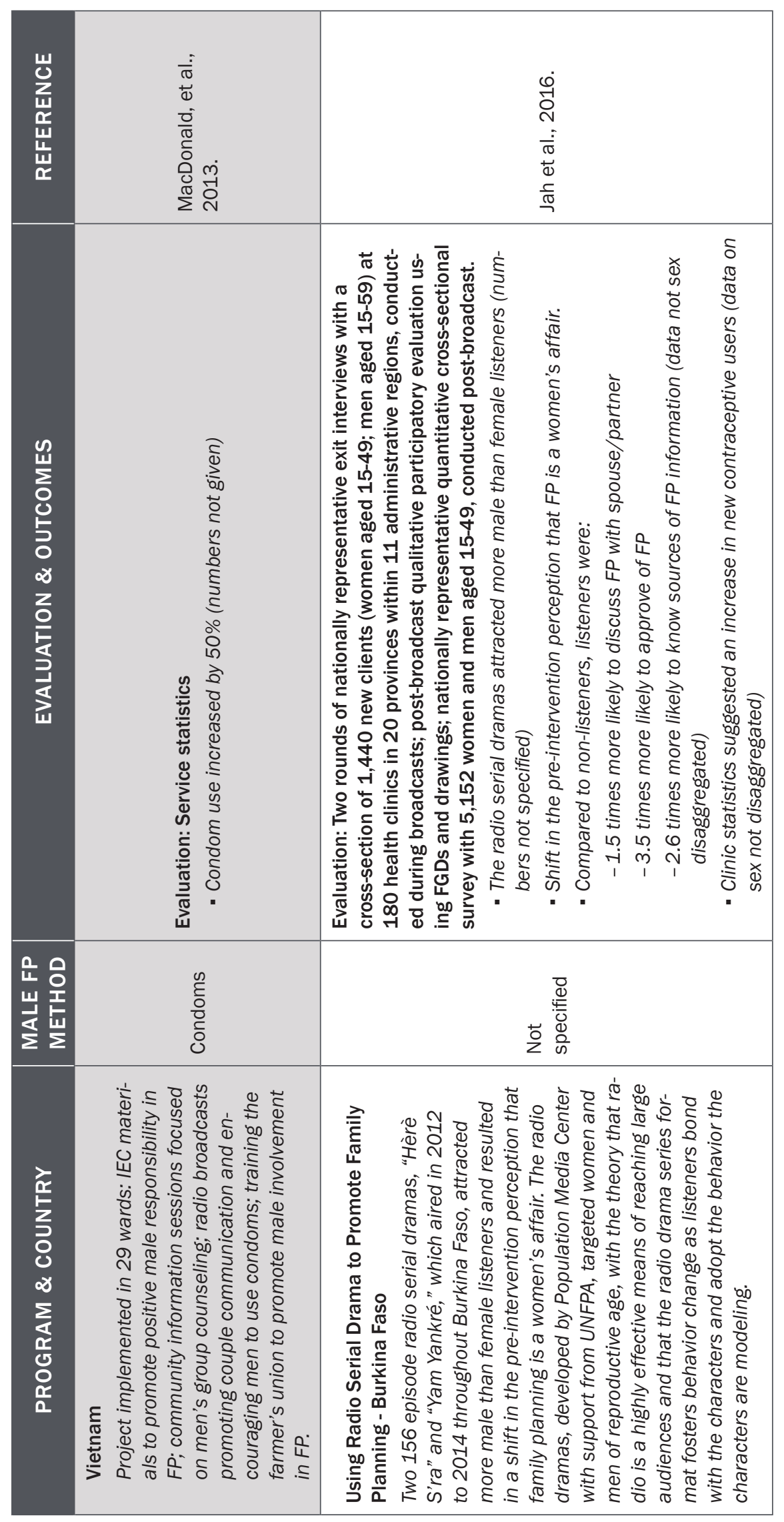




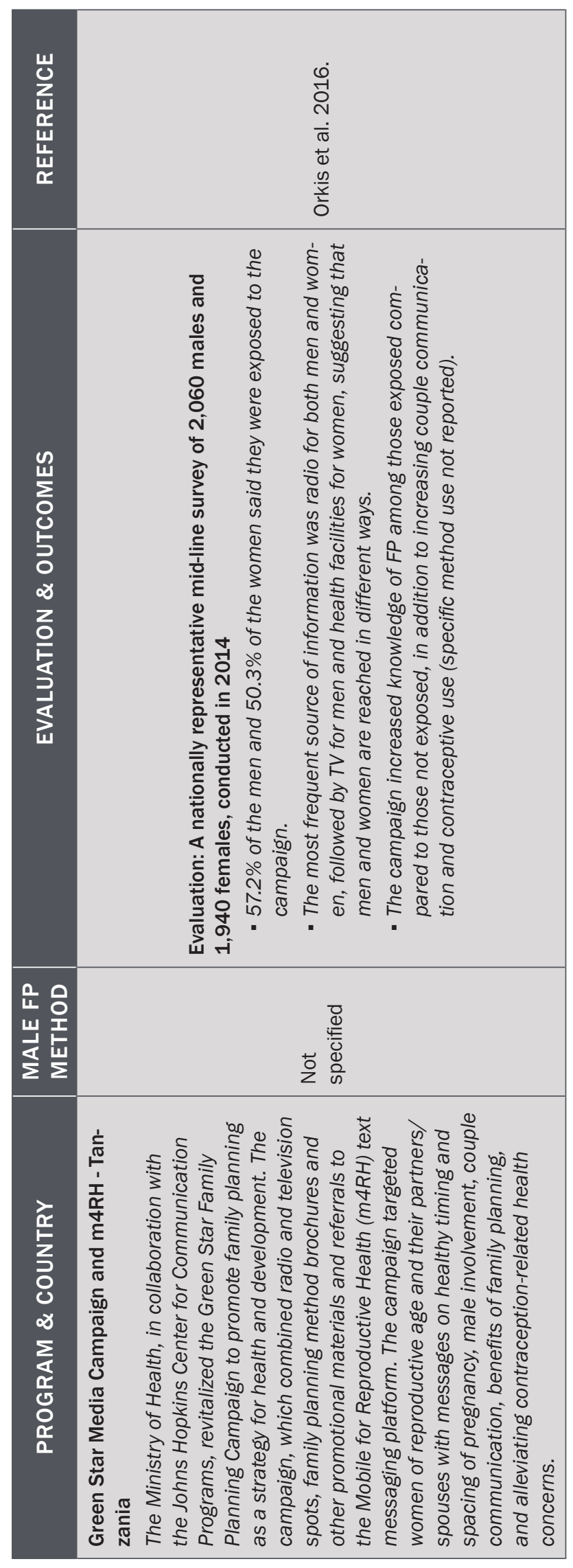




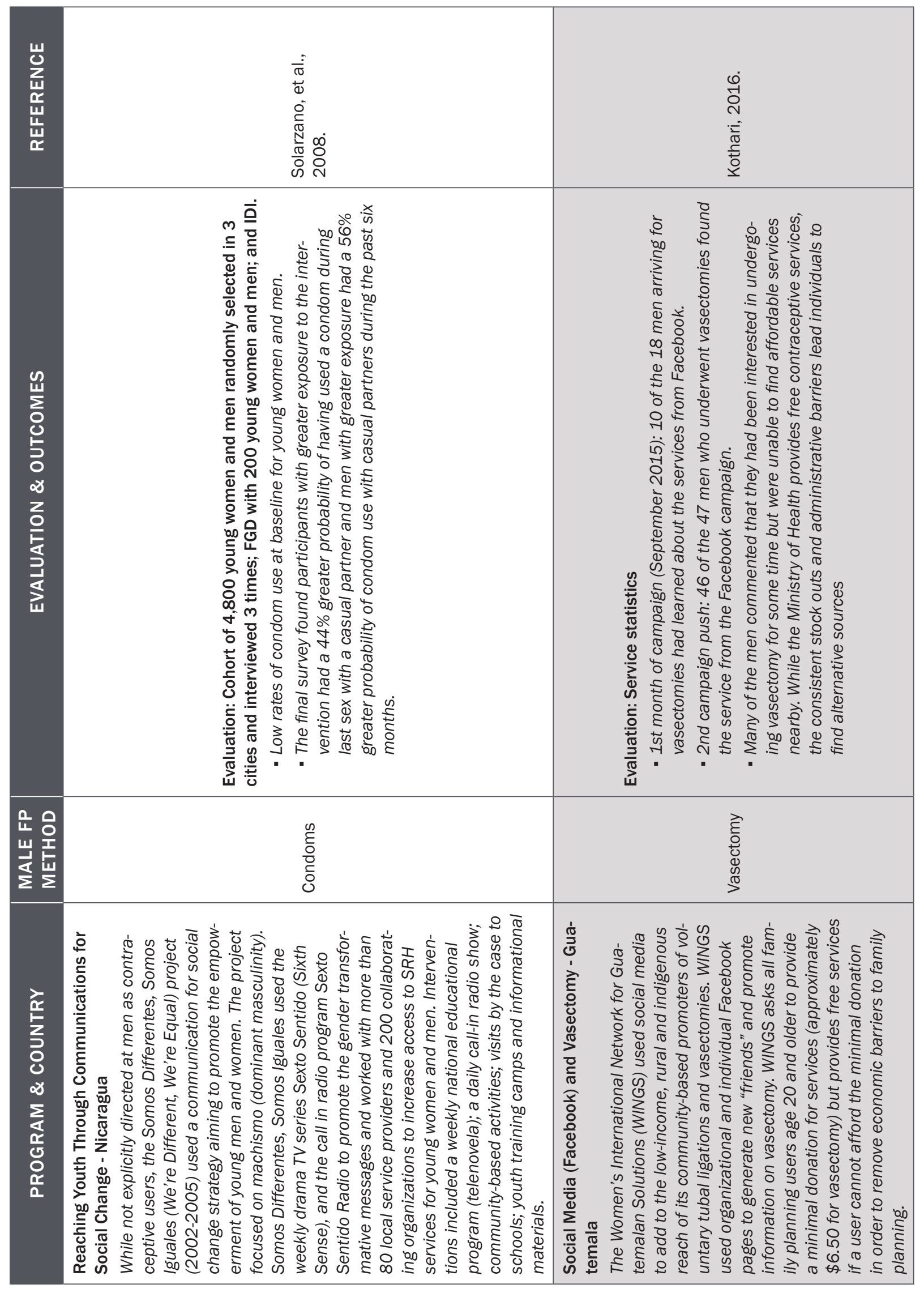




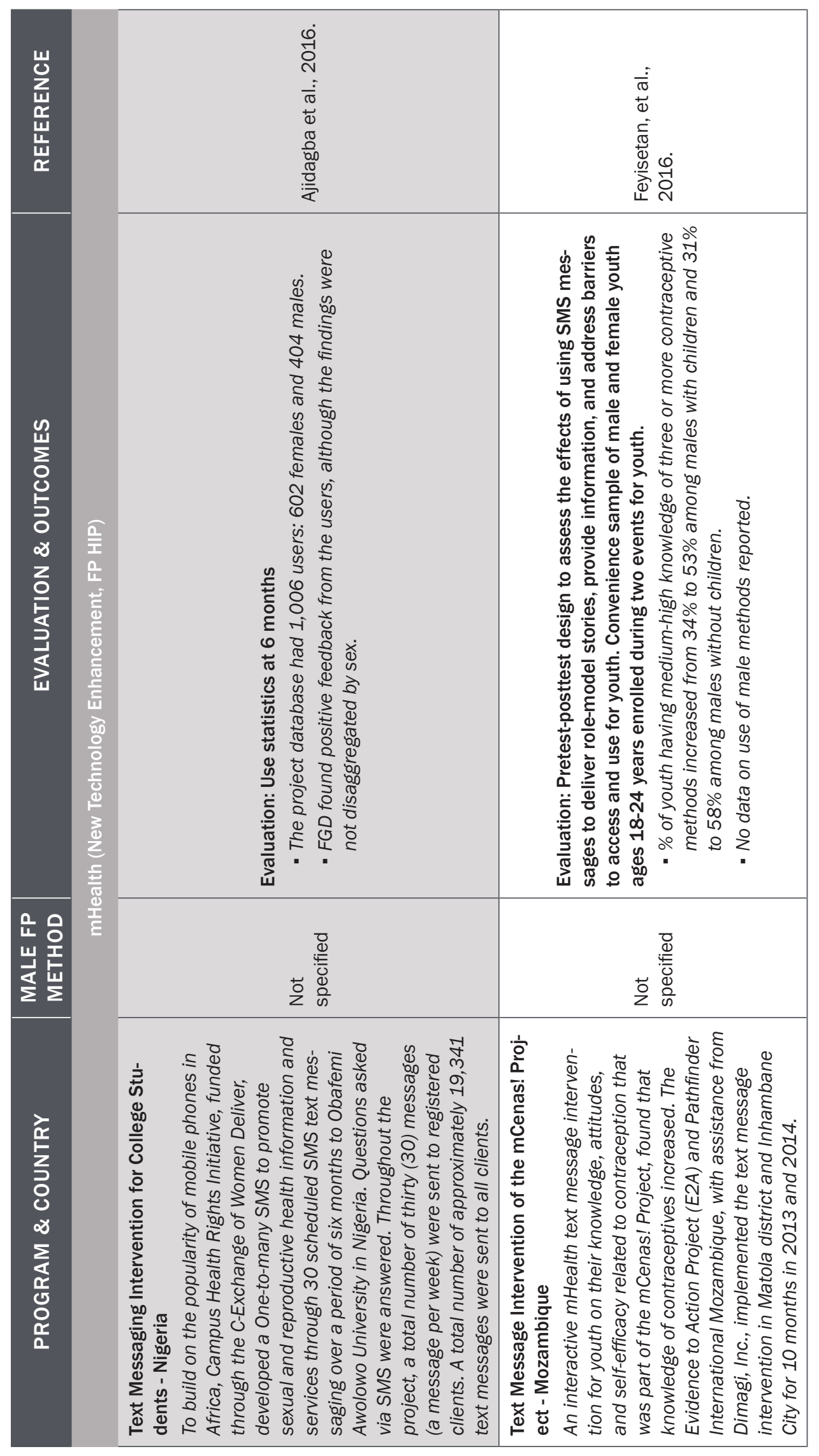




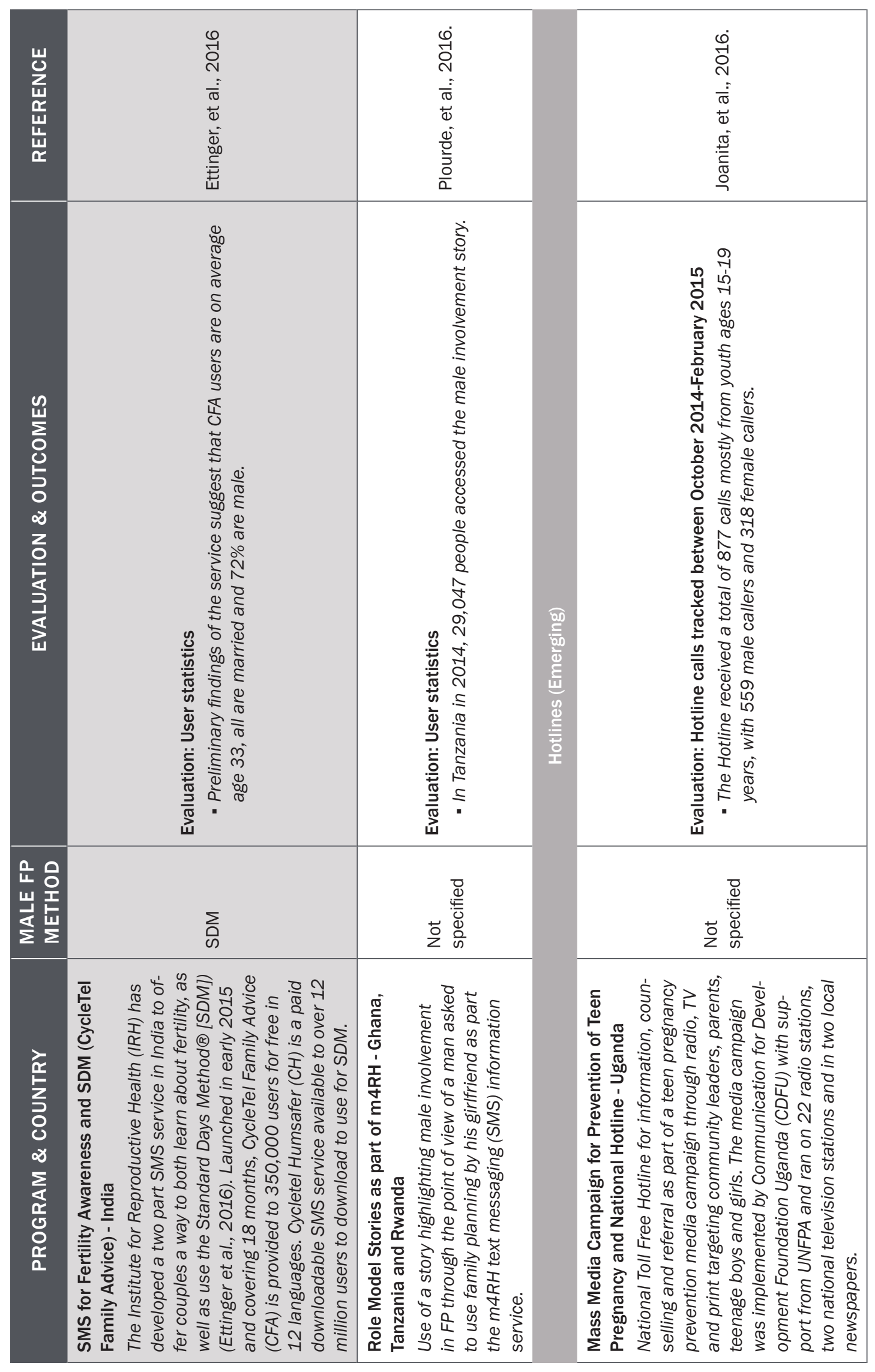




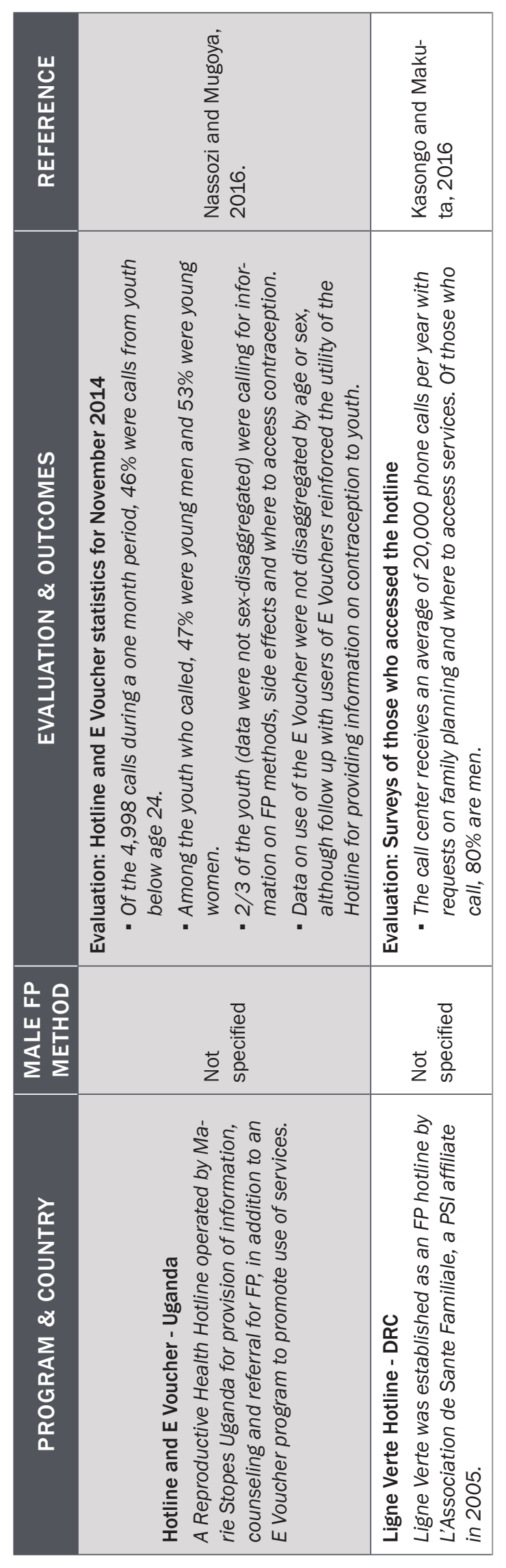




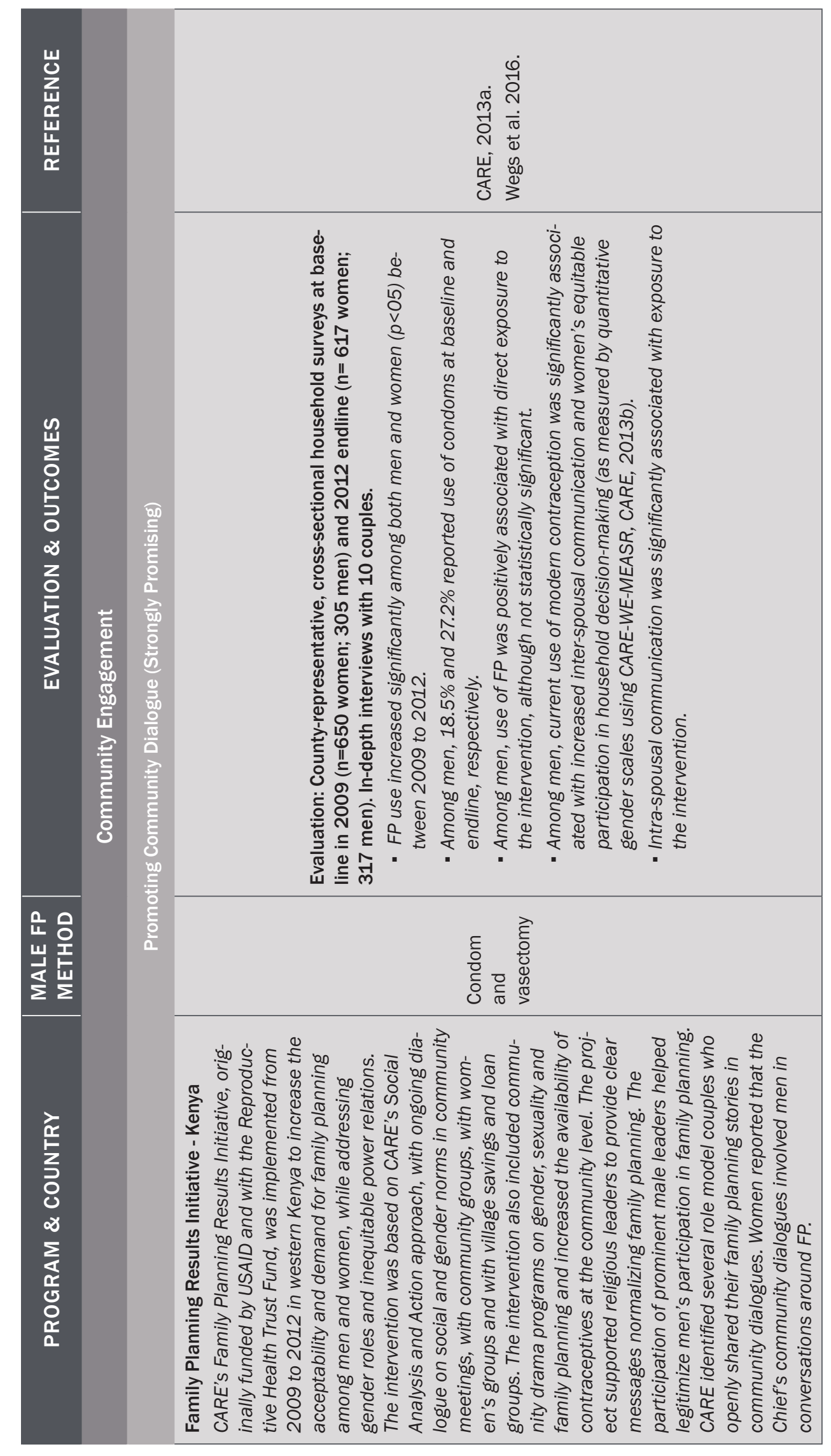




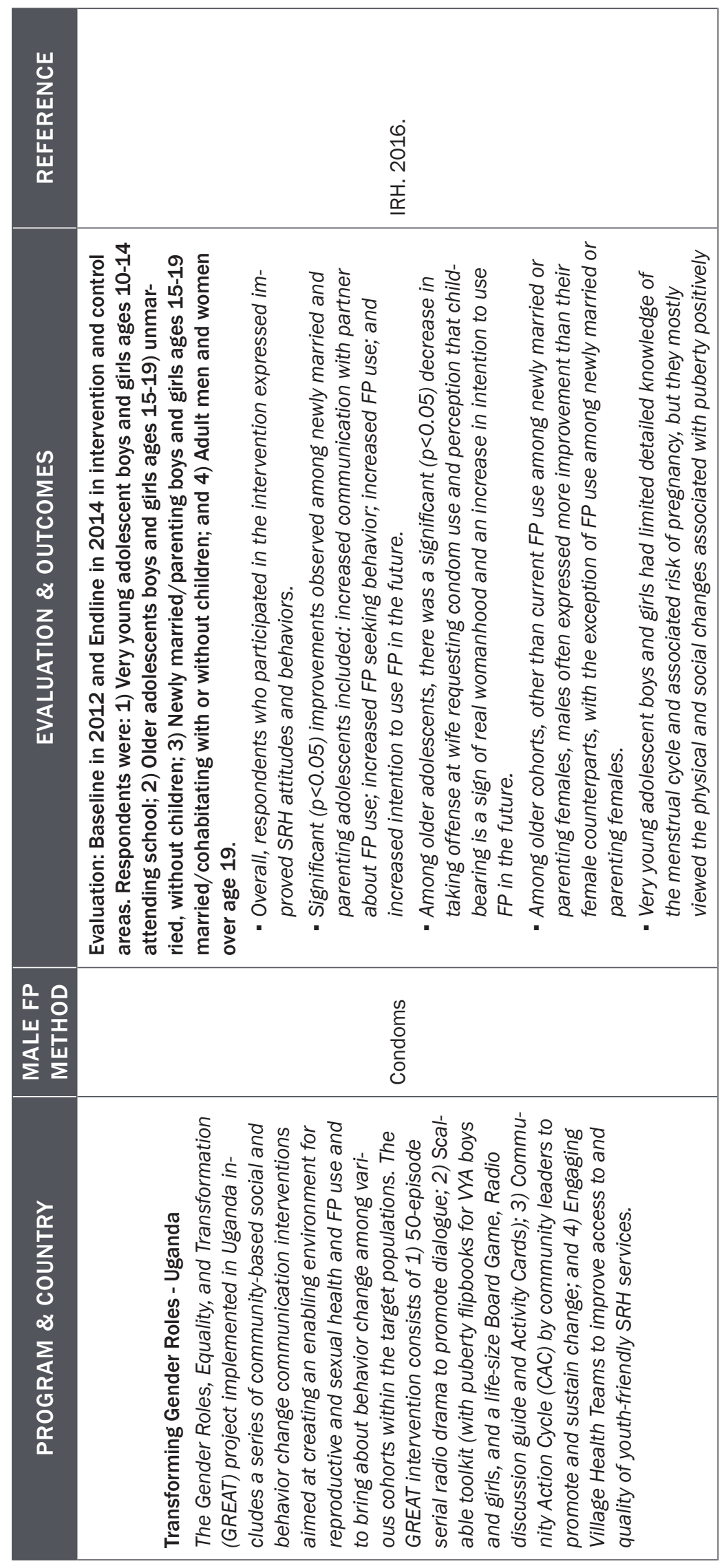




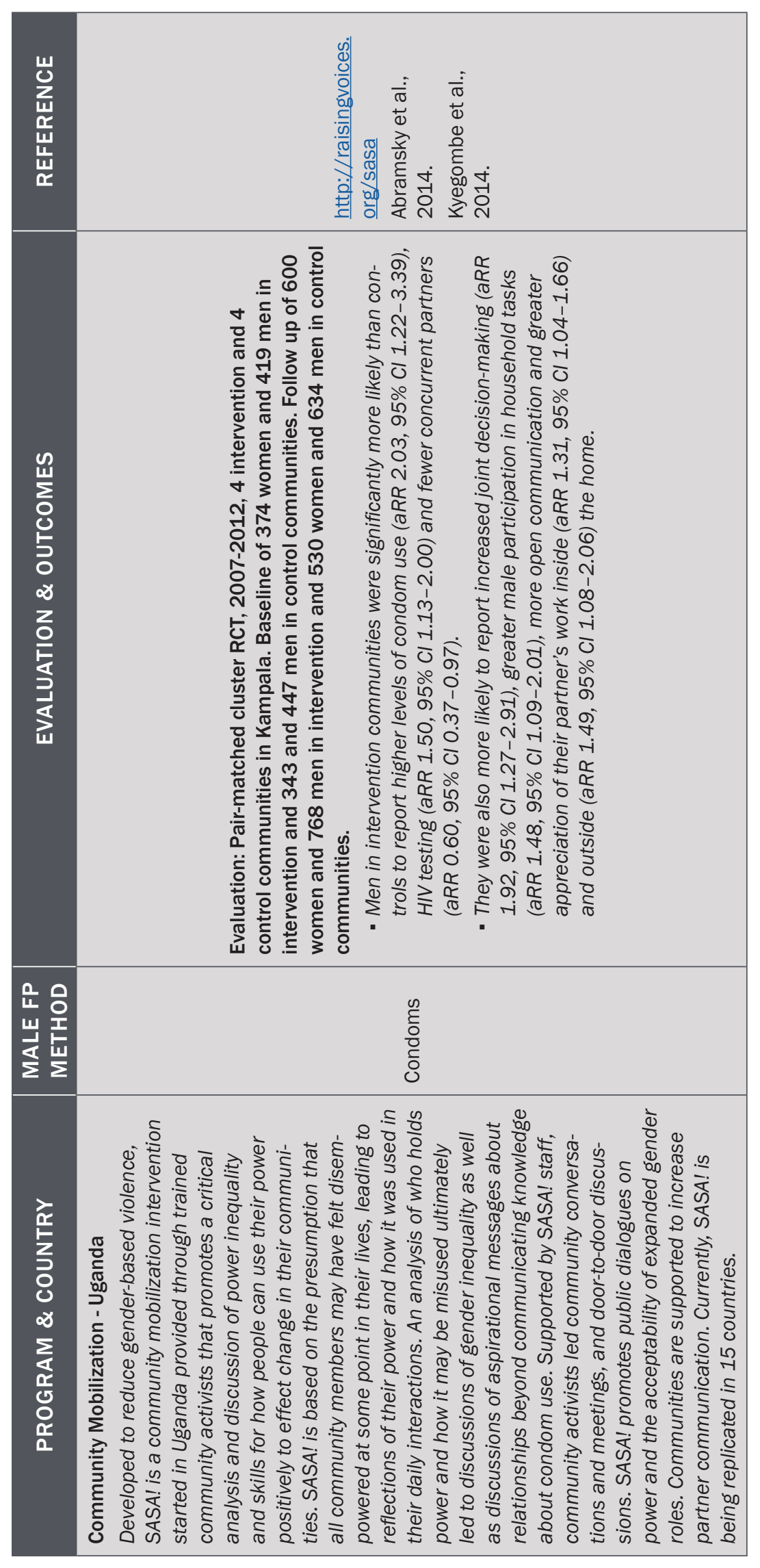




\begin{tabular}{|c|c|c|}
\hline 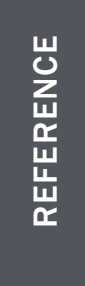 & 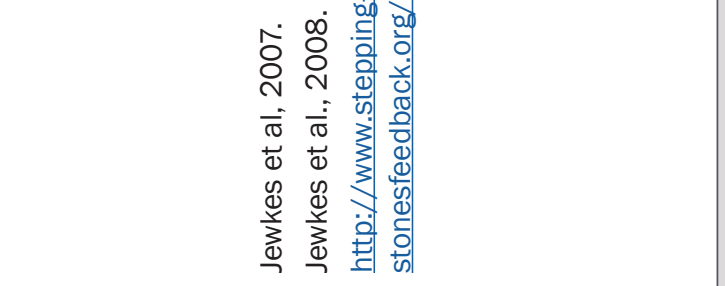 & 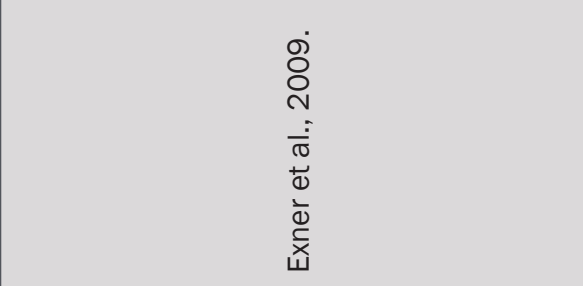 \\
\hline 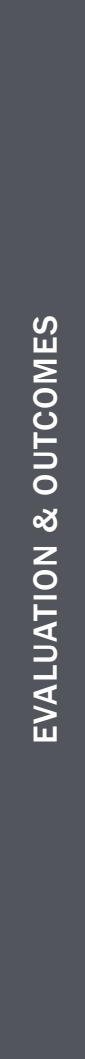 & 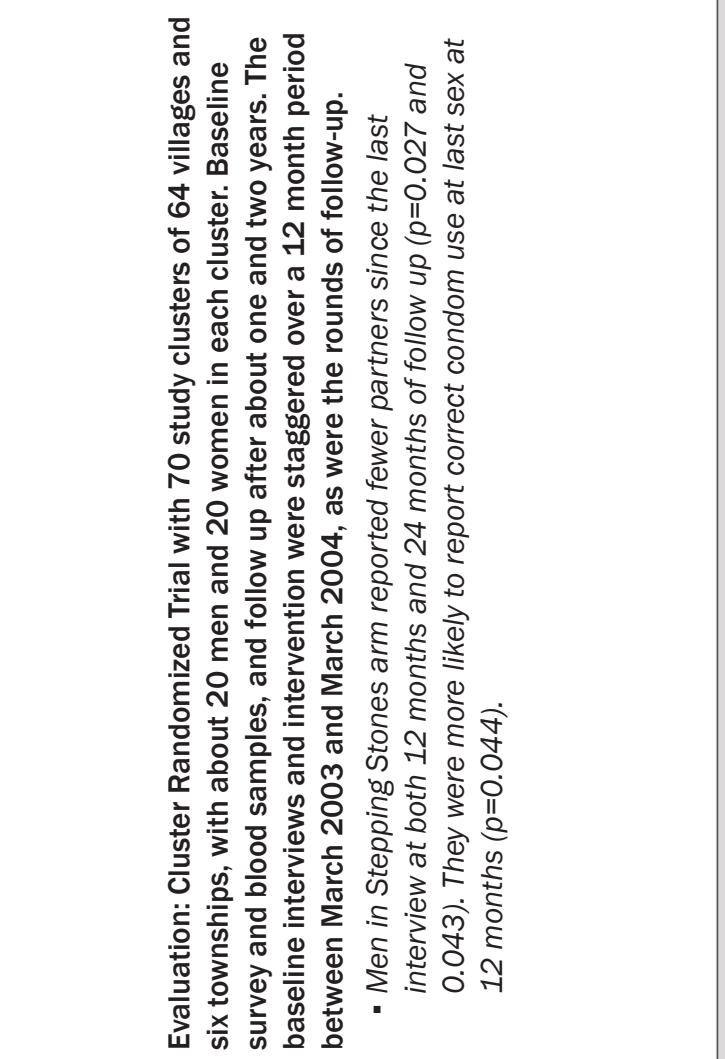 & 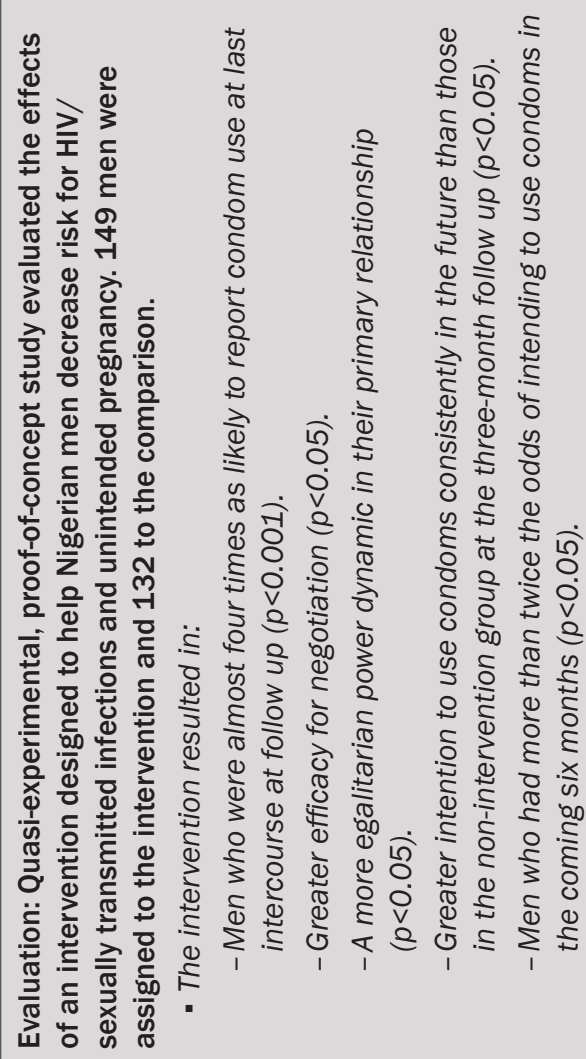 \\
\hline 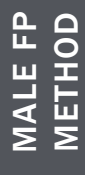 & 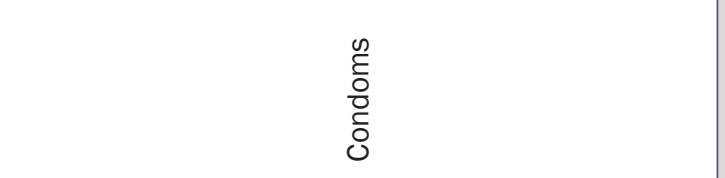 & 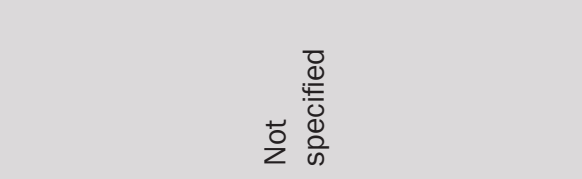 \\
\hline 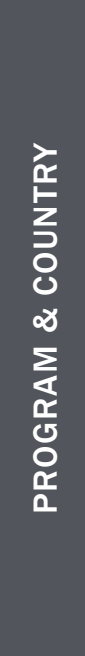 & 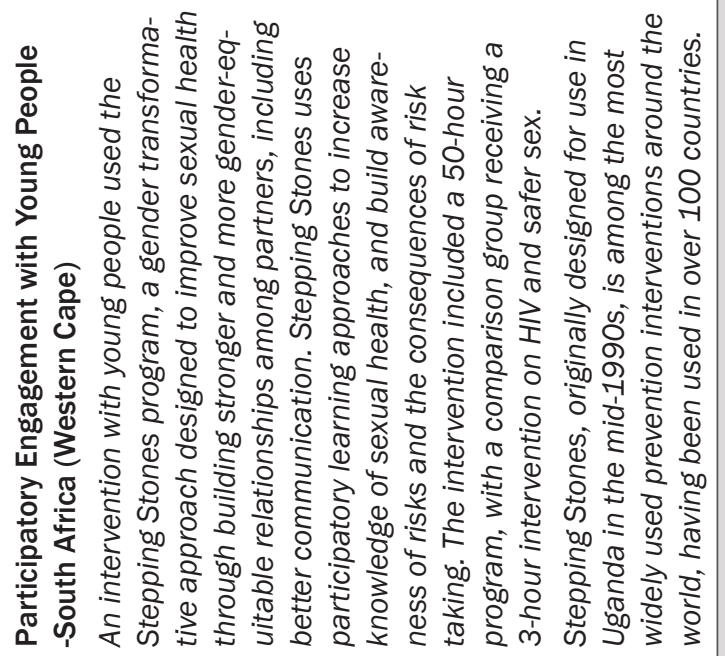 & 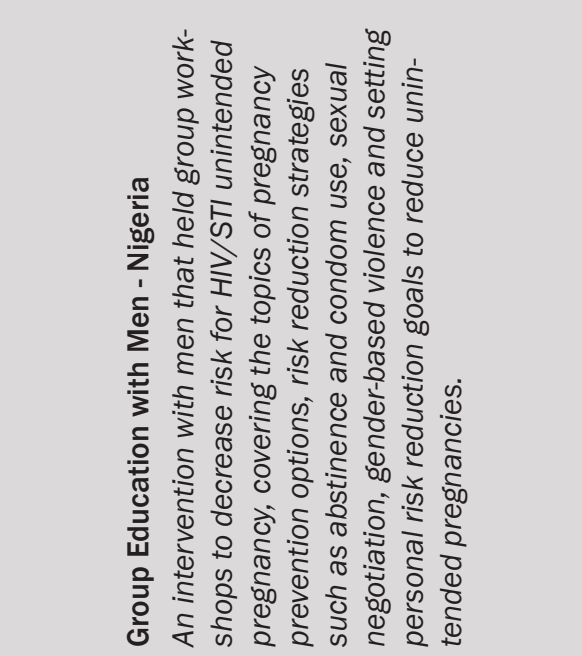 \\
\hline
\end{tabular}




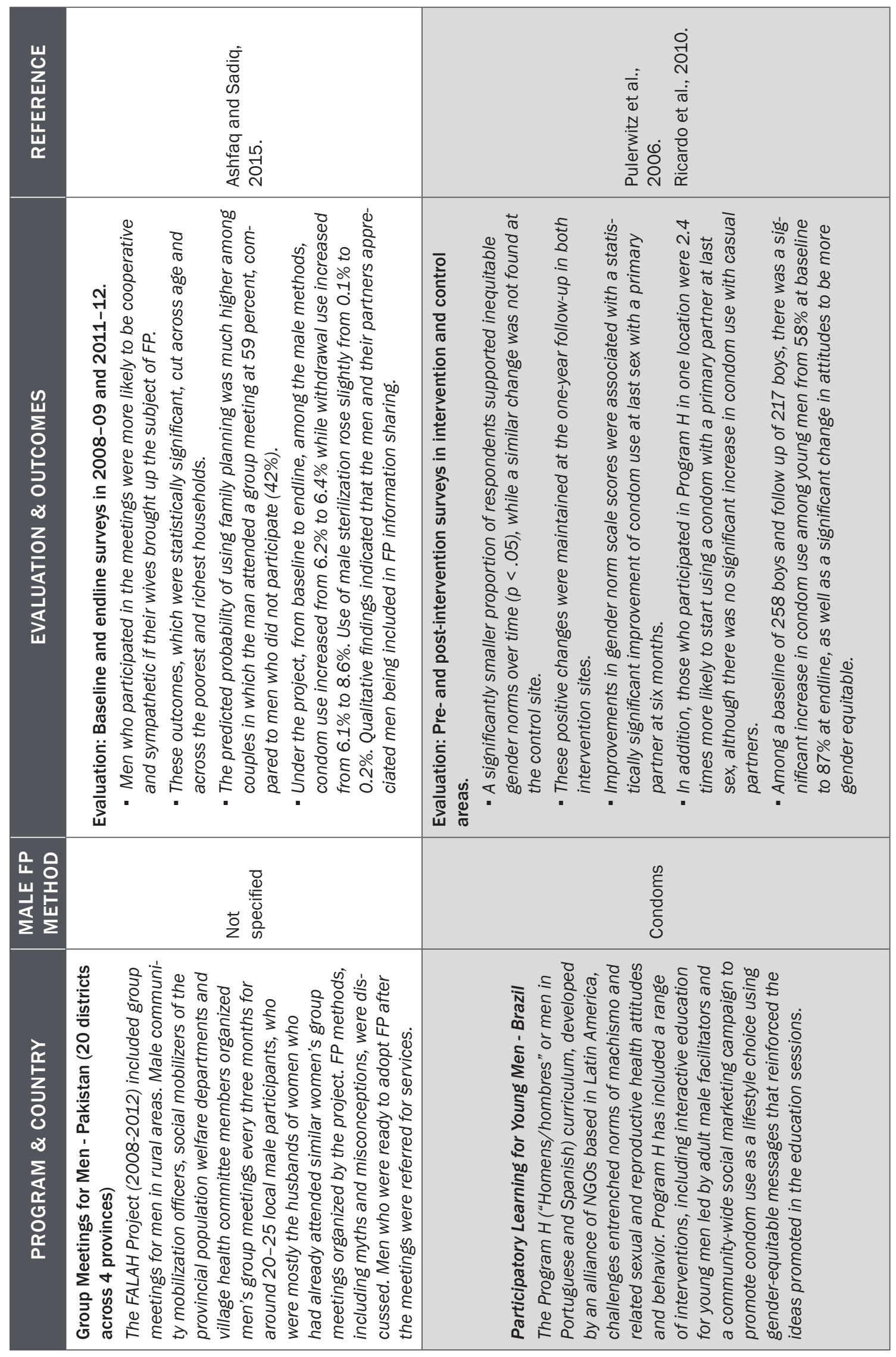

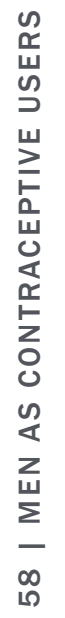




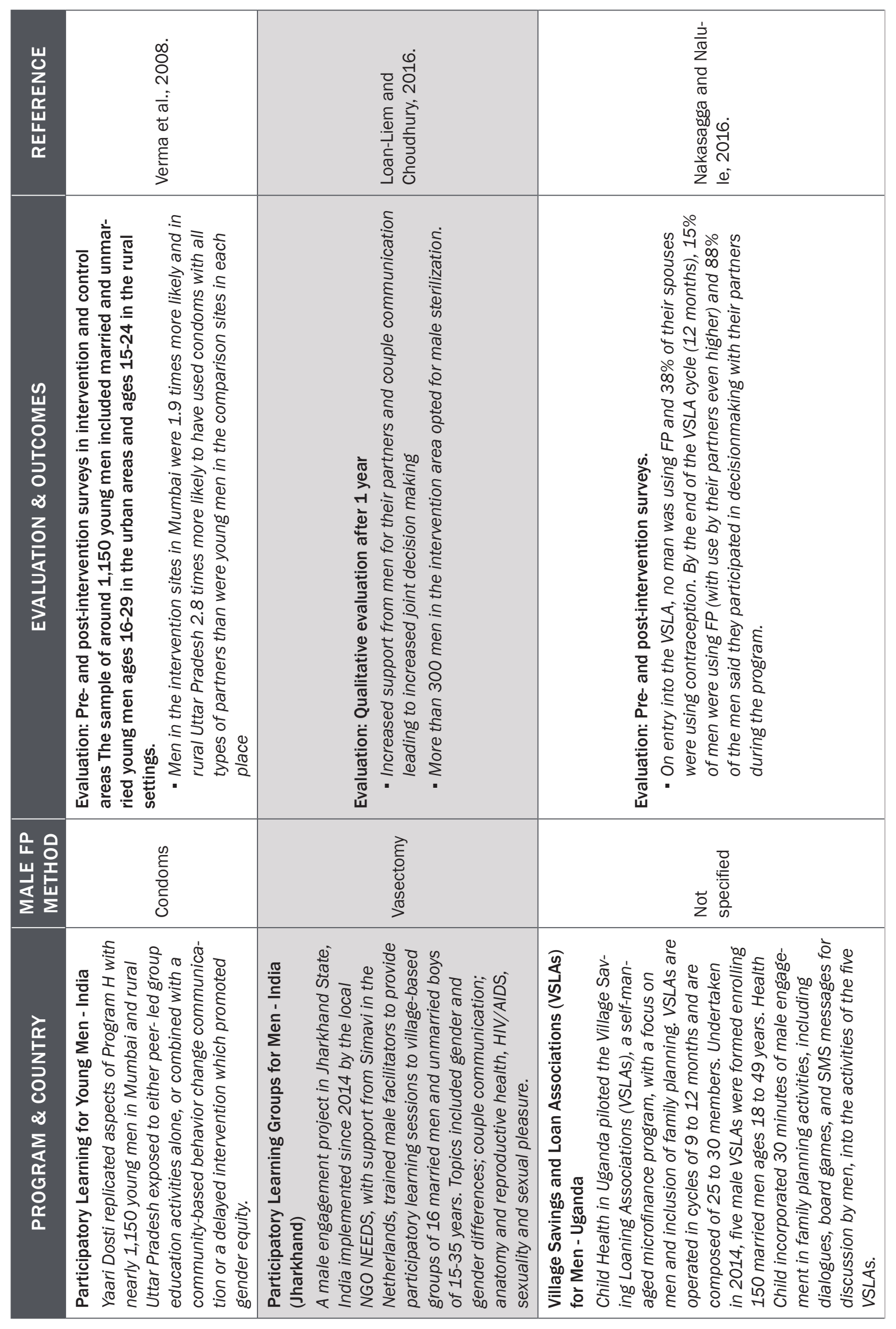

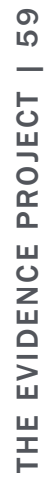




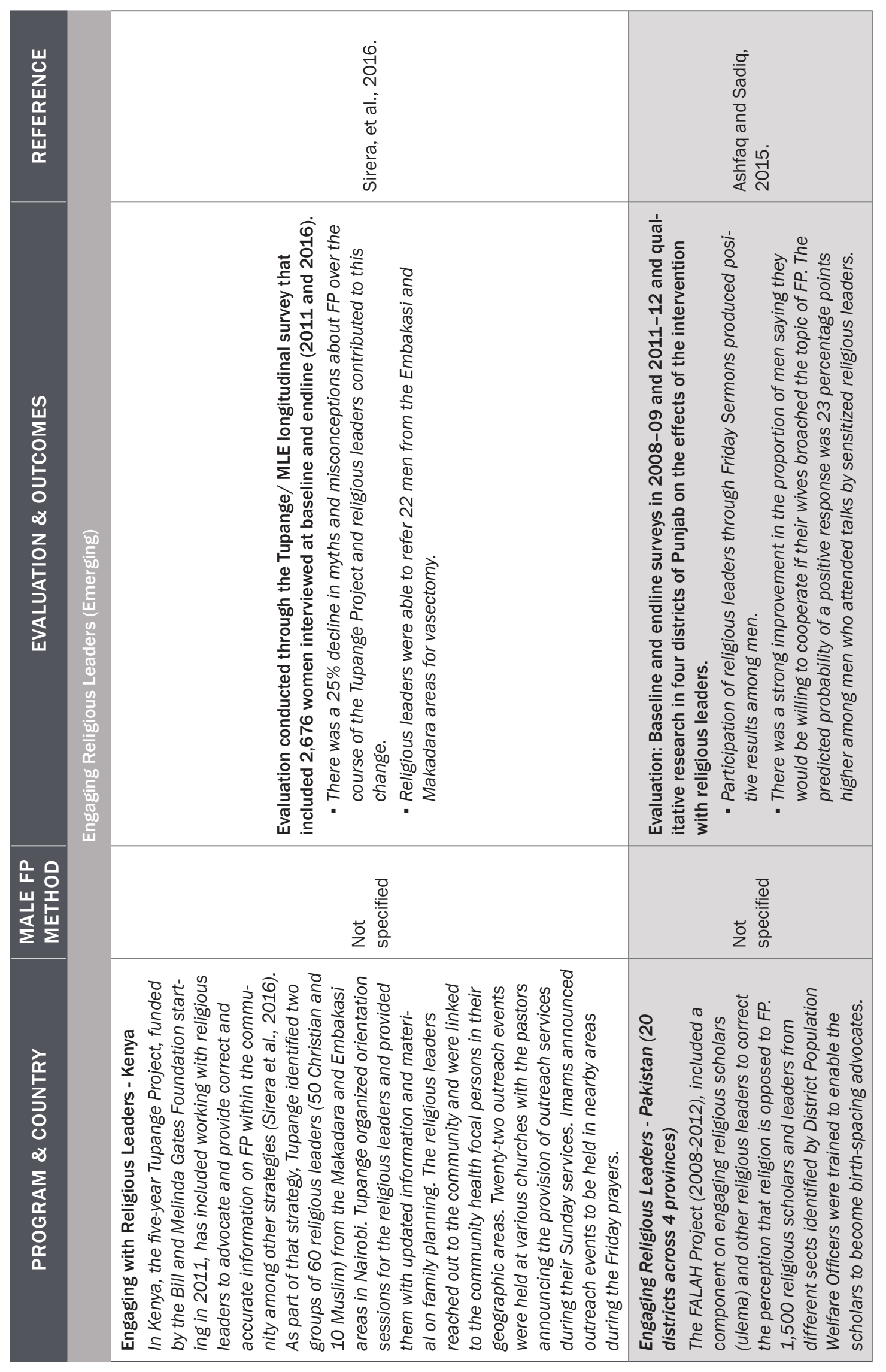




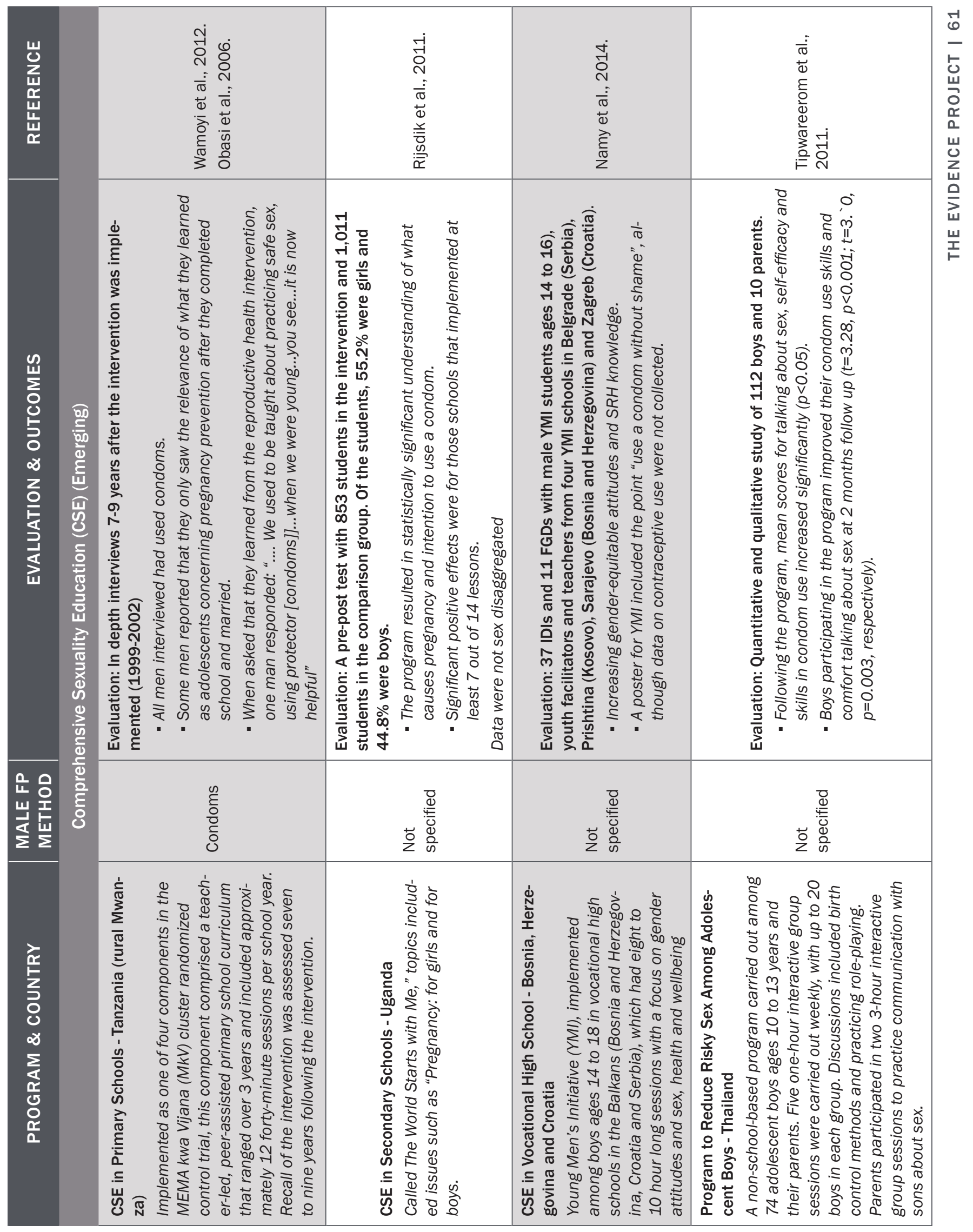





\section{The Evidence Project}

Population Council

4301 Connecticut Avenue, NW, Suite 280

Washington, DC 20008 USA

tel +12022379400

evidenceproject.popcouncil.org 